University of Louisville ThinkIR: The University of Louisville's Institutional Repository

Electronic Theses and Dissertations

$5-2019$

\title{
Student perceptions and persistence : taking a person-centered approach to understand undergraduate engineering retention.
}

Brittany Flanery Crawford

University of Louisville

Follow this and additional works at: https://ir.library.louisville.edu/etd

Part of the Educational Psychology Commons, Engineering Education Commons, and the Higher Education Commons

\section{Recommended Citation}

Crawford, Brittany Flanery, "Student perceptions and persistence : taking a person-centered approach to understand undergraduate engineering retention." (2019). Electronic Theses and Dissertations. Paper 3238.

https://doi.org/10.18297/etd/3238

This Doctoral Dissertation is brought to you for free and open access by ThinkIR: The University of Louisville's Institutional Repository. It has been accepted for inclusion in Electronic Theses and Dissertations by an authorized administrator of ThinkIR: The University of Louisville's Institutional Repository. This title appears here courtesy of the author, who has retained all other copyrights. For more information, please contact thinkir@louisville.edu. 


\title{
STUDENT PERCEPTIONS AND PERSISTENCE: TAKING A PERSON-CENTERED APPROACH TO UNDERSTAND UNDERGRADUATE ENGINEERING RETENTION
}

\author{
By \\ Brittany Flanery Crawford \\ B.S., University of Kentucky, 2015
}

\begin{abstract}
A Dissertation
Submitted to the Faculty of the College of Education and Human Development of the University of Louisville In Partial Fulfillment of the Requirements for the Degree of

Doctor of Philosophy

In Counseling and Personnel Services

Department of Counseling and Human Development University of Louisville

Louisville, Kentucky
\end{abstract}

May 2019 

STUDENT PERCEPTIONS AND PERSISTENCE: TAKING A PERSON-CENTERED APPROACH TO UNDERSTAND UNDERGRADUATE ENGINEERING

RETENTION

\author{
By \\ Brittany Flanery Crawford \\ B.S., University of Kentucky, 2015
}

A Dissertation Approved on

February 12, 2019

by the following Dissertation Committee:

Dr. Kate E. Snyder

Dr. Jill L. Adelson

Dr. Jeffrey C. Valentine

Dr. Patricia A. S. Ralston 


\section{ACKNOWLEDGEMENTS}

I wouldn't have made it to this point without the support of several people. More than anything, I want to thank my husband, Ben, for supporting me throughout my doctoral program. Thank you for providing words of encouragement when I ran out of steam, for being understanding when I devoted weekends to writing rather than spending time together, and for often sitting up with me late at night so that I didn't have to stay up alone while writing. I also want to say thank you to my parents. Your constant support and words of encouragement have fueled me through not only this degree, but throughout my entire educational career. Thank you for always lending an ear to listen to my worries and struggles, but never letting me underestimate myself.

I also would like to thank my advisors at the University of Louisville, Drs. Jill Adelson and Kate Snyder, for always pushing me to achieve more and to be a better researcher. To my dissertation committee, thank you for providing thoughtful feedback and sharing in my enthusiasm for this project. Thank you to my colleagues at HumRRO for not only providing constant encouragement to finish my dissertation, but for celebrating with me throughout many milestones. Finally, thank you to my mentor at the University of Kentucky, Dr. Molly Fisher. You were the first person who saw my potential as an education researcher, even as a curious undergraduate student. You helped set the foundation for what has turned out to be a valuable experience as a graduate student. You have all played such an important role in this process. Thank you. 


\section{ABSTRACT \\ STUDENT PERCEPTIONS AND PERSISTENCE: TAKING A PERSON-CENTERED APPROACH TO UNDERSTAND UNDERGRADUATE ENGINEERING RETENTION

\author{
Brittany Flanery Crawford
} \\ February 12, 2019}

Many students are leaving their engineering programs as early as the first semester of their undergraduate studies. Although some of the factors related to engineering retention are largely academic, others are tied closely to students' beliefs or perceptions. Student perceptions data are useful, but often overlooked by researchers who wish to take a person-centered approach to uncover profiles of student beliefs, both adaptive and maladaptive, when it comes to understanding engineering retention. The sample consisted of full-time undergraduate engineering students $(N=834)$ in the first semester of their undergraduate engineering programs.

I used latent transition analysis (LTA) to examine the latent profiles that emerged from measures of student beliefs, including expectations of brilliance, perceived belonging uncertainty, and self-efficacy. Additionally, changes were examined in latent profile memberships over the course of the students' first semesters in their engineering programs. As anticipated, both adaptive and maladaptive latent statuses emerged at the beginning and end of students' first semester. Contrary to my original hypothesis, students were more likely to transition to more-adaptive latent statuses or remain in 
adaptive latent statuses across transition periods, as opposed to transitioning to lessadaptive latent statuses. Additionally, students belonging to specific demographic subgroups were more likely to be classified into less-adaptive latent statuses, including females, students who identified as Black/African American, first-generation college students, students from low-income households, and students who were enrolled in a lower-level, first-semester mathematics course. Finally, students who were best classified into the less-adaptive latent statuses at the end of the first semester of their engineering programs were less likely to remain in their undergraduate engineering programs one year later.

Ultimately, the results emphasize the importance of examining student perceptions data when designing interventions related to engineering retention. Researchers also should consider examining the interactions between a student's environment, latent profiles of perceptions, and the student's behavior when seeking to understand undergraduate engineering retention. 
TABLE OF CONTENTS

PAGE

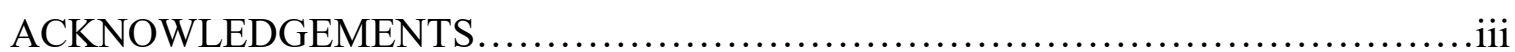

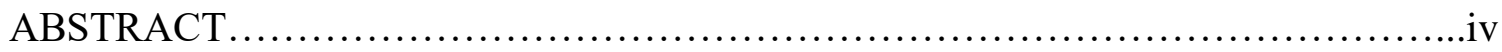

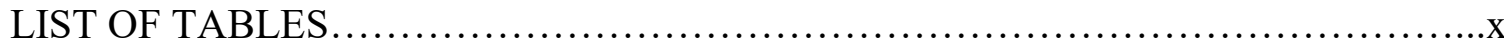

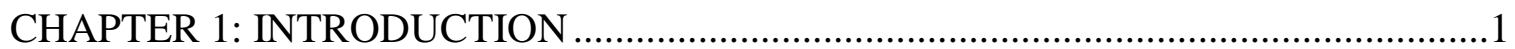

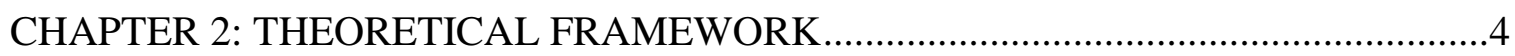

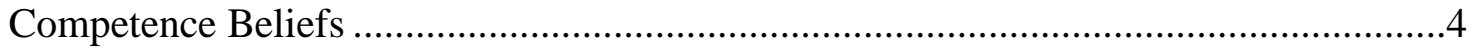

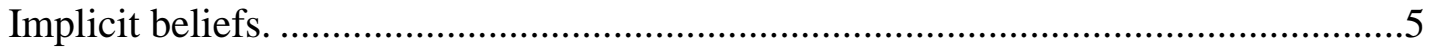

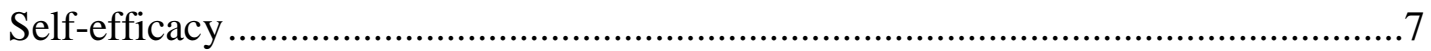

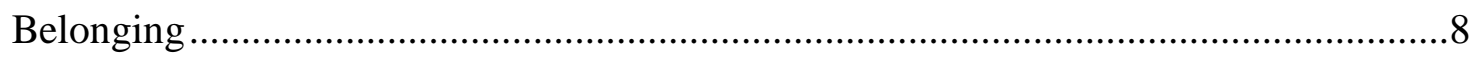

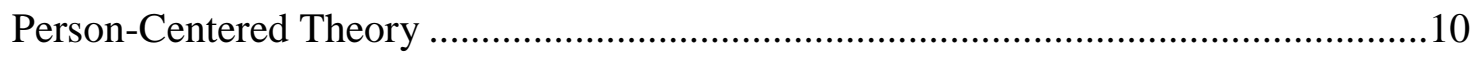

Predictors of Profile Membership and Transitions ……….........................................14

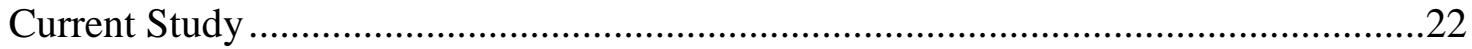

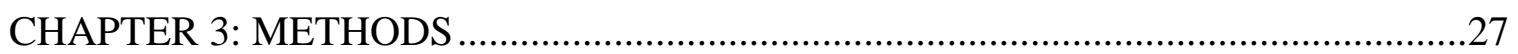

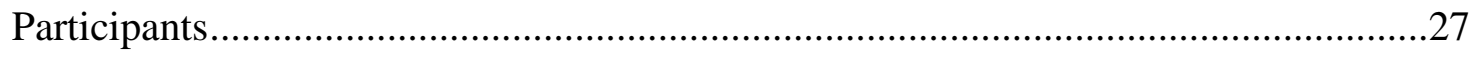

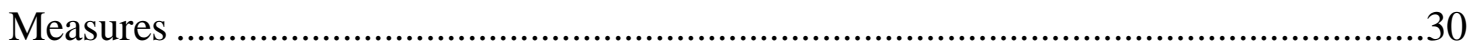

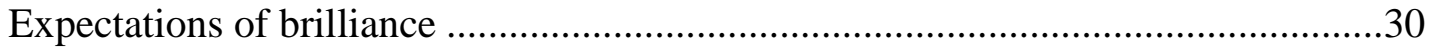


Perceived belonging uncertainty

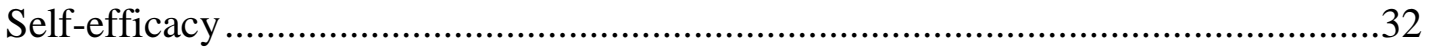

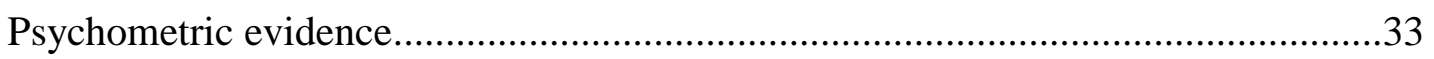

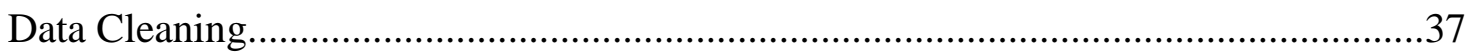

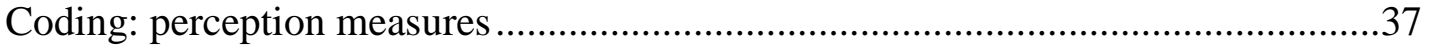

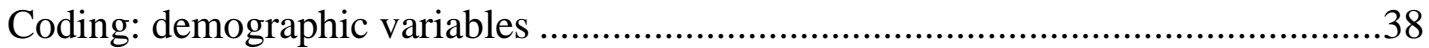

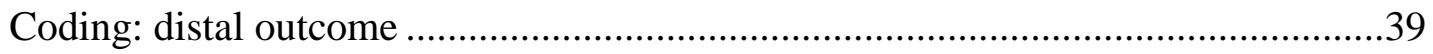

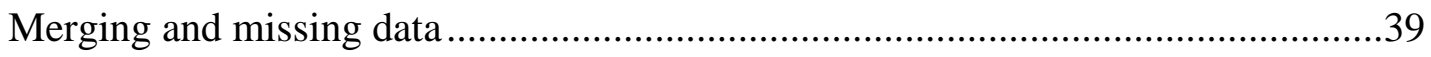

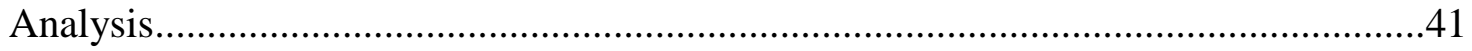

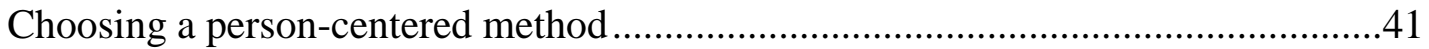

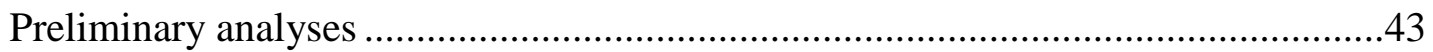

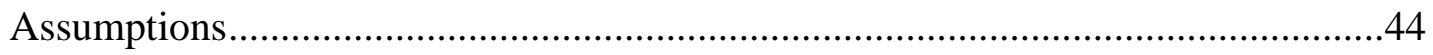

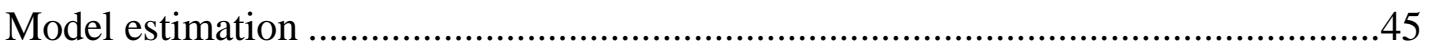

Anticipating potential model identification issues .............................................45

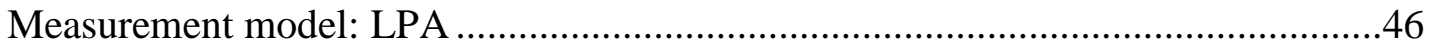

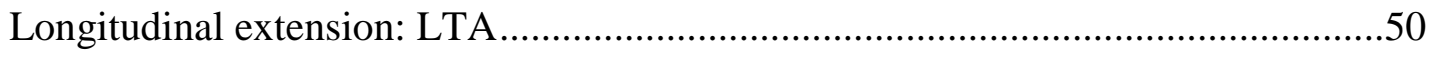

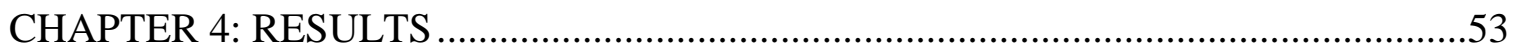

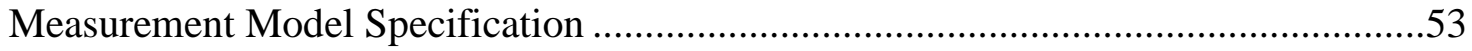

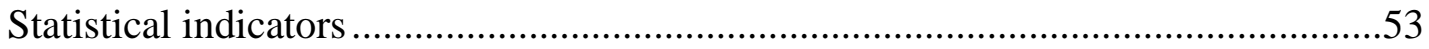


Interpretability.

Measurement Invariance .64

LTA Model Specification .66

Including covariates .66

Including the distal outcome .79

CHAPTER 5: DISCUSSION .96

CHAPTER 6: CONCLUSION

REFERENCES.

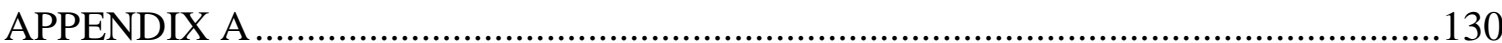

A1: Model Fit Indices Prior to Including Post Hoc Correlations

APPENDIX B

B1: Time 1/Pre-Survey LPA Fit Indices Including Hispanic/Latinx Students

B2: Time 2/Post-Survey LPA Fit Indices Including Hispanic/Latinx Students

APPENDIX C

C1: Mplus Syntax: Time 1 LPA, 4-Profile Solution, No Covariates, No Distal Outcome

C2: Mplus Syntax: Time 2 LPA, 4-Profile Solution, No Covariates, No Distal Outcome.

C3: Mplus Syntax: Baseline LTA Model, Full Measurement Noninvariance, No

Covariates, No Distal Outcome 135 
C4: Mplus Syntax: Baseline LTA Model, Full Measurement Invariance, No

Covariates, No Distal Outcome .136

C5: Mplus Syntax: LTA Model Covariates Included ..........................................137

C6: Mplus Syntax: LTA Model Covariates and Distal Outcome Included .................138

CURRICULUM VITA..................................................... 140 


\section{LIST OF TABLES}

TABLE

PAGE

1. Demographics for Cohort 1, Cohort 2, and the Overall Sample. .28

2. Internal Consistency Reliability and Model Fit Indices for the Student Perceptions Measures .37

3. Coding Scheme for Demographic Variables

4. Time 1/Pre-Survey LPA Fit Indices for the Sample Without Hispanic/Latinx

Students .56

5. Time 2/Post-Survey LPA Fit Indices for the Sample Without Hispanic/Latinx

Students .57

6. 4- and 5-Profile Solutions at Times 1 and 2 .58

7. Within-Profile Item Means by Latent Profile and Time - Separate LPAs .....

8. Proportion of Students in Each Profile at Times 1 and 2 - Separate LPAs.

9. Within-Status Item Means by Latent Status and Time: LTA Model with Covariates

10. Logistic Regression Coefficients by Latent Status and Time - LTA Model with Covariates (The Most-Adaptive Latent Statuses Served as the Reference Status) ....74

11. Latent Transition Probabilities by Latent Status and Time: LTA Model with Covariates 
12. Membership Proportions Based on Latent Status Patterns: LTA Model with Covariates

13. Within-Status Item Means by Latent Status and Time: Final LTA Model with Covariates and the Distal Outcome .81

14. Logistic Regression Coefficients by Latent Status and Time - Final LTA Model with Covariates and the Distal Outcome (The Most-Adaptive Latent Statuses Served as the Reference Status) .88

15. Latent Transition Probabilities by Latent Status and Time: Final LTA Model with Covariates and the Distal Outcome

16. Membership Proportions Based on Latent Status Patterns: Final LTA Model with Covariates and the Distal Outcome.

17. Retention Rates Based on Final Latent Status at the End of the Students' First Two Semesters .95 


\section{CHAPTER ONE}

\section{INTRODUCTION}

Of the students who enter college planning to major in a science, technology, engineering, or mathematics (STEM) program, approximately $60 \%$ will not go on to finish their degrees (President's Council of Advisors on Science and Technology, 2012). Generally, students who choose to drop out of their STEM programs do so within the first two years of their undergraduate programs (Griffith, 2010). However, other researchers have found that students begin to leave their engineering majors even earlier- as early as the students' first semester (Bettinger, 2010; Besterfield-Sacre, Moreno, Shuman, \& Atman, 2001). The results of one study focusing on four-year colleges in Ohio indicated that approximately half of the students who expressed interest in the STEM disciplines and went on to declare STEM majors did not end up completing their degrees, and this attrition rate was maintained even after considering only the highest-performing students (Bettinger, 2010). This is slightly lower than the previously mentioned national attrition rate of approximately 60\% (President's Council of Advisors on Science and Technology, 2012), but still a major cause for concern.

Over the past decade, the number of jobs in the United States that required skills from STEM fields has grown by almost one-third (National Science Board, 2018). Unfortunately, while some countries, including China, have seen a vast increase in the 
number of citizens obtaining four-year degrees in science and engineering (specifically, an increase of approximately $360 \%, 359,478$ to $1,653,565$ degrees between $2000-2014$ ), the increase in the number of Americans earning the same degrees was far fewer (approximately 53\%,483,764 to 741,763 degrees within the same time frame; National Science Board, 2018). Therefore, increasing the retention of students in college STEM programs has been described as the "lowest-cost, fastest policy option to providing the STEM professionals that the nation needs for economic and societal well-being" (President's Council of Advisors on Science and Technology, 2012, p. i).

STEM attrition is associated with a range of factors, including course selection during the first semester (Attewell, Heil, \& Reisel, 2012), differing academic expectations between high school teachers and college professors (Daempfle, 2003), viewing intelligence as an immutable trait (Hill, Corbett, \& St. Rose, 2010), attraction of other fields outside of STEM (Strenta, Elliott, Adair, Matier, \& Scott, 1994), precollegiate grades and coursework (Rask, 2010), and grades earned during introductory STEM courses (Rask, 2010; Strenta et al., 1994). When looking specifically at the factors associated with engineering attrition, it is evident that many of the factors are largely academic (e.g., concerns regarding mathematics and science prerequisites, difficult course loads, lack of guidance from faculty or advisors), and others are tied more closely to students' beliefs or perceptions (e.g., lack of self-efficacy in engineering; Marra, Rodgers, Shen, \& Bogue, 2012).

Examining students' perceptions can provide additional insight into persistence, or lack thereof, in undergraduate engineering programs (Burtner, 2005; Marra et al., 2012). Scholars can drive existing research forward by examining combinations of 
student perceptions in order to better understand why some students enrolled in undergraduate engineering programs decide to leave their programs while others choose to persist. Understanding these processes better will help educators to foster program completion within the engineering field, as it is not only important to provide academic support, but also to develop an understanding of students' perceptions about their own abilities within their respective STEM fields (Marra et al., 2012). 


\section{CHAPTER TWO THEORETICAL FRAMEWORK}

In line with social cognitive theory, students' beliefs influence interpretations of their experiences and, therefore, these beliefs can either positively or negatively affect students' behavior, including persistence (Dweck \& Leggett, 1988). The network of reciprocal interactions between an individuals' beliefs, social or environmental factors, and their behavior is the foundation of the social cognitive theory (Bandura, 1986, 2001). Consequently, students shape the goals that they set for themselves and the behaviors that they take to reach these goals based on ongoing self-evaluation (e.g., competence-related beliefs) and their current social context (e.g., whether the current learning environment fosters a sense of community or belonging; Bandura, 2001). In the context of this study, students' beliefs regarding their competence and their experiences related to engineering will likely be associated with their decisions to either leave their engineering programs or to persist. Although students' perceptions of competence-related beliefs and belonging have been studied to some extent as independent factors affecting engineering retention, as discussed below, these types of beliefs have yet to be studied together.

\section{Competence Beliefs}

According to the social cognitive theory, competence beliefs determine the challenges students accept, their persistence when faced with setbacks, and whether students consider their failures to be motivating or defeating (Bandura, 2001). Related to 
students' competence beliefs are their implicit beliefs about intelligence, expectations of brilliance, and self-efficacy in engineering. In the extant literature focusing on engineering retention, more is known about the relationship between engineering competence or self-efficacy and engineering retention (e.g., Huang, Taddese, \& Walter, 2000) compared to students' implicit beliefs about intelligence (e.g., Snyder, Barr, Honken, Pittard, \& Ralston, 2018) or expectations of brilliance (e.g., Leslie, Cimpian, Meyer, \& Freeland, 2015). In this section, I describe some of the competence- and experience-related beliefs that are often studied independently before later examining which profiles emerge from the combinations of these types of beliefs.

Implicit beliefs. Students can differ in their beliefs about the malleability of intelligence. While some students endorse a fixed mindset regarding intelligence (i.e., entity beliefs, or beliefs that intelligence cannot be changed or improved), others endorse a growth mindset (i.e., incremental beliefs, or beliefs that intelligence can be improved through increased practice or effort; Dweck, Chiu, \& Hong, 1995; Dweck \& Leggett, 1988; Yeager \& Dweck, 2012). This suggests that students vary in their perceptions of whether or not they can improve their own intelligence, and these perceptions are likely be related to their persistence in their undergraduate engineering programs. Although there is potential for within-semester changes in students' implicit beliefs about intelligence and effort beliefs, these beliefs tend to remain relatively stable over time (Robins \& Pals, 2002; Snyder et al., 2018). However, students may grow to view effort as more critical to their academic success compared to ability or intelligence (Snyder et al., 2018). 
Students who believe academic success is based on hard work and effort are more likely to see academic challenges (e.g., struggling with engineering coursework) as reasons to persist, while students who believe intelligence is intrinsic, or a fixed trait, are more likely to question their ability to succeed (Aronson, 2002). In our example, students who endorse a growth mindset likely believe they can improve upon their abilities in their engineering courses and, as a result, they may decide to persist in their engineering programs. However, students who endorse a fixed mindset may likely feel that, if they are struggling with engineering-related course content, little can be done to improve the situation. These students may decide to switch majors or leave their undergraduate studies all together.

Similarly, Grant and Dweck (2003) found that students who hold incremental beliefs (i.e., endorse growth mindsets) are more likely to sustain motivation and employ coping strategies to persist. On the other hand, students who hold entity beliefs (i.e., endorse fixed mindsets) are more likely to withdraw and experience lower levels of academic performance (Grant \& Dweck, 2003). As students enter adolescence, these mindsets become more concrete and influence their beliefs about effort and shape their responses to challenging situations (Dweck, 2002). Although teachers and parents can instill incremental beliefs in their students and children, the outcomes may vary as children develop at different rates and vary in their responses to challenging circumstances during adolescence (Blackwell, Trzesniewski, \& Dweck, 2007).

Little existing research focuses on students' expectations of brilliance, let alone the relationship between students' expectations of brilliance and retention in engineering programs. This is an area worth studying given the insight that can be gained from 
incorporating student perceptions data when studying engineering retention (Burtner, 2005; Marra et al., 2012). Expectations of brilliance are, in essence, students' perceptions about the role that raw, innate talent (sometimes referred to by researchers as genius, and less frequently referred to as giftedness) plays in success within a given discipline, compared to traits, such as hard work and effort (Leslie et al., 2015). Leslie and colleagues (2015) showed that these beliefs contribute to the underrepresentation of female and Black/African American students in various academic disciplines; however, they did not discuss expectations of brilliance as a predictor of retention in engineering. Practitioners, faculty, and university students from a variety of disciplines have reported that the engineering discipline places a relatively large amount of emphasis on brilliance compared to other academic disciplines (e.g., disciplines in the social sciences or humanities; Leslie et al., 2015). Considering this, students' expectations of brilliance may provide important but previously overlooked insight into engineering retention.

Self-efficacy. Students' self-efficacy beliefs are related to the amount of effort they will exert and how long they will persist when it comes to overcoming an obstacle or challenge (Bandura, 1989). Throughout the present study, I discuss students' self-efficacy beliefs interchangeably with their competence beliefs and their confidence, specific to engineering. Students' perceived competence beliefs can be described as the abilities that the students believe they possess and their perceptions of whether or not they could use these abilities to be successful in a given domain or at a specific task (Bong \& Skaalvik, 2003). Thus, students' perceived competence in completing specific tasks or activities (e.g., engineering coursework) is likely related to the effort they exert in their engineering courses and persistence in their undergraduate engineering programs. 
Students' beliefs about their abilities can be domain-specific (Bong \& Skaalvik, 2003; Patterson, Kravchenko, Chen-Bouck, \& Kelley, 2016). While some students in disciplines such as the arts or humanities might believe that they can improve their academic abilities through hard work or increased effort, in areas such as mathematics or science, these same students may feel as if their abilities are fixed (Patterson et al., 2016). Regardless, students' perceptions of their own abilities have significant consequences for their academic outcomes. For instance, beliefs regarding one's abilities begin to negatively or positively influence retention in undergraduate engineering programs as early as students' first year of undergraduate study (Burtner, 2005).

Having high expectations for one's own intellectual abilities is strongly related to engineering retention, so much so that high expectations have been shown in some cases to mediate the relationship between parents' educational background (i.e., first-generation college student status), financial support (i.e., socioeconomic status), and degree completion (Huang et al., 2000). Similarly, increased expectations for students' abilities and success have been tied to women's and minority students' decisions to persist in engineering programs (Huang et al., 2000). Competence beliefs are discussed further when I describe the potential factors that predict retention in undergraduate engineering programs for specific groups of students.

\section{Belonging}

As previously mentioned, the current social context influences the goals that students set and the behaviors they take to reach their goals (Bandura, 2001). Students who are more likely to persist generally report a sense of belonging or community and increased interaction between themselves, their peers, and the engineering faculty 
members (Amelink \& Creamer, 2010; Litzler \& Young, 2012). Belonging may even be considered more influential than other academic factors when it comes to understanding why students leave their engineering programs, and a lack of belonging is often closely related to a lack of self-efficacy for undergraduate engineering students (Marra et al., 2012).

Positive relationships between engineering faculty and students play an important role in feelings of belonging and persistence in engineering programs (Amelink \& Creamer, Litzler \& Young, 2012). Although faculty members play an important role in students' persistence in engineering, many are unaware of the shortage of engineering graduates or how they can have a positive impact on current retention efforts (GandhiLee, Skaza, Marti, Schrader, \& Orgill, 2017). Faculty members' awareness of engineering retention is often informed by enrollment in their courses rather than degree completion, and they often attribute the factors that negatively influence student retention to students' experiences outside, rather than inside, of their classrooms (Gandhi-Lee et al., 2017).

Because a sense of belonging has a positive relationship with students' engineering persistence, positive relationships among students is also necessary. However, there often is a perceived competitive atmosphere (i.e., feelings of social comparison) among students in the early years of their engineering programs (Veenstra, Dey, \& Herrin, 2009). This is due in part to the quantitative and analytical skills necessary to make it through the introductory "weeding-out" courses (Seymour \& Hewitt, 1997). Given that these skills are typically developed in high school, this shows the 
significance of considering both pre-college and undergraduate experiences when studying engineering retention (Veenstra et al., 2009).

Students' feelings of belonging often vary based on the students' demographic characteristics. For example, researchers have found that feeling as if one does not belong in their academic programs is more closely tied to decreased interest in academics for students identifying with a racial or ethnic minority group compared to those who identify with a majority group (Walton \& Cohen, 2007; Zirkel, 2004). Further, students from less privileged social class backgrounds (i.e., lower household income, parents who do not hold advanced degrees) are less likely to report a sense of belonging within their academic settings, and this has important implications for their undergraduate program performance (Ostrove \& Long, 2007). There are also significant differences based on the student's gender, and, later in the review, feelings of belonging are discussed as a critical factor influencing female students' persistence in undergraduate engineering programs (e.g., Amelink \& Creamer, 2010).

\section{Person-Centered Theory}

Compared to measures of academic achievement (e.g., GPA, standardized test scores), student perceptions data are sometimes overlooked by researchers seeking to understand undergraduate engineering attrition (Burtner, 2005). However, student perceptions data are particularly suitable for researchers taking a person-centered approach to understand how combinations of various student perceptions predict students' academic achievement and educational experiences. Unlike a variable-centered approach that focuses on the individual variables and the overall sample, a personcentered approach focuses on understanding the individuals who provide the data for 
these variables and the grouping of various behaviors and responses among individuals (von Eye \& Bogat, 2006). Using a person-centered approach allows researchers to uncover different patterns or profiles endorsed by the individuals within the sample and examine how certain latent profiles may be more adaptive than others when it comes to understanding the outcome of interest (Bergman \& Trost, 2006; Laursen \& Hoff, 2006; Magnusson, 1998).

Although a person-centered approach can help researchers better understand students' academic achievement and educational experiences (Roeser, Strobel, \& Quihuis, 2002; Wormington, Corpus, \& Anderson, 2012), there is a limited amount of research using this type of approach to understand how different profiles of student perceptions help predict students' academic outcomes, especially persistence in undergraduate engineering programs. There isn't always a clear or direct link between specific constructs and students' academic outcomes. Rather, looking at combinations of various constructs might provide a more holistic picture of the outcome of interest. For example, extrinsic motivation is sometimes considered maladaptive in the academic setting; however, specific forms of extrinsic motivation combined with high levels of intrinsic motivation can result in adaptive profiles for high school students (Wormington et al., 2012). Thus, focusing on combinations of constructs, including student motivation can be particularly insightful.

Before moving forward, it is important to address a couple of arguments frequently woven throughout person-centered research. First, a person-centered approach is not necessarily superior to a variable-centered approach, but rather, it can be advantageous to use a person-centered approach when it comes to answering certain 
types of questions (Wormington \& Linnenbrink-Garcia, 2017). Further, both techniques can be used to complement each other, again, depending on the type of research question (Bergman \& Trost, 2006; Hayenga \& Corpus, 2010; Murdock \& Miller, 2003). After examining previous person-centered research in student motivation, many advantages of using this approach become easier to understand.

To begin with, relying on a variable-centered approach to understanding motivation generally shifts the focus towards students with high levels of a particular trait, even when only a small proportion of the sample belongs to this group (Wormington \& Linnenbrink-Garcia, 2017). Upon examining combinations of achievement goals in order to better understand students' academic outcomes (e.g., motivation, social and emotional well-being, engagement, and achievement), researchers found that students who endorsed average levels of goal endorsement had the leastadaptive profile regardless of the specific outcome (Wormington \& Linnenbrink-Garcia, 2017). However, in a study of mathematics achievement and affect, motivation beliefs functioned differently among students with average levels of goal endorsement (Conley, 2012). Among the students with average endorsement, two adaptive profiles and one lessadaptive profiles emerged. The two adaptive profiles were 1) students with moderatecompetency beliefs who reported a greater desire to develop rather than display their competency or avoid looking incompetent, 2) students with high-competency beliefs who reported a greater desire to develop and display their competency, rather than avoid looking incompetent. The one less-adaptive profile was 3) students with low-competency beliefs who sought to develop their competency, but were more focused on avoiding looking incompetent compared to displaying their competency (Conley, 2012). This 
provides new insight into the challenges faced by a group of students who have consistently been overlooked in variable-centered research and theoretical work because of the tendency to group similar students together and the practice of focusing on high and low levels of endorsement (Wormington \& Linnenbrink-Garcia, 2017). Traditional linear models likely would not have uncovered these unique profiles among students reporting average levels of motivation and, instead, would have grouped these students into a single homogeneous category (Conley, 2012; Magnusson, 1999).

A student's reported motivation, including their implicit theories about ability, is related to either adaptive or maladaptive academic outcomes for the students (Dweck \& Molden, 2005). In one study, combinations of middle and high school students' selfefficacy, goal orientations, implicit theories of science ability, and epistemic beliefs about science were examined (Chen, 2012). In doing so, four profiles emerged: 1) highest achievement, high science self-efficacy, strong desire to develop competency, highly incremental views of ability, less sophisticated views of scientific knowledge, 2) high achievement, concerned about appearing incompetent, fixed views of their scientific abilities, and sophisticated views of scientific knowledge, 3) below-average achievement, strong desire to display competency, highly incremental views of ability, passive views of scientific knowledge, and 4) lowest achievement, low science self-efficacy, highly concerned about appearing incompetent, no clear position regarding views of their scientific abilities or scientific knowledge (Chen, 2012). In a separate study of students' academic motivation, social-emotional functioning, and engagement, students who felt their abilities were fixed and were concerned about appearing incompetent in front of their peers (characteristic of the second profile described above) were highly likely to 
experience distress, which negatively affected their classroom engagement (Roeser et al., 2002). However, without a person-centered approach, it is likely that the high achieving students would have been studied together and researchers would have overlooked the second profile of students who are susceptible to academic distress (Chen, 2012).

Expectations of brilliance and belonging were described in the previous discussion of student perceptions. There is little to no person-centered research focused on these types of student perceptions. Based on the findings from the other personcentered studies in this section, it is likely that specific profiles would form from these types of perceptions data- some profiles potentially more adaptive than others when it comes to retention in undergraduate engineering programs. Further, students are likely to transition between these latent profiles over time, and this provides additional insight into how student perceptions changes over time based on their academic experiences. Instability in students' latent profiles can be due to a range of factors, including, but not limited to, changes in students' self-efficacy (Harter, Whitesell, \& Kowalski, 1992) and sense of belonging (Deci \& Ryan, 2002). In order to understand each profile, researchers must also consider student-related factors (i.e., demographic characteristics) that might predict each profile and predict transitions between profiles.

\section{Predictors of Profile Membership and Transitions}

Should researchers and educators who are developing early program interventions target specific groups of students? Students identifying as racial or ethnic minorities, females, students from low-income households, and/or first-generation college students are at an elevated risk of leaving their undergraduate engineering programs (e.g., Chen, 2013; Hill et al., 2010; NSF; NCSES, 2017; Shaw \& Barbuti, 2010). This is a significant 
loss, considering many of these students have the skills and potential to make important contributions to the engineering classroom and workplace (Chen, 2013). The untapped talent of undergraduate students traditionally at risk for attrition in engineering programs helps emphasize the value of understanding why these students decide to forgo their engineering degrees (President's Council of Advisors on Science and Technology, 2012).

Compared to White and Asian students, Black/African American and Hispanic/Latinx students remain underrepresented among engineering degree recipients and within the engineering workforce (NSF; NCSES, 2017). Although Black/African American and Hispanic/Latinx individuals account for 12\% and 15\% (respectively) of the United States population at or above the age of legal employment, members of the same racial groups account for only 5\% and 6\% (respectively) of United States citizens employed in science and engineering occupations (National Science Board, 2018). For racial and/or ethnic minority students, retention in undergraduate engineering programs has been closely tied to mathematics and science preparation prior to college, student enrichment and engineering intervention programs, financial assistance, peer support beginning during a student's first year of study, to name a few factors affecting engineering persistence (May \& Chubin, 2003).

Many researchers have examined the relationship between confidence and engineering retention using a variable-centered approach, and some have suggested this relationship varies as a function of race (e.g., Besterfield-Sacre et al., 2001; Burtner, 2004; Tate \& Linn, 2005). Minority students traditionally report lower levels of engineering confidence which negatively affects retention (Litzler, Samuelson, \& Lorah, 2014). Litzler and colleagues (2014) used a social-cognitive framework and student 
perception data to explain these differences and this has provided new insight into the intersection between race, gender, and confidence. Specifically, Black/African American and Hispanic/Latinx males report higher levels of engineering confidence compared to White male students, after accounting for factors including, but not limited to: feelings toward their engineering professors, sense of belonging to an engineering community, perceptions of students' own academic abilities compared to their peers, major desirability, perceptions of how rewarding the students felt an engineering career would be, first-generation college student status, prior experience, current year in the program, and GPA (Litzler et al., 2014). Once more, this study draws attention to the importance of examining previously overlooked constructs to understand persistence in undergraduate engineering programs.

During the first year of undergraduate studies, female students are less likely than male students to express interest in pursuing STEM-related majors and, by graduation, females earn only $20 \%$ of engineering degrees (Hill et al., 2010). This pattern continues as males outnumber females in the engineering fields during graduate school and later within the workplace (Hill et al., 2010). Academic achievement is not always to blame; in fact, females who decide to leave their STEM majors often are performing well academically and have higher mean GPAs compared to their male counterparts who also elect to leave their engineering majors (Marra et al., 2012). Beyond concerns regarding academic standing, factors contributing to the attrition of females in engineering include tension between female and male students, low self-confidence, professors' differing expectations for male versus female students, and perceptions that some fields require attributes such as brilliance or raw talent (Blickenstaff, 2005; Leslie et al., 2015). 
Peer-support from fellow female students is critical not only in the retention of females in engineering programs, but also in the intent of females to pursue engineeringrelated careers upon graduation (Amelink \& Creamer, 2010). Female students' perceptions that they must exert more effort than their male peers in order to be successful in the male-dominated STEM fields can negatively influence their feelings of belonging, and, consequently, this can negatively influence their motivation to persist in these fields (Smith, Lewis, Hawthorne, \& Hodges, 2013). Comradery between females in engineering provides an outlet for students to discuss concerns over work-life balance, improves the views that females have of their own academic abilities, and creates a sense of community and feelings of belonging to a group that is already considered a minority in a male-dominated field (Amelink \& Creamer, 2010). Females who lack this support from female peers or faculty members tend to report low levels of self-confidence and self-efficacy in engineering compared to their male peers (Marra, Rodgers, Shen, Bogue, 2009).

Unfortunately, regardless of peer support, females generally possess lower levels of confidence compared to males regarding their abilities to succeed in their undergraduate engineering programs and potential to contribute to the engineering workforce (e.g., Besterfield-Sacre et al., 2001; Cech, Rubineau, Silbey, \& Seron, 2011; Cordero, Porter, Israel, \& Brown, 2010; Huang \& Brainard, 2001; Marra et al., 2009). These findings appear to be exacerbated for White women, as their levels of self-reported confidence in engineering are significantly lower than males and females of any other racial or ethnic group (Litzler et al., 2014). Beliefs in one's ability to succeed is one facet 
of students' perception data that continues to serve as a potential explanation for low retention rates in undergraduate engineering programs.

It is only recently that policy makers have started to place emphasis on socioeconomic status (SES) when considering the diversity in engineering education (Strutz, Orr, \& Ohland, 2012). Although research surrounding the relationship between socioeconomic status and undergraduate engineering retention is limited, it suggests that students from low-income households are at an increased risk of leaving STEM programs and dropping out of college compared to their peers with more financial stability (Chen, 2013). Specifically, high-SES students are five times more likely than their low-SES peers to complete their engineering programs within six years (Orr, Ramirez, Ohland, 2011). This is worse than the 6-year rate of completion of low-SES students in all majors. Specifically, students who have graduated from high-income high schools are approximately twice as likely as students who have graduated from low-income high schools (i.e., a least 50 percent of students qualify for free or reduced lunch) to complete a college degree within six years (45\% versus $24 \%$, respectively; National Student Clearinghouse, 2016). The low retention rates are an injustice to students from lowincome households, as these students should be afforded the opportunity to thrive in engineering programs (Strutz et al., 2012).

Regardless of gender, one of the top reasons that students from low-income households are attracted to and persist in engineering programs is a strong scientific curiosity; however, males, more often than females, report being attracted to engineering programs in hopes of obtaining a lucrative career post-graduation (Conrad, Canetto, MacPhee, \& Farro, 2009). Researchers have found that high SES females and males are 
approximately 1.5 and 2 times more likely (respectively) than low-SES females and males to enroll in undergraduate engineering programs (Orr et al., 2011). There appears to be a downward trend in the number of students from low-income households that are admitted to engineering programs, especially at selective universities (George-Jackson, Rincon, \& Martinez, 2012). Thus, for engineering programs that have larger tuition differentials compared to other university majors, financial aid packages are necessary to assist low-income students in offsetting these costs and persisting in their programs (George-Jackson et al., 2012).

Continuing with my discussion of student perception data, it has been suggested that low-SES students generally have lower levels of confidence or self-efficacy with skills related to engineering, including mathematics, science, and problem solving, and this can contribute to lower levels of persistence (Donaldson, Lichtenstein, \& Sheppard, 2008). However, given the limited amount of research focusing on SES and engineering persistence, it is difficult to paint a clear picture as to why low-SES students have lower levels of confidence in their engineering skills. Similar to previous studies (e.g., Angrove, 2017; Belasco, Rosinger, \& Hearn, 2015; Douglass \& Thomson, 2012; Hollifield-Hoyle \& Hammons, 2015), in the present study, Pell Grant eligibility was used as a proxy for student income status, with students who are eligible for a Pell Grant being considered low income.

Another group at risk of engineering attrition is first-generation college students. First-generation college students often face more uncertainty when selecting undergraduate majors, are less likely to earn engineering credits, and less likely to major in engineering (Chen \& Carroll, 2005). Martin, Miller, and Simmons (2014) found that, 
compared to continuing-generation college students (CGC), first-generation college students (FGC) are less likely to have mentors that have provided them with recommendations on engineering courses (CGC: $84.4 \%$; FGC: $75.0 \%$ ), talked to them about potential engineering careers (CGC: 83.6\%; FGC: 74.8\%), paid for them to attend science or engineering camps or programs (CGC: $52.6 \%$; FGC: 37.7\%), helped them with work in their engineering courses (CGC: 85.5\%; FGC: 75.0\%), helped them find internships, research opportunities, and/or available jobs and scholarships (CGC: 78.4\%; FGC: 70.3\%), and written letters of recommendation for these opportunities when they arise (CGC: $77.6 \%$; FGC: 69.1\%). Each of these factors can negatively impact students' decisions to enroll in engineering programs and persist in the programs once they've enrolled.

Unfortunately, first-generation college students are less likely to persist in their engineering majors and more likely to leave college without earning a degree when faced with difficulty in their engineering courses compared to students whose parents had some work toward a postsecondary degree (Chen, 2013; Shaw \& Barbuti, 2010). Firstgeneration college students do not typically persist in engineering programs for the sole purpose of gaining respect or earning a degree that is valued by their family because the students understand that their family and friends are likely less familiar with their future engineering careers (Garriott, Navarro, \& Flores, 2017). Similarly, Fernandez, Trenor, Zerda, and Cortes (2008) found that one of the largest barriers for first-generation college students in engineering programs is that their family members often do not understand the difficulties and challenges that accompany earning an engineering degree (or higher education, in general). Although there appears to be an overall consensus that first- 
generation college students face unique challenges when it comes to persistence in engineering programs, this group is considerably understudied in existing research. In general, there seems to be more emphasis placed on race and gender when seeking to explain low engineering retention rates.

Students' interpretations of what it means to have been previously identified as gifted also can shape their perceptions of their abilities and, as a result, how they respond to academic challenges in their engineering programs. While some researchers believe giftedness is associated with a fixed mindset regarding intelligence (i.e., gifted students possess an innate ability for academic success; Dweck, 2000; Lohman \& Korb, 2006; Simonton, 2005), others have shown that the term "giftedness" is not necessarily associated with beliefs about innate ability (Makel, Snyder, Thomas, Malone, \& Putallaz, 2015; Snyder, Barger, Wormington, Schwartz-Bloom, Linnenbrink-Garcia, 2013). Thus, there is not only disagreement among students regarding the relationship between giftedness and ability, but there is also variability among how researchers perceive this relationship.

Although it is important to understand educators' perceptions of students' abilities, I am primarily interested in understanding students' perceptions of their own academic abilities. Students who have been identified as gifted have a heightened awareness of their own academic abilities and expectations for success (Preckel, Goetz, Pekrun, \& Kleine, 2008). Thus, their awareness and expectations can shape interpretations of their experiences during their engineering programs and, ultimately, their persistence. Students vary in their implicit beliefs regarding giftedness. While some students endorse fixed mindsets (i.e., students perceive that giftedness is a trait that only 
some students possess and cannot be improved), others endorse growth mindsets (i.e., students perceive that giftedness is a trait that can be improved; Makel et al., 2015). Because of this, we cannot be certain how students' previous gifted identifications (i.e., formally identified as gifted in elementary, middle, or high school) will influence their perceptions of their own abilities during their undergraduate engineering programs. Examining students' previous gifted identification statuses as a potential predictor of profile membership and transitions provided additional insight into the role that students' competence beliefs play in undergraduate engineering retnetion.

\section{Current Study}

According to the social-cognitive theory, students' beliefs affect their interpretations of their academic experiences, and these interpretations drive students' behaviors, whether positive or negative (Dweck \& Leggett, 1988). Student perceptions, including expectations of brilliance (e.g., Leslie et al., 2015), belonging (e.g., Marra et al., 2012), and self-efficacy (e.g., Litzler et al., 2014) affect students' persistence in engineering. Based on other motivation-related, person-centered research (e.g., Chen, 2012; Wormington \& Linnenbrink-Garcia, 2017), adopting a person-centered approach would help researchers identify which adaptive and maladaptive profiles result from combinations of student perceptions when studying undergraduate engineering retention. Similarly, upon reviewing the existing literature on the topic of students' experiences in engineering programs and engineering retention, students' demographic characteristics would likely predict profile membership (e.g., Conrad et al., 2009; Leslie et al., 2015; Litzler et al., 2014). 
Most researchers have taken a variable-centered (Bergman \& Trost, 2006) approach to examining retention in engineering programs by looking at how specific student demographic variables (primarily race and gender) are independently related to success (e.g., achievement, retention) in engineering programs. In contrast, a personcentered approach is helpful, as it not only has the potential to uncover profiles of perceptions endorsed by different groups of students, but also to provide insight into which profiles are more- or less-adaptive for engineering retention (Bergman \& Trost, 2006; Laursen \& Hoff, 2006; Magnusson, 1998). As is the case with the majority of existing person-centered research, taking a variable-centered approach runs the risk of leading researchers to overlook the unique challenges faced by students with average or neutral beliefs (Conley, 2012; Wormington \& Linnenbrink-Garcia, 2017). Further, a variable-centered approach can mask the differences in the profiles of students reporting the highest levels of a particular set of beliefs (Chen, 2012).

I wanted to move away from the tendency to look for direct links between predominately high or low levels of a single type of student perception and engineering retention, as these "direct links" often end up being conditional on students' endorsement of related perceptions and can vary according to students' demographic characteristics. Variable-centered research indicates that the relationship between engineering selfefficacy and retention for certain racial groups depends on other factors, including students' sense of belonging and students' perceptions of their own academic abilities (Litzler et al., 2014). Additionally, using a variable-centered approach, Marra and colleagues (2012) found that both lack of belonging and low self-efficacy significantly contribute to students' decisions to leave their engineering programs, and even these 
factors varied by students' genders and ethnicities. What profiles might have emerged from each of these studies had a person-centered approach been used? When considering engineering retention, which of these profiles would have been adaptive or maladaptive? I wanted to drive research forward by using a person-centered approach to uncover these consistently overlooked profiles.

In general, little research exists that focuses on student perceptions and engineering retention. Although university students perceive that the engineering discipline places heavier emphasis on brilliance compared to many other disciplines (Leslie et al., 2015), little is known about how this predicts engineering retention. Similarly, researchers have yet to study the latent profiles resulting from students' expectations of brilliance, belonging, and self-efficacy, let alone to understand undergraduate engineering retention. When considering demographic characteristics that could predict profile membership and transitions, most studies have focused on the interaction between race and gender with students' engineering competence (e.g., Amelink \& Creamer, 2010; Litzler et al., 2014). As a result, less is known about other potential interactions involving students' previous gifted identifications, socioeconomic status, and first-generation college student status, though these factors can influence persistence (Preckel et al., 2008; Shaw \& Barbuti, 2010; Strutz et al., 2012). I addressed several of these existing gaps.

The research questions guiding this study include:

RQ 1) What latent profiles emerge from measures of student beliefs, including students' expectations of brilliance, perceived belonging uncertainty, and self- 
efficacy? How do the number and types of latent profiles change over the course of a semester?

RQ 2) How does the proportion of students who are best classified into each latent profile change over the course of a semester?

RQ 3) How do student demographic characteristics (i.e., students' race/ethnicity, gender, Pell Grant eligibility, first-generation college student status, reported previous identification as Gifted/Talented, and first-semester mathematics course) predict latent status membership?

RQ 4) Ultimately, how do latent transitions predict one-year retention in undergraduate engineering programs?

As previously mentioned, this combination of student perceptions has not been studied; however, general hypotheses were made. (RQ 1) Based on previous personcentered research (e.g., Chen, 2012; Wormington, \& Linnenbrink-Garcia, 2017), both adaptive and maladaptive perception profiles should emerge. An "adaptive triad" might include lower expectations of brilliance, lower levels of perceived belonging uncertainty, and high self-efficacy, while a "maladaptive triad" would likely include higher expectations of brilliance, higher levels of perceived belonging uncertainty, and low selfefficacy. I anticipated that additional latent profiles consisting of various combinations of these perceptions also would likely emerge.

(RQ 2) It is difficult to predict exactly how students will transition over the course of the semester. However, previous researchers have found that, if students transition between different latent profiles, they typically move from more-adaptive to less-adaptive profiles or remain in less-adaptive profiles across transition periods (e.g., 
Hayenga \& Corpus, 2010; Nurmi \& Aunola, 2005). Given that the academic rigor for engineering programs tends to increase over the course of a semester, I anticipated that several students would either transition toward less-adaptive profiles or remain in maladaptive profiles if that is their initial status.

(RQ 3) Students who identify with a racial/ethnic minority group (Litzler et al., 2014), female (Marra et al., 2009), low-income (Donaldson et al., 2008), or as a firstgeneration college student (Chen, 2013) typically experience lower levels of engineering confidence, which can negatively affect retention. It was also anticipated that students who did not report having been previously identified as Gifted/Talented may not have the same heightened awareness of their academic abilities or expectations for success compared to students who report having previously been identified as Gifted/Talented (Preckel et al., 2008). There also was interest among professors in the engineering school in examining how students' first-semester mathematics course might predict latent status memberships, as some professors have noticed motivation and achievement-related differences between students who were enrolled in a lower-level introductory mathematics course (while completing the pre- and post-surveys) versus students who were not in the lower-level course. These attributes are likely predictive of classification into less-adaptive latent statuses.

(RQ 4) Overall, my original hypotheses included that the adaptive latent statuses should be predictive of higher rates of retention in undergraduate engineering programs. On the other hand, the maladaptive, or less-adaptive, latent statuses should predict lower rates of undergraduate engineering retention. 


\section{CHAPTER THREE}

\section{METHODS}

\section{Participants}

Participants included full-time freshman engineering students matriculated at a large, public university in the Midwest. There were two cohorts of undergraduate engineering students, including students beginning in the fall of 2016 (Cohort $1 ; N=438$, $52.52 \%$ ) and students beginning in the fall of 2017 (Cohort 2; $N=396,47.48 \%$ ). Cohorts 1 and 2 were combined for an overall analytical sample size of $834^{1}$ students with an average age of 18 years old $(S D=.42$; range: $16-19$ years old $)$. Table 1 provides a breakdown of a selection of the student demographic characteristics for Cohort 1, Cohort 2 , and for the overall sample. These variables served as covariates in the latent transition analysis (LTA). As shown in the table, the sample was predominantly male $(N=647$, $77.58 \%)$ and White $(N=736,88.25 \%)$, with the remainder of the participants identifying as Asian $(N=49,5.88 \%)$, Black/African American $(N=37,4.44 \%)$, or Hispanic/Latinx

\footnotetext{
${ }^{1}$ The original sample consisted of 960 students. Students who identified with a racial or ethnic group other than White, Asian, Black/African American, or Hispanic/Latinx and students who were enrolled in a firstsemester mathematics course other than ENGR 101 or ENGR 190 were excluded from the overall sample to prevent potential model identification issues due to small sample sizes. This resulted in 76 students being removed from the original sample. The exclusion of these racial/ethnic groups is described in greater detail in the 'Analysis' section. Further, 50 additional students were eliminated from the original sample due to missing data on all student perception items and/or missing data on one or more of the covariates. This is described in greater detail in the 'Data Cleaning' section. Both eliminations (126 students total) resulted in a sample of 834 students. This sample is described above.
} 
$(N=12,1.44 \%)$. The largest group of students majored in the Mechanical Engineering discipline $(N=229,27.46 \%)$, followed by Computer Engineering and Computer Science $(N=163,19.54 \%)$, Bioengineering $(N=120,14.39 \%)$, Chemical Engineering $(N=106,12.71 \%)$, Civil and Environmental Engineering $(N=86,10.31 \%)$, Electrical Engineering $(N=68,8.15 \%)$, Industrial Engineering $(N=27,3.24 \%)$, and the remainder of the students were undecided in their majors $(N=35,4.20 \%)$.

Table 1

Demographics for Cohort 1, Cohort 2, and the Overall Sample

\begin{tabular}{|c|c|c|c|c|c|c|c|}
\hline Sample & $N$ & Female & Race & $\begin{array}{c}\text { Pell } \\
\text { Grant } \\
\text { Eligible }\end{array}$ & $\begin{array}{c}\text { First- } \\
\text { Generation } \\
\text { College } \\
\text { Student }\end{array}$ & $\begin{array}{c}\text { Reported } \\
\text { Previous } \\
\text { Identification } \\
\text { as Gifted/ } \\
\text { Talented }\end{array}$ & $\begin{array}{l}\text { Lower- } \\
\text { Level } \\
\text { Math } \\
\text { Course }\end{array}$ \\
\hline $\begin{array}{c}\text { Cohort } \\
1 \\
\text { Fall } \\
2016\end{array}$ & 438 & $22.37 \%$ & $\begin{array}{c}\text { W: } 87.90 \% \\
\text { A: } 6.62 \% \\
\text { B: } 4.11 \% \\
\text { H: } 1.37 \%\end{array}$ & $24.20 \%$ & $12.56 \%$ & $76.71 \%$ & $24.89 \%$ \\
\hline $\begin{array}{c}\text { Cohort } \\
2 \\
\text { Fall } \\
2017\end{array}$ & 396 & $22.47 \%$ & $\begin{array}{c}\text { W: } 88.64 \% \\
\text { A: } 5.05 \% \\
\text { B: } 4.80 \% \\
\text { H: } 1.52 \%\end{array}$ & $24.24 \%$ & $9.85 \%$ & $78.03 \%$ & $29.04 \%$ \\
\hline Overall & 834 & $22.42 \%$ & $\begin{array}{c}\text { W: } 88.25 \% \\
\text { A: } 5.88 \% \\
\text { B: } 4.44 \% \\
\text { H: } 1.44 \%\end{array}$ & $24.22 \%$ & $11.27 \%$ & $77.34 \%$ & $26.86 \%$ \\
\hline
\end{tabular}

Notes. Race: $\mathrm{W}=$ White, $\mathrm{A}=$ Asian, $\mathrm{B}=$ Black/African American, $\mathrm{H}=$ Hispanic/Latinx

Pell Grant eligibility was used as the proxy for low-income status, and $24.22 \%(\mathrm{~N}$ $=202$ ) of students were eligible for a Pell Grant, as indicated on the students' Free Applications for Federal Student Aid (FAFSA). First generation college students 
accounted for only $11.27 \%(N=94)$ of the overall sample. $77.34 \%(N=645)$ of the students reported that they previously had been identified as Gifted/Talented, with $3.36 \%$ $(N=28)$ of the students reporting that they had first been identified in the $1^{\text {st }}$ grade, $8.03 \%(N=67)$ in $2^{\text {nd }}$ grade, $45.80 \%(N=382)$ in $3^{\text {rd }}$ grade, $14.51 \%(N=121)$ in $4^{\text {th }}$ grade, and $5.40 \%(N=45)$ in $5^{\text {th }}$ grade.

Data were collected via online surveys that were administered during Week 1 (pre-survey) and Week 13 (post-survey) of the students' first semester enrolled in the engineering school. Pre- and post-surveys were administered during instructional time during a required Introduction to Engineering course. Students' first-semester mathematics course was also included as a covariate in the LTA. 73.14\% $(N=610)$ of students were enrolled in Engineering Analysis I (ENGR 101). Students in ENGR 101 are introduced to vector methods and the development and use of differentiation and integration to solve common engineering problems, including those involving motion, related rates, optimization, moments, and centers of mass. $26.86 \%(N=224)$ of students were enrolled in Introductory Calculus (ENGR 190), a lower-level course compared to ENGR 101. ENGR 190 reviews algebra, trigonometry, analytic geometry, and introduces the elementary calculus concepts that students will need for ENGR 101.

Students did not receive course credit or payment for participation. Students were invited to participate as part of a broader study aimed at understanding retention in engineering. In the overall sample of 834 students, only 600 (71.94\%) students were enrolled in the engineering school one year later (information regarding retention was obtained through institutional records). Although fall 2018 enrollment data were preliminary, the data were obtained well after the window closed for students to drop or 
add classes. Thus, few changes were anticipated between the preliminary fall 2018 data and the official fall 2018 data.

\section{Measures}

Expectations of brilliance. The Field-Specific Ability Beliefs scale (Leslie et al., 2015) was used to measure students' expectations for brilliance in engineering. The original instrument was validated on a sample $(N=1,820 ; 103$ participants from the engineering discipline) of faculty, postdoctoral fellows, and graduate students from 30 different disciplines (12 STEM, 9 social sciences, and 9 humanities) at multiple public and private universities across the United States. The scale has been supported by evidence that scores demonstrate good internal reliability consistency across disciplines (average $\alpha=.90$; Leslie et al., 2015). The scale consists of four items answered on a 7point Likert scale $(1=$ Strongly disagree to $7=$ Strongly agree $)$ with higher scores reflecting a higher emphasis on raw ability in one's field. Items for the current study were identical to the original items, with the exception of replacing "[discipline]" with “engineering".

On the pre- and post-survey, students' expectations for brilliance in engineering were measured using all four items: 1) Being a top scholar of engineering requires a special aptitude that just can't be taught; 2) If you want to succeed in engineering, hard work alone just won't cut it; you need to have an innate gift or talent; 3) With the right amount of effort and dedication, anyone can become a top scholar in engineering; 4) When it comes to engineering, the most important factors for success are motivation and sustained effort; raw ability is secondary. For this study, I reverse-scored entity-phrased 
items (i.e., higher emphasis on raw ability and talent compared to hard work and effort; items 1 and 2), so that higher scores reflected a greater emphasis on hard work and effort.

Perceived belonging uncertainty. The Perceptions of Belonging Uncertainty scale (Walton \& Cohen, 2007, 2011) was adapted to measure engineering students' perceptions of belonging uncertainty (i.e., uncertainty about the quality of the social bonds that one creates in an academic setting). The original instrument was validated on a sample of students enrolled in an introductory psychology course $(N=189)$ and included three items (sample item: "Sometimes I feel that I belong at [school name], and sometimes I feel that I don't belong at [school name]"). The scale has been found to demonstrate relatively poor internal reliability consistency $(\alpha=.63$; Walton $\&$ Cohen, 2007); however, in an earlier study, reliability improved after the removal of one item (eliminated item: "When something good happens, I feel that I really belong at [college name J"; $\alpha=.82$; Walton \& Cohen, 2011).

Although the items used to measure engineering students' perceptions of belonging uncertainty were based on the items developed by Walton and Cohen (2007), they were heavily adapted by the research team. Specifically, on the pre- and post-survey, students' perceptions of belonging uncertainty were measured using the following items: 1) Sometimes I worry that I do not belong in college; 2) I am anxious about whether I fit in at college; 3) I feel confident that I belong in college; 4) When I face difficulties in college, I wonder if I really fit in. In addition to adding an item, the research team used a 5-point Likert scale $(1=$ Not at all true to $5=$ Completely true $)$ for the modified perceived belonging uncertainty scale in lieu of the 7-point Likert scale $(1=$ Strongly disagree to $7=$ Strongly agree $)$ used by Walton and Cohen $(2007 ; 2011)$. As a result, one 
limitation of this study is that the modified instrument does not have prior reliability or validity evidence.

For the modified perceived belonging uncertainty scale, higher scores originally reflected higher levels of uncertainty regarding one's perceptions of belonging uncertainty. For this study, I reverse-scored the negatively-phrased items (i.e., items 1, 2, and 4) so higher values reflected lower levels of uncertainty. This helped to facilitate interpretations such that higher values for each of the measures used in this study reflected more positive student perceptions.

Self-efficacy. The Self-Efficacy subscale of the Motivated Strategies for Learning Questionnaire (MSLQ; Pintrich \& DeGroot, 1990; Pintrich, Smith, Garcia, \& McKeachie, 1991) was adapted by the research team to measure students' self-efficacy in regard to an introductory mathematics course required for engineering students. The original instrument was validated on a sample $(N=173)$ of seventh-grade students in English and Science classrooms. The MSLQ includes 56 items on motivation, cognitive and metacognitive strategy use, and effort management (Pintrich \& DeGroot, 1990). Nine of these items measured self-efficacy (sample item: "I expect to do very well in this class"). The self-efficacy subscale has previously been supported with good internal reliability consistency ( $\alpha=.89$; Pintrich $\&$ DeGroot, 1990).

Similar to the perceived belonging uncertainty items, the self-efficacy items were heavily adapted by the research team for the current study, resulting in the same limitations (i.e., lack of prior reliability or validity evidence for the modified instrument). The research team selected eight items answered on the same 7-point Likert scale $(1=$ Not at all true to $7=$ Very true) used by Pintrich and DeGroot (1990). On the pre- and 
post-survey, students' self-efficacy was measured using the following items: 1) I believe I will receive an excellent grade in this class; 2) I'm certain I can understand the most difficult material presented in this course; 3) I'm confident I can understand the basic concepts taught in this course; 4) I'm confident I can understand the most complex material presented by the instructor in this course; 5) I'm confident I can do an excellent job on the assignments and tests in this course; 6) I expect to do well in this class; 7) I'm certain I can master the skills being taught in this class; 8) Considering the difficulty of this course, the teacher, and my skills, I think I will do well in this class. All items were positively phrased with higher scores reflecting higher self-efficacy; therefore, reversescoring was not necessary for any items.

Psychometric evidence. To check the psychometric properties of the expectations of brilliance, perceived belonging uncertainty, and self-efficacy items, I used SPSS 25.0 to conduct a reliability analysis for each scale from the pre- and postsurveys. Cronbach's alpha $(\alpha)$ values above .80 were considered good (Kline, 2013). Internal consistency reliability for the four expectations of brilliance items was poor for the pre- $(\alpha=.64 ; 95 \%$ CI $[.60, .68])$ and post-surveys $(\alpha=.72 ; 95 \%$ CI $[.68, .76])$. I used the "scale if item deleted" option in SPSS 25.0 to observe how internal consistency reliability would have changed for the overall scale if one or more of the problematic items had been removed, while simultaneously considering how removing the item(s) would change the scope of what the instrument measured. Based on the adjusted Cronbach's alpha value, reliability would not have improved for the scale by removing any of the items. Internal consistency reliability for the perceived belonging uncertainty items was good for the pre- $(\alpha=.83 ; 95 \%$ CI $[.81, .85])$ and post-surveys $(\alpha=.85 ; 95 \%$ 
CI $[.83, .87])$. Similarly, internal consistency reliability for the self-efficacy items also was good for the pre- $(\alpha=.94 ; 95 \% \mathrm{CI}[.93, .94])$ and post-surveys $(\alpha=.92 ; 95 \%$ CI [.91, $.93])$.

In addition to the results from the reliability analysis, I used Mplus 8.0 (Muthén \& Muthén, 1998-2015) and maximum likelihood (ML) estimation to conduct a separate confirmatory factor analysis (CFA) for each scale to ensure that model fit was acceptable for each of the three student perception measures. Acceptable model fit was evaluated based on the following criteria: Root Mean Square Error of Approximation (RMSEA) values less than .05 for good model-data fit and .08 for acceptable, and Comparative Fit Index (CFI) and Tucker Lewis Index (TLI) values greater than .95 (Hu \& Bentler, 1999). Although RMSEA values for the perceived belonging uncertainty and self-efficacy scales were high, given the small degrees of freedom, RMSEA is not always considered a useful criterion for judging model-data fit (Kenny, Kaniskan, \& McCoach, 2015). In fact, most fit indices have been found to perform poorly with models that have small degrees of freedom (Kenny et al., 2015).

First, model-data fit was examined for the expectations of brilliance scale (see Appendix A for model fit indices prior to modification). A post hoc correlation was included between two items (Being a top scholar of engineering requires a special aptitude that just can't be taught and If you want to succeed in engineering, hard work alone just won't cut it; you need to have an innate gift or talent"; pre-survey: $r=.47$, standardized residual covariance $=0.43$; post-survey: $r=.61$, standardized residual covariance $=0.54)$ because 1$)$ these items were conceptually similar- measuring students' perceptions regarding innate abilities, and 2) both items were entity-phrased and, as a 
result, were reverse-scored. Upon including the correlation, there was good model-data fit for the expectations of brilliance scale (pre-survey: $\chi^{2}(1)=1.60, p=.21$; CFI $=1.00$; TLI $=.99 ; \mathrm{RMSEA}=.03,90 \% \mathrm{CI}[.00, .10]$ and post-survey: $\chi^{2}(1)=0.12, p=.73 ; \mathrm{CFI}=$ $1.00 ; \mathrm{TLI}=1.00 ; \mathrm{RMSEA}=.00,90 \% \mathrm{CI}[.00, .07])$. Given the improvements in modeldata fit upon including the correlation, the expectations of brilliance scale was included in the remaining analyses. However, a limitation is that it was included as a mean score (which does not account for the correlated error terms), not as a latent variable.

Next, model-data fit was examined for the perceived belonging uncertainty scale (see Appendix A for model fit indices prior to modification). A post hoc correlation was included between two items (Sometimes I worry that I do not belong in college and I am anxious about whether I fit in at college; pre-survey: $r=.63$, standardized residual covariance $=-0.88 ;$ post-survey: $r=.73$, standardized residual covariance $=-1.58$ ) because 1) these items were conceptually similar- measuring students' anxiety or worry over a prolonged period of time, and 2) both items were negatively-phrased and, as a result, were reverse-scored. Upon including a post hoc correlation, model fit was acceptable for the perceived belonging uncertainty scale (pre-survey: $\chi^{2}(1)=25.90, p<$ $.001 ; \mathrm{CFI}=.98 ; \mathrm{TLI}=.88 ; \mathrm{RMSEA}=.17,90 \% \mathrm{CI}[.12, .23]$ and post-survey: $\chi^{2}(1)=$ $17.01, p<.001 ; \mathrm{CFI}=.99 ; \mathrm{TLI}=.92 ; \mathrm{RMSEA}=.15,90 \% \mathrm{CI}[.10, .22])$. Similar to the expectations of brilliance scale, given the improvements in model-data fit after including the correlation, the perceived belonging uncertainty scale was included in the remaining analyses. Additionally, the same limitation holds- the perceptions of belonging measure was included as a mean score (which does not account for the correlated error terms), not as a latent variable. 
Model fit also was acceptable for the self-efficacy scale pre-survey but was poor for the post-survey (pre-survey: $\chi^{2}(20)=423.22, p<.001$; CFI $=.92$; TLI $=.89$; RMSEA $=.16,90 \%$ CI $[.14, .17]$ and post-survey: $\chi^{2}(20)=915.46, p<.001 ; \mathrm{CFI}=.79 ; \mathrm{TLI}=.71$; RMSEA $=.26,90 \%$ CI $[.24, .27])$. No post hoc correlations were added to this model given that the items did not meet the two criteria for including a post hoc correlation (i.e., conceptually similar and reverse-scored). Given that model-data fit was acceptable at one time point, I decided to include the scale in the analyses. However, issues regarding model data fit will be addressed in the limitations section of the discussion.

Given the small degrees of freedom in the models (Kenny et al., 2015), the high RMSEA values for the perceived belonging uncertainty and self-efficacy scales were overlooked, and model fit for each scale was considered good. I decided to move forward with the analyses using the three student perceptions scales for expectations of brilliance, belonging uncertainty, and self-efficacy. Mean scores were used for the three perceptions measures as opposed to factor scores given that mean scores are the standard for these instruments (e.g., Leslie et al., 2015; Pintrich \& DeGroot, 1990; Pintrich et al., 1991; Walton \& Cohen, 2007). Internal consistency reliability and model-data fit indices for each scale are provided in Table 2. Model fit indices prior to including the post hoc correlations for the expectations of brilliance and perceived belonging uncertainty scales are provided in Appendix A. 
Table 2

Internal Consistency Reliability and Model Fit Indices for the Student Perceptions Measures

\begin{tabular}{|c|c|c|c|c|c|}
\hline Model & $\alpha[95 \% \mathrm{CI}]$ & $\chi^{2}(\mathrm{df}), p$ & CFI & TLI & RMSEA $[90 \% \mathrm{CI}]$ \\
\hline $\begin{array}{l}\text { Expectations } \\
\text { of Brilliance } \\
\text { Pre-Survey }^{\mathrm{a}}\end{array}$ & $.64[.60, .68]$ & $\begin{array}{c}\chi^{2}(1)=1.60 \\
p=.21\end{array}$ & 1.00 & .99 & $.03[.00, .10]$ \\
\hline $\begin{array}{l}\text { Expectations } \\
\text { of Brilliance } \\
\text { Post-Survey }^{\mathrm{a}}\end{array}$ & $.72[.68, .76]$ & $\begin{array}{c}\chi^{2}(1)=0.12 \\
p=.73\end{array}$ & 1.00 & 1.00 & $.00[.00, .07]$ \\
\hline $\begin{array}{l}\text { Perceived } \\
\text { Belonging } \\
\text { Uncertainty } \\
\text { Pre-Survey }\end{array}$ & $.83[.81, .85]$ & $\begin{array}{c}\chi^{2}(1)=25.90 \\
p<.001\end{array}$ & .98 & .88 & $.17[.12, .23]$ \\
\hline $\begin{array}{c}\text { Perceived } \\
\text { Belonging } \\
\text { Uncertainty } \\
\text { Post-Survey }^{\mathrm{a}}\end{array}$ & $.85[.83, .87]$ & $\begin{array}{c}\chi^{2}(1)=17.01 \\
p<.001\end{array}$ & .99 & .92 & $.15[.10, .22]$ \\
\hline $\begin{array}{l}\text { Self-Efficacy } \\
\text { Pre-Survey }\end{array}$ & $.94[.93, .94]$ & $\begin{array}{c}\chi^{2}(20)=423.22 \\
p<.001\end{array}$ & .92 & .89 & $.16[.14, .17]$ \\
\hline $\begin{array}{l}\text { Self-Efficacy } \\
\text { Post-Survey }\end{array}$ & $.92[.91, .93]$ & $\begin{array}{c}\chi^{2}(20)=915.46 \\
p<.001\end{array}$ & .79 & .71 & $.26[.24, .27]$ \\
\hline
\end{tabular}

Note. ${ }^{\text {a }}$ indicates that the scale included post hoc correlated errors in the model.

\section{Data Cleaning}

Coding: perception measures. Responses were collected using the Blue Surveys platform. The data were saved as separate pre- (Week 1) and post- (Week 13) survey Excel files for each year. The codebooks already had been created by individuals within the engineering school, but the raw data needed to be recoded for most variables. Initially, most responses to items for the three perception measures were not in numerical format. As previously mentioned, the expectations of brilliance and self-efficacy 
measures were on a 7-point Likert scale. The Blue Surveys system numerically coded response values 2-6 but did not numerically code response values 1 or 7 for either scale. These responses were provided as Strongly disagree (1) and Strongly agree (7) for the expectations of brilliance scale and as Not at all true (1) and Very true (7) for the selfefficacy scale. Thus, values for these items had to be numerically recoded. The Blue System also did not numerically code any of the responses for the perceived belonging uncertainty scale. These responses had to be numerically recoded such that $1=$ Not at all true, $2=$ Slightly true, $3=$ Somewhat true, $4=$ Very true, $5=$ Completely true . For each of the indicator variables above, I previously described in the 'Measures' section which, if any, of the items needed to be reverse-scored before imputing missing values and calculating mean scores

Coding: demographic variables. Table 3 provides the coding scheme for the dummy-coded demographic variables that served as covariates in the LTA. As I discuss further in the 'Analysis' section, given that the LTA covariates were dummy coded, I removed data for students who did not belong to the dummy-coded groups for race (i.e., Multiracial and other), and students who were not enrolled in the two largest introductory mathematics courses in the engineering school (i.e., ENGR 102 and ENGR 201 students). Students belonging to these smaller demographic groups were removed from the sample, rather than combining these students with the reference groups. This process was completed in order to prevent potential issues with model identification during the LTA (Collins \& Lanza, 2010). 
Table 3

Coding Scheme for Demographic Variables

\begin{tabular}{cc}
\hline Variable & Coding scheme \\
\hline $\begin{array}{c}\text { Reported previous identification as } \\
\text { Gifted/Talented } \\
\text { Race/ethnicity }\end{array}$ & no $=0$, yes $=1$ \\
& $\begin{array}{c}\text { Dummy codes for Asian, Black/African } \\
\text { American, and Hispanic/Latinx. } \\
\text { Reference group }=\text { White }\end{array}$ \\
Gender & male $=0$, female $=1$ \\
First-generation college student status & no $=0$, yes $=1$ \\
First-semester math course & no $=0$, yes $=1$ \\
\end{tabular}

Notes. Data for the demographic variables were collected using the following questions on the pre-survey: Reported previous identification as Gifted/Talented: "Have you ever been identified as academically gifted/talented in school?"; Race/ethnicity: "What is your racelethnicity? Please select all that apply."; First-generation college student status: "Are you the first member of your immediate family to attend college?". ENGR 190 is a lowerlevel course compared to ENGR 101. Data for Pell Grant eligibility (used as a proxy for income status), gender, and first-semester math course were obtained from institutional records.

Coding: distal outcome. To examine the distal outcome, 1-year retention, I obtained student enrollment information from the engineering school. For Cohort 1 (2016), I checked to see whether or not the student was still enrolled at the engineering school in 2017. Similarly, for Cohort 2 (2017), I checked to see whether or not the student was still enrolled at the engineering school in 2018. I then combined these data (0 $=$ not enrolled 1 year later; 1 = enrolled 1 year later) to create the one-year retention variable.

Merging and missing data. In SPSS 25.0, I used the original Research ID variable to merge pre- and post-survey data into a single file for Cohorts 1 and 2 . I then 
created a dummy-coded variable (Cohort: $0=2016,1=2017$ ) that was added to the models to control for any potential differences between cohorts. There was one set of demographic variables in the file, and these came from either the pre-survey responses (given that demographic data were only collected during the pre-survey administrations) or institutional records. The binary outcome variable, one-year retention, also was included in the file. Finally, I recoded any missing data (blank or D/A) as -99 before importing data from SPSS 25.0 into Mplus 8.0.

After importing the combined data into Mplus 8.0, I checked basic descriptive statistics for each variable using the "type = BASIC" command. This output provided information regarding the number of observations and variables, a summary of missing data, variable sample sizes, means, and variances. From this output, I checked to make sure that missing data had been handled correctly. I also checked for any potential coding or input errors (e.g., checking for accurate sample size, minimum and maximum values reflect the range of the scale used for each measure).

Prior to creating mean scores in Mplus 8.0 for the expectations of brilliance, perceived belonging uncertainty, and self-efficacy measures, missing data on the scale items were handled using maximum likelihood (ML) estimation via the expectation maximization (EM) algorithm. The process behind ML estimation and EM are discussed further in the 'Model Estimation' section. Given that certain likelihood-based estimation procedures, including Full Information Maximum Likelihood (FIML) and Expectation Maximization (EM), cannot handle missing data on the covariates, students with missing data on one or more of the demographic covariates were excluded from the sample. In the end, 15 students provided no valid data for any of the student perceptions items. 38 
students had missing race/ethnicity data, 27 students had missing reported previous identification as Gifted/Talented, 34 students had missing first-generation college student status data, and 11 students had missing first-semester mathematics course data. After accounting for overlap between complete missing data on the perception measures and missing data on one or more of the demographic covariates, 50 students were removed from the sample. This accounted for only $5.21 \%$ of the initial student sample.

\section{Analysis}

Choosing a person-centered method. There are numerous person-centered methods available to assist researchers whose goal is to take a person-centered approach; however, each method varies greatly in which person-centered theoretical principle(s) it was designed to test (Sterba \& Bauer, 2010). There are six principles to consider when choosing a person-centered method. These principles state that developmental trajectories and behaviors are specific to the individual (individual specificity principle), include multiple factors that interact (complex interactions principle), include differences between individuals and changes within an individual (inter-individual differences/ intraindividual change principle), can be described by patterns of factors (pattern summary principle) that are meaningful because of the interactions among the factors (holism principle), with some patterns occurring less often than anticipated (pattern parsimony principle; Bergman, 2001; Bergman \& Magnusson, 1997; Sterba \& Bauer, 2010, p. 239; von Eye \& Bogat, 2006, p. 392). Researchers taking a person-centered approach rarely explain why they chose a specific method over others or how it relates to the personcentered principles described above (Sterba \& Bauer, 2010). 
Latent growth curve modeling (LGM), which is considered a variable-centered method, is used to predict development over time. These models provide the average rate of change for a continuous outcome across multiple time points, as well as the variance in individual growth at each time point (Nylund, 2007). LGM is not able to address the pattern summary or pattern parsimony principle, as individuals vary only in their initial status and rate of change across a continuous growth curve (Sterba \& Bauer, 2010). Additionally, like other variable-centered methods, this model can only address the complex interactions principle through added interaction terms (Bauer \& Shanahan, 2007; Sterba \& Bauer, 2010). For this study, it was important to consider a personoriented method that allowed for discontinuous change, or individual variation in latent status memberships and transitions, over time, compared to methods such as LGM where individuals primarily differ in their intercepts and rates of change along a mean growth slope.

I chose to conduct a latent transition analysis (LTA), a classification method that uses multiple indicators to predict latent status membership and discontinuous change or transitions between latent statuses over time (Collins \& Lanza, 2010). This is similar to another classification method known as latent class growth analysis (LCGA). However, LCGA models are unidimensional and individuals are assumed to follow a continuous growth trajectory across multiple time points (Jung \& Wickrama, 2008; Nagin, 2005), which is not applicable to this study given the interest in latent transitions between profiles. Classification methods, including latent transition analysis, are among the most commonly used person-oriented methods (Bergman \& Trost, 2006). However, one restriction of this type of method is that variability in transition probabilities exists only 
between latent statuses, not within latent statuses (i.e., individuals within the same latent status are assumed to vary only due to random error), and this limits the model's ability to test the individual specificity and inter-individual differences/ intra-individual change principles (Sterba \& Bauer, 2010). Classification methods can address the other personcentered principals if researchers work under the assumption that profile exist (i.e., the pattern summary principle is true), even if they do not yet know which profiles exist (Sterba \& Bauer, 2010).

There are other methods that can be used to facilitate a person-centered approach. One method that could be confused with the LTA is the growth mixture model (GMM). Unlike LGCM, a subtype of GMM, the GMM allows for variance in individual growth around the trajectories (Jung \& Wickrama, 2008; Muthén \& Asparaouhov, 2006; Muthén \& Shedden, 1999). Although GMM relaxes some of the assumptions restricted by the other person-oriented methods, GMM was not applicable to this study because, like LGCM, this method models continuous change over time based on latent trajectory classes (Jung \& Wickrama, 2008; Sterba \& Bauer, 2010). GMMs can conditionally test each of the person-centered principles; however, these types of model are prone to specification errors (Bauer \& Curran, 2004; Sterba \& Bauer, 2010). Understanding the connections between person-centered methods and theory can become somewhat confusing, but researchers would be hard-pressed to find a method, variable- or personcentered, that is free from restrictive assumptions or principles (Sterba \& Bauer, 2010).

Preliminary analyses. After an initial check of the data frequencies for the demographic variables in SPSS 25.0, it was evident that the sample sizes for certain racial/ethnic and introductory mathematics course groups in each cohort would be small. 
Small samples tend to produce issues with model identification during LTA (Collins \& Lanza, 2010). To increase the total sample size and the sample sizes for different demographic groups, I combined data from Cohorts 1 and 2. As previously mentioned, I included a dummy-coded variable, cohort, to control for any potential differences between the 2016 and 2017 cohorts.

Although combining data for Cohorts 1 and 2 increased the total sample size (Cohort 1: $N=516$; Cohort 2: $N=444$; Combined: $N=960)^{2}$, the sample sizes for certain racial/ethnic groups (White: $N=761,79.27 \%$; Asian: $N=50,5.21 \%$; Black/African American: $N=38,3.96 \%$; Hispanic/Latinx: $N=12,1.25 \%$; Multiracial: $N=53,5.52 \%$; other: $N=8, .83 \%$; missing: $N=38,3.96 \%$ ) and students enrolled in specific firstsemester mathematics courses (ENGR 101: $N=676,70.42 \%$; ENGR 190: $N=257$, 26.77\%; ENGR 102: $N=15,1.56 \%$; ENGR 201: $N=1,0.10 \%$ ) in the combined sample were still quite small. Given that covariates for LTA must be continuous or dummy coded (Collins \& Lanza, 2010), I analyzed data from four different racial/ethnic groupsWhite, Asian, Black/African American, and Hispanic (3 dummy codes with White as the reference group) and for students enrolled in ENGR 101 and 190. Removing data for the other groups of students resulted in only a small decrease in the total sample size $(N=76$, $7.92 \%$ removed).

Assumptions. Given that continuous indicators are necessary for an LPA, the assumption of normality was checked for each indicator by examining skewness and kurtosis statistics and observing the shape of the distribution in each histogram. Skewness and kurtosis values between -2 and 2 are considered ideal (Field, 2009; Gravetter \&

\footnotetext{
2 This is the original sample, prior to removing missing data as previously discussed in the 'Data Cleaning' section.
} 
Wallnau, 2014; Trochim \& Donnelly, 2006). Skewness and kurtosis were acceptable for the expectations of brilliance (pre-survey: skewness $=-0.01, S D=0.09$, kurtosis $=-0.35$, $S D=0.18$; post-survey: skewness $=0.03, S D=0.10$, kurtosis $=0.01, S D=0.20$ ), perceived belonging uncertainty (pre-survey: skewness $=-0.85, S D=0.09$, kurtosis $=$ 0.04, $S D=0.17$; post-survey: skewness $=-0.89, S D=0.09$, kurtosis $=0.07, S D=0.19$ ), and self-efficacy measures (pre-survey: skewness $=-0.44, S D=0.09$, kurtosis $=-0.17$, $S D=0.17$; post-survey: skewness $=-0.64, S D=0.10$, kurtosis $=0.40, S D=0.19)$. The three measures also appeared to be mostly normally distributed upon visual inspection of the shape of each histogram. Thus, the variables were not transformed and were included in the models as is.

Model estimation. I used Mplus 8.0 to first conduct an LPA for each time point. I then extended the measurement models (LPAs) by conducting an LTA. Model estimates were obtained using maximum likelihood (ML) via the expectation maximization (EM) algorithm. As previously discussed, this method was used to account for missing data on the indicator variables- expectations of brilliance, perceived belonging uncertainty, and self-efficacy mean scores. The EM algorithm produces estimates for correlations and means in two steps: 1) several iterations produce expected values for the missing data conditional on the original correlation matrix and observed values of the other variables in the dataset; 2) expected values are combined with the observed data, maximization occurs, and, after several iterations, final estimates are produced (Dempster, Laird, \& Rubin, 1977).

Anticipating potential model identification issues. Even when total sample sizes are relatively large, model identification issues are common with LTA, as models 
that are more complex (i.e., multiple indicators and/or covariates) lead to sparseness of the data (Collins \& Lanza, 2010). I first tried to address these issues by testing different sets of random starting values, as suggested by Collins and Lanza (2010). When this process did not produce the maximum likelihood solution, the next step was to reduce the amount of unknown information or estimate fewer parameters (i.e., in this study, removing the students associated with the problematic Hispanic/Latinx race covariate; Collins \& Lanza, 2010). After eliminating the students from the sample that identified as Hispanic/Latinx, I decided to rerun the LPAs and continue with the rest of the analyses. Upon removing these students, model identification issues that would compromise the LPA solution subsided.

Measurement model: LPA. Latent profile analysis (LPA) produced the measurement model used to identify the number of latent profiles at each time point for the latent transition analysis (LTA) extension. The analysis plan provided below was established by adapting and combining Nylund's (2007) and Collins and Lanza's (2010) guidelines for specifying an LTA model.

To address RQ 1 (i.e., What latent profiles emerge from measures of student beliefs, including students' expectations of brilliance, perceived belonging uncertainty, and self-efficacy? How do the number and types of latent profiles change over the course of a semester?), I began by conducting an LPA at each time point to identify models with the number of latent subgroups that accurately described the population. For both time points, my best-fitting models consisted of three continuous indicators, including expectations of brilliance, perceived belonging uncertainty, and self-efficacy mean scores. As suggested by Collins and Lanza (2010), I completed the following process 
without covariates to fit baseline models and to understand the underlying latent structures. To arrive at the best-fitting model at each time point (without covariates), I started by specifying a two-profile model (i.e., the smallest number of potential latent subgroups) and then continued to fit a series of models by increasing the number of latent profiles (one at a time) while observing changes in model fit, monitoring potential convergence issues, and considering the interpretability of the latent profiles.

I compared nested models using the log-likelihood, Akaike Information Criterion (AIC), and Bayesian Information Criterion (BIC) values. I also based model selection on Entropy values for each model (i.e., a measure of classification uncertainty on a scale from 0-1 with higher values indicating higher levels of certainty; Pastor, Barron, Miller, \& Davis, 2007). I looked for the model with the highest log-likelihood values (i.e., closest to 0; Pastor et al., 2007) and lowest AIC and BIC values (Akaike, 1987; Schwartz, 1978), while looking for the model with an entropy value closest to 1 (Pastor et al., 2007).

I also examined evidence for support of my decision for the number of profiles by conducting a series of bootstrap likelihood ratio tests (BLRT; McLachlan \& Peel, 2000). I conducted these tests by specifying "TECH14" in the Output command. I also specified "LRTSTARTS = 0010020 " in the Analysis command to prevent log likelihoods not being replicated in the bootstrap draws (Asparouhov \& Muthén, 2012). This is similar to the log likelihood difference test; however, log likelihood difference tests are not applicable to LPA because the necessary conditions are not met (i.e., the difference does not follow a chi-square distribution), yielding unreliable results (McLachlan \& Peel, 2000). A statistically significant BLRT between nested models would indicate 
improvement in model fit from specifying an additional latent profile (McLachlan \& Peel, 2000). Of the different criteria used to determine the most accurate number of latent profiles, BLRT is regarded as one of the best indicators of the number of profiles (Nylund, 2007; Nylund, Asparouhov, \& Muthén, 2007), especially when used in combination with BIC values (Nylund, 2007).

Additionally, I considered the Lo-Mendell-Rubin (LRT) test. The LRT works similarly to the BLRT by comparing model fit between models with neighboring numbers of profiles ( $k-1$ and $k$ profile models), and if the LRT identifies a model, it is typically an overestimation of the number of profiles (Nylund et al., 2007). A significant $p$-value indicates that model fit improved as a result of the additional latent profile (Nylund et al., 2007). LRT results can be obtained by specifying "TECH 11" in the Output command when the estimation method is specified as MLR.

As previously mentioned, the final selection of the number of profiles that best represented both time points also depended heavily on the interpretability of the latent profiles that emerged. When two or more latent profiles seemed to provide the same information (which was the case between the 4- and 5-profile solutions), I opted for the model with the fewest number of latent profiles (i.e., the most parsimonious solution; Lanza \& Collins, 2008). As Collins and Lanza (2010) discuss, it is important before proceeding to ensure that 1) baseline models have been established without covariates, 2) the data are represented adequately, 3) the latent profiles are interpretable, and 4) the models are identified. Before proceeding, these criteria were met (after removing the Hispanic/Latinx student sample). 
To address RQ 2 (i.e., How does the proportion of students who are best classified into each latent profile change over the course of a semester?), I explored transitions by observing the membership proportions for each profile of the best fitting model at both time points. This did not provide information on who transitioned or how individuals moved between latent profiles. Rather, these proportions described the changes in the number of the students who were best classified into each profile over time (i.e., stability versus movement; Nylund, 2007). This also provided an indication of whether or not the proportion of students who are best classified into the maladaptive or less-adaptive profiles increased across the semester (though, again, I was not able to infer exactly how students were moving at this point).

The final step before moving on to the longitudinal extension, LTA, is to do a formal test for measurement invariance. Given that the same number and types of profiles emerged at each time point, this step was necessary to determine if the latent profiles could be interpreted in the same way across time points (Collins \& Lanza, 2010). I used LRT between two models, one with complete measurement invariance (i.e., constraining $\rho$ parameters to be equal across time points) and another with complete measurement non-invariance (i.e., all parameters are free across both time points) to test formally for measurement invariance (Collins \& Lanza, 2010).

When measurement non-invariance significantly improves model fit, latent profiles can not necessarily be considered the same across time points and transitions should be interpreted carefully (Nylund, 2007). Measurement non-invariance does not hinder subsequent analysis, but it can affect interpretations, as it becomes necessary to not only interpret changes in latent profile memberships but also to interpret change over 
time in the meaning of the profiles (Collins \& Lanza, 2010; Lanza, Bray, \& Collins, 2013). Although it is easier to interpret changes in latent profile memberships when the meanings of the profiles are the same across time points, full non-invariance has the potential to uncover important developmental differences that may not have emerged had invariance been applied to the model (Collins \& Lanza, 2010). In this case, measurement invariance would serve as a potential limitation (Nylund, 2007).

Longitudinal extension: LTA. The following analyses address RQ 3 (i.e., How do student demographic and prior achievement characteristics (i.e., students' racelethnicity, gender, Pell Grant eligibility, first-generation college student status, reported previous identification as Gifted/Talented, and first-semester mathematics course) predict latent status membership?) The LTA expanded on the previous LPAs by incorporating the longitudinal aspect into the analysis and the number of profiles that served as the most likely solution for each time point. Throughout most of the analysis description, I use the term latent status(es) rather than latent class(es) or latent profile(s), to indicate that I am discussing individuals' membership that had the potential to change over time, unlike latent classes or profiles where membership is static (Lanza \& Collins, 2008).

To preface, LTA models produce four important sets of parameters: 1) $\delta$ (delta) parameters - probability of membership in a latent status at Time 1 (latent status membership probabilities); 2) $\tau$ (tau) parameters - probability of membership in a latent status at Time 2 conditional on membership in a specific latent status at Time 1 (transition probabilities); 3) $\rho$ (rho) parameters - probability of response to an indicator conditional on membership in a latent status and time (item-response probabilities); 4) $\beta$ 
(beta) parameters - provide information regarding the relation between the covariates, membership in latent statuses, and transitions (logistic regression coefficients; Chung, Park, \& Lanza, 2005; Lanza \& Collins, 2008).

I specified an LTA model without the covariates to ensure that the model had been specified correctly and to observe any changes in the underlying latent structure after adding the longitudinal component. This also served as a means of comparison to describe the effect of including the covariates into the model. Including the covariates in the LTA model provided insight into potential heterogeneity in student transitions across the semester. For each covariate, one $\beta$ regression coefficient was estimated for each latent status at each time point. These parameters reflected the log odds of Time 1 membership compared to membership in the specified reference status (Collins \& Lanza, 2010). These parameters also were used to examine the change in the log odds of transitioning between latent statuses over time relative to staying in the same latent status (Collins \& Lanza, 2010).

Mplus 8.0 generally selects the profile with the largest thresholds or greatest probability of item endorsement as the reference status for each time point, unless otherwise specified. In most models, this was what would be considered the mostadaptive latent status, which also happened to be the latent status with the greatest probability of endorsement. For the LTA models, I had to test several models with an increasing number of random starting values for each model in order to produce a solution where the best log likelihood values had been replicated and model parameters did not need to be fixed due to empty cells in the joint distribution of the latent variables. 
Finally, to address RQ 4 (i.e., Ultimately, how do latent transitions predict 1-year retention in undergraduate engineering programs?), I built upon the previous LTA model by including the binary, distal outcome of 1-year retention. Including a binary, distal outcome in an LTA model is essentially the same as including an additional latent profile indicator on the final time point. This analysis predicted the proportion of students who were enrolled in the undergraduate engineering program in 2017 or 2018 for Cohorts 1 and 2, respectively, based on the latent status transition and the student's latent status at the end of the semester (i.e., Time 2). 


\section{CHAPTER FOUR \\ RESULTS}

\section{Measurement Model Specification}

Statistical indicators. A series of latent profile models were specified for each time point, beginning with the smallest number of potential latent profiles (two) and continuing until the models began having issues converging on a stable solution and/or until fit indices indicated the likely solution had already been produced. Model fit was assessed at each time point and compared to the previously specified model with one fewer profile. Covariates were not included in the models at this point. A variety of fit indices were used to gauge model fit, including AIC, BIC, log-likelihood values, entropy, BLRT, and LMR values. In addition, the interpretability of the latent profiles that emerged was heavily considered. As previously mentioned, although all fit indices were considered, the most commonly used fit indices for profile selection are BIC and BLRT values (Nylund, 2007). LPA fit indices for Times 1 and 2 including the sample of Hispanic/Latinx students are provided in Appendix B. These fit indices are provided only for reference because, as I will discuss next, the analyses were replicated after removing the small sample of Hispanic/Latinx students in order to resolve model fit issues.

Issues with model specification occurred when specifying four or more latent profiles. Upon investigating the problematic parameter (i.e., the Hispanic/Latinx covariate for the Time 14-profile model for the perceptions of belonging uncertainty 
measure for the largest latent profile), it became clear that the small sample size for the Hispanic/Latinx subgroup would be problematic in subsequent analyses. Thus, Hispanic/Latinx students $(N=12,1.44 \%)$ were removed from the sample. LPA fit indices for Times 1 and 2 (excluding the sample of Hispanic/Latinx students) are provided in Tables 4 and 5, respectively. Removing the Hispanic/Latinx student group did not drastically change the fit indices or number of profiles selected at each time point. It did, however, prevent persistent issues with model identification. The remainder of the analyses and the discussion of the results represent the student sample without Hispanic/Latinx students.

It is not uncommon for sample sizes to vary from time point to time point, especially as students elect to or are unable to complete the post-survey for various reasons. According to Collins and Lanza (2010) data also can be used for LTA when participants only have responses for some of the items (i.e., missing data addressed through ML estimation) and/or when participants are only present at a subset of the time points. There were 822 students who provided useful data at Time 1 (after removing the Hispanic/Latinx sample). Because there were 147 students missing data on all postsurvey items, the sample size at Time 2 was slightly smaller at 678 students (687 students originally at Time 2 after the 147 were removed for missing data, reduced by an additional 9 students who were Hispanic/Latinx and not originally included in the all missing data group).

Based on the LPA results in Tables 4 and 5, fit indices supported the selection of a 5-profile model at both time points. The 5-profile model produced the lowest AIC and BIC values at Time 1 (6432.78 and 6536.44, respectively). Although, at Time 2, AIC 
values tended to decrease from the 5-profile model to the 6-profile model (5548.88 compared to 5527.26), the decrease in BIC values from the 5-profile model to the 6profile model was minimal (5648.30 compared to 5644.76). Entropy also was highest for the 5-profile model for both time points (.82 and .89, respectively). At Time 1, the BLRT first became non-significant $(p=1.00)$ following the 5-profile model, suggesting that there was not improvement in model fit by adding an additional latent profile. Although there were other instances where the LMR test switched between significant and nonsignificant $p$-values, the LMR test switched from significant to non-significant $p$-values between the 5- and 6-profile solutions $(p=.71$ and $p=.10$ for the 6-profile model at Times 1 and 2, respectively). Given this, results from the LMR test suggest that model fit did not significantly improve with the addition of the sixth profile. 
Table 4

Time 1/Pre-Survey LPA Fit Indices for the Sample Without Hispanic/Latinx Students

\begin{tabular}{|c|c|c|c|c|c|c|c|}
\hline $\begin{array}{l}\text { Number } \\
\text { of } \\
\text { Profiles }\end{array}$ & $\begin{array}{l}\text { Counts and } \\
\text { Proportion of } \\
\text { Participants }\end{array}$ & AIC & BIC & $\begin{array}{c}\text { Log } \\
\text { Likelihood }\end{array}$ & Entropy & BLRT & LMR \\
\hline 2 & $\begin{array}{l}\text { Profile 1: } 191.63(.23) \\
\text { Profile 2: } 630.37(.77)\end{array}$ & 6534.06 & 6581.18 & -3257.03 & .82 & $<.001$ & $<.001$ \\
\hline 3 & $\begin{array}{l}\text { Profile } 1: 74.46(.09) \\
\text { Profile 2: } 201.63(.25) \\
\text { Profile 3: } 545.91(.66)\end{array}$ & 6497.71 & 6563.68 & -3234.86 & .79 & $<.001$ & .11 \\
\hline 4 & $\begin{array}{l}\text { Profile } 1: 349.42(.43) \\
\text { Profile } 2: 50.96(.06) \\
\text { Profile } 3: 146.57(.18) \\
\text { Profile } 4: 275.05(.33)\end{array}$ & 6456.33 & 6541.14 & -3210.16 & .79 & $<.001$ & .004 \\
\hline 5 & $\begin{array}{l}\text { Profile } 1: 88.18(.11) \\
\text { Profile } 2: 35.49(.04) \\
\text { Profile } 3: 123.23(.15) \\
\text { Profile } 4: 268.57(.33) \\
\text { Profile } 5: 306.52(.37)\end{array}$ & 6432.78 & 6536.44 & -3194.39 & .82 & $<.001$ & .02 \\
\hline 6 & $\begin{array}{l}\text { Profile } 1: 35.40(.04) \\
\text { Profile } 2: 79.32(.10) \\
\text { Profile } 3: 247.60(.30) \\
\text { Profile } 4: 141.63(.17) \\
\text { Profile 5: } 301.22(.37) \\
\text { Profile } 6: 16.83(.02)\end{array}$ & 6434.17 & 6556.68 & -3191.09 & .76 & 1.00 & .71 \\
\hline
\end{tabular}

Notes. $N=822$; AIC $=$ Akaike Information Criterion; $\mathrm{BIC}=$ Bayesian Information Criterion; BLRT = Bootstrap Likelihood Ratio Test; LMR = Lo-Mendell-Rubin Test; Final class solutions were also guided by theory. 
Table 5

Time 2/Post-Survey LPA Fit Indices for the Sample Without Hispanic/Latinx Students

\begin{tabular}{|c|c|c|c|c|c|c|c|}
\hline $\begin{array}{l}\text { Number } \\
\text { of } \\
\text { Profiles }\end{array}$ & $\begin{array}{l}\text { Counts and } \\
\text { Proportion of } \\
\text { Participants }\end{array}$ & AIC & BIC & $\begin{array}{c}\text { Log } \\
\text { Likelihood }\end{array}$ & Entropy & BLRT & Г LMR \\
\hline 2 & $\begin{array}{l}\text { Profile } 1: 183.50(.27) \\
\text { Profile } 2: 494.50(.73)\end{array}$ & 5719.32 & 5764.51 & -2849.66 & .82 & $<.001$ & $<.001$ \\
\hline 3 & $\begin{array}{l}\text { Profile } 1: 436.91(.64) \\
\text { Profile } 2: 54.70(.08) \\
\text { Profile } 3: 186.39(.27)\end{array}$ & 5667.52 & 5730.79 & -2819.76 & .82 & $<.001$ & .12 \\
\hline 4 & $\begin{array}{l}\text { Profile } 1: 28.29(.04) \\
\text { Profile } 2: 330.94(.49) \\
\text { Profile } 3: 130.77(.19) \\
\text { Profile 4: } 188.00(.28)\end{array}$ & 5600.36 & 5681.71 & -2782.18 & .87 & $<.001$ & .87 \\
\hline 5 & $\begin{array}{l}\text { Profile } 1: 8.35(.01) \\
\text { Profile } 2: 319.21(.47) \\
\text { Profile } 3: 187.19(.28) \\
\text { Profile } 4: 48.58(.07) \\
\text { Profile } 5: 114.68(.17)\end{array}$ & 5548.88 & 5648.30 & -2752.44 & .89 & $<.001$ & $<.001$ \\
\hline 6 & $\begin{array}{l}\text { Profile } 1: 8.55(.01) \\
\text { Profile } 2: 45.27(.07) \\
\text { Profile } 3: 100.79(.15) \\
\text { Profile } 4: 144.30(.21) \\
\text { Profile 5: } 284.84(.42) \\
\text { Profile 6: } 94.25(.14)\end{array}$ & 5527.26 & 5644.76 & -2737.63 & .87 & $<.001$ & .10 \\
\hline
\end{tabular}

Notes. $N=678$; AIC = Akaike Information Criterion; BIC = Bayesian Information Criterion; BLRT = Bootstrap Likelihood Ratio Test; LMR = Lo-Mendell-Rubin Test; Final class solutions were also guided by theory.

Interpretability. As previously mentioned, interpretability of the latent profiles was a critical factor when deciding on a final solution for the number of profiles that best represented both time points. For the 5-profile model at each time point, the proportion of students assigned to one of the profiles was quite small. Specifically, around 35 students 
(.04) at Time 1 and 8 students (.01) at Time 2. After comparing the item means for the 4and 5-profile models, it became evident that the smallest profiles for the 5-profile models were created by splitting the smallest profile of the 4-profile solutions. Although the smallest profiles were split, there was little change in the remaining profiles between the 4- and 5-profile models. Item means are provided for the profiles under question (i.e., for each time point, the two profiles in the 5-profile model that are assumed to have been split from a single profile in the 4-profile model) in Table 6. Considering that little information would likely be gained from the additional profile in the 5-profile models and that the proportion of students assigned to these profiles was quite small, I selected the 4-profile model as the best solution for both time points.

Table 6

4- and 5-Profile Solutions at Times 1 and 2

\begin{tabular}{cccccc}
\hline Time & $\begin{array}{c}\text { Profile } \\
\text { Solution }\end{array}$ & $\begin{array}{c}\text { Number } \\
\text { (Proportion) } \\
\text { of Students }\end{array}$ & $\begin{array}{c}\text { Expectations } \\
\text { of Brilliance }\end{array}$ & $\begin{array}{c}\text { Perceived } \\
\text { Belonging } \\
\text { Uncertainty }\end{array}$ & $\begin{array}{c}\text { Self- } \\
\text { Efficacy }\end{array}$ \\
\hline 1 & 4-profile & $51(.06)$ & 4.37 & 1.93 & 4.31 \\
& 5-profile (1) & $35(.04)$ & 4.29 & 1.78 & 4.34 \\
& 5-profile (2) & $88(.11)$ & 4.79 & 2.59 & 4.69 \\
& 4-profile & $28(.04)$ & 3.81 & 1.72 & 4.07 \\
& 5-profile (1) & $8(.01)$ & 4.14 & 1.19 & 2.98 \\
& 5-profile (2) & $49(.07)$ & 3.72 & 2.20 & 4.77 \\
\hline
\end{tabular}

Notes. Time 1: $N=822$; Time 2: $N=678$

Table 7 provides the within-profile item means for each latent profile across both time points. These means also are presented in Figures 1 and 2 for Times 1 and 2, 
respectively. These reflect the within-profile item means before testing for full measurement invariance and before adding covariates into the model. Therefore, it is important to keep in mind that the common profile names are only temporary and for the sake of facilitating discussion until a test is conducted for full measurement invariance across time points (which would support that the latent profiles are the same across time). Additionally, it is necessary to remember that profile means and prevalences changed after the covariates were included in the LTA model (Nylund, 2007).

Revisiting RQ 1 (What latent profiles emerge from measures of student beliefs, including students' expectations of brilliance, perceived belonging uncertainty, and selfefficacy? How do the number and types of latent profiles change over the course of a semester?), we see that, compared to the perceptions of belonging uncertainty measure, there is less variability in the expectations of brilliance measure (mean score range: Time $1=4.37$ to 4.98 , Time $2=3.81$ to 4.55 ; score range: 1 to 7 ) and the self-efficacy measure (mean score range: Time $1=4.31$ to 5.70 , Time $2=4.07$ to 5.48 ; score range 1 to 7 ). The increased variability in the perceptions of belonging uncertainty measure (mean score range: Time $1=1.93$ to 4.69 , Time $2=1.72$ to 4.75 ; score range: 1 to 5 ) allows for both adaptive and less-adaptive attributes to the Time 2 profiles. Given the similarity in the within-profile item means for the expectations of brilliance and self-efficacy measures, the profiles are easiest to distinguish based on the within-profile item means for the perceived belonging uncertainty measure. This is easy to see upon examination of Figures 1 and 2. 
Table 7

Within-Profile Item Means by Latent Profile and Time - Separate LPAs

\begin{tabular}{|c|c|c|c|c|c|c|}
\hline & Items & $\begin{array}{l}\text { Overall } \\
\text { Item } \\
\text { Means }\end{array}$ & $\begin{array}{c}\text { Some- } \\
\text { Brilliance/ } \\
\text { Excluded/ } \\
\text { Semi- } \\
\text { Confident }\end{array}$ & $\begin{array}{c}\text { Less- } \\
\text { Brilliance/ } \\
\text { Uncertain/ } \\
\text { Semi- } \\
\text { Confident }\end{array}$ & $\begin{array}{l}\text { Less- } \\
\text { Brilliance/ } \\
\text { Included/ } \\
\text { Confident }\end{array}$ & $\begin{array}{c}\text { Less- } \\
\text { Brilliance/ } \\
\text { Included/ } \\
\text { Quite- } \\
\text { Confident }\end{array}$ \\
\hline \multicolumn{7}{|l|}{$\begin{array}{l}\text { Membership } \\
\text { Proportions } \\
\text { Time } 1\end{array}$} \\
\hline & & & & \multicolumn{3}{|c|}{ Within-Profile Item Means Time 1} \\
\hline & $\mathrm{EB}$ & 4.74 & 4.37 & 4.75 & 4.86 & 4.98 \\
\hline & PBU & 3.37 & 1.93 & 2.91 & 3.93 & 4.69 \\
\hline & SE & 5.02 & 4.31 & 4.88 & 5.19 & 5.70 \\
\hline & & & & \multicolumn{3}{|c|}{ Within-Profile Item Means Time 2} \\
\hline \multicolumn{7}{|l|}{$\begin{array}{l}\text { Membership } \\
\text { Proportions } \\
\text { Time } 2\end{array}$} \\
\hline & $\mathrm{EB}$ & 4.28 & 3.81 & 4.35 & 4.41 & 4.55 \\
\hline & PBU & 3.29 & 1.72 & 2.81 & 3.86 & 4.75 \\
\hline & SE & 4.77 & 4.07 & 4.66 & 4.88 & 5.48 \\
\hline
\end{tabular}

Notes. Time 1: $N=822$; Time 2: $N=678 ; \mathrm{EB}=$ expectations of brilliance (range: $1-7$ ); $\mathrm{PBU}=$ perceived belonging uncertainty (range: $1-5$ ); $\mathrm{SE}=$ self-efficacy (range: 1-7). 


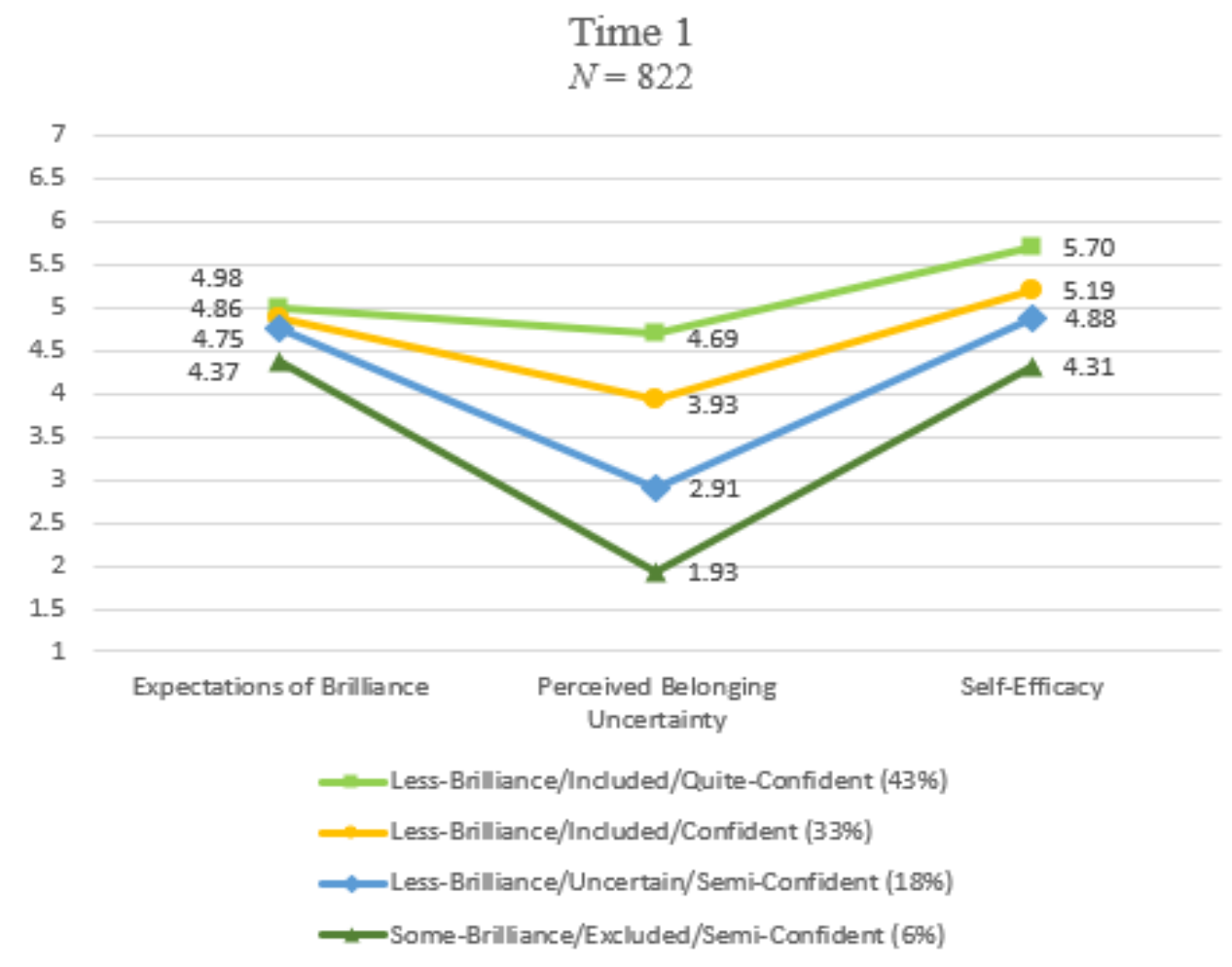

Figure 1. Within-Profile Item Means at Time 1. 
Time 2

$N=678$

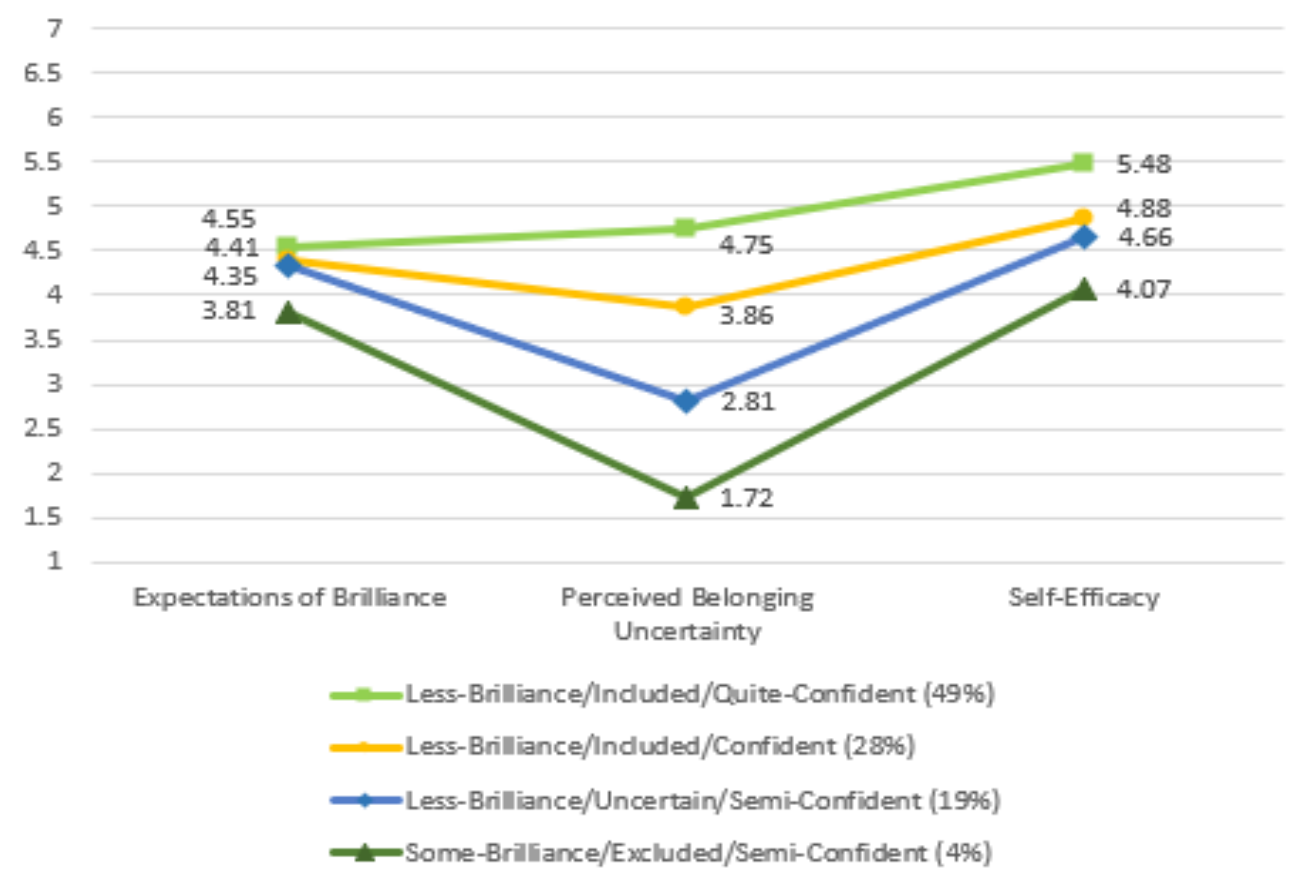

Figure 2. Within-Profile Item Means at Time 2.

As previously described, a 4-profile model was the best solution for Times 1 and 2. Of the profiles that emerged, one would be considered the profile with the leastadaptive student perceptions and lowest within-profile item means at each time point and another would be considered the profile with the most-adaptive student perceptions and highest within-profile item means at each time point. Based on the items means, these profiles could be referred to as Some-Brilliance/Excluded/Semi-Confident and LessBrilliance/Included/Quite-Confident, respectively. There are two additional profiles that emerged. One was indicative of more neutral or uncertain student perceptions (LessBrilliance/Uncertain/Semi-Confident). The other (Less-Brilliance/Included/Confident) represented student perceptions that were more positive than the neutral profile but below the most-adaptive profile. Although the within-profile item means appear to be similar 
across time points, it cannot be said that the profiles are the same across time points until measurement invariance is tested.

These findings align with the hypothesis that both adaptive and less-adaptive profiles would emerge. However, there is not a clear "adaptive triad" that included lower expectations of brilliance, lower levels of perceived belonging uncertainty, and high selfefficacy, or a "maladaptive triad" that included higher expectations of brilliance, higher levels of perceived belonging uncertainty, and low self-efficacy given the lack of variability in the expectations of brilliance and self-efficacy measures.

Although latent profile membership proportions were previously provided in Table 7, the proportion of students in each profile at Time 1 and Time 2 is provided once more in Table 8 to make it easier to observe the changes in the proportion of students who were best classified into each profile over time. Revisiting RQ 2 (How does the proportion of students who are best classified into each latent profile change over the course of a semester?), we see that the rank ordering of the classes by size is the same at both time points. The smallest profile is Some-Brilliance/Excluded/Semi-Confident, followed by the Less-Brilliance/Uncertain/Semi-Confident profile, then the LessBrilliance/Included/Confident profile, and finally, the largest profile, Less-

\section{Brilliance/Included/Quite-Confident.}

The proportion of students in the least-adaptive profile decreased slightly by the end of the students' first semesters (from .06 to .04). There was little change in the proportion of students who were best classified into the more neutral or uncertain profile (.18 at Time 1 and .19 at Time 2). When looking at the first profile that could be considered adaptive, Less-Brilliance/Included/Confident, we see that the proportion of 
students classified into this profile decreased by the end of the semester (from .33 to .28). However, the change in the proportion of students best classified into the most-adaptive profile from Time 1 to Time 2 resulted in a substantial increase (from .43 to .49).

Table 8

Proportion of Students in Each Profile at Times 1 and 2 - Separate LPAs

\begin{tabular}{lcc}
\hline \multicolumn{1}{c}{ Profiles } & Time 1 & Time 2 \\
\hline Some-Brilliance/Excluded/Semi-Confident & .06 & .04 \\
Less-Brilliance/Uncertain/Semi-Confident & .18 & .19 \\
Less-Brilliance/Included/Confident & .33 & .28 \\
Less-Brilliance/Included/Quite-Confident & .43 & .49 \\
\hline Notes. Time 1: $N=822 ;$ Time 2: $N=678$ & &
\end{tabular}

These findings somewhat contradict my hypothesis. Although the proportion of students best classified into the less-adaptive profiles were similar across transition periods, a higher proportion of students were classified into the most-adaptive profile at the end of the semester compared to the beginning of the semester. As previously mentioned, these proportions changed after the addition of the covariates into the LTA model, which is discussed in greater detail later. Additionally, this did not provide information on how individuals moved between latent profiles. At this point, we are only able to observe changes in the proportion of the students who were classified in each profile at each time point.

\section{Measurement Invariance}

After the measurement models were established for each time point, it was necessary to do a formal test for measurement invariance to determine if the latent profiles could be interpreted the same way across time points. In the end, several factors 
suggested that measurement invariance would not hold across both time points. First, two models were compared: one with full measurement non-invariance (i.e., item-response probabilities were not constrained to be equal across time points) and another will full measurement invariance (i.e., item-response probabilities were constrained to be equal across time points). Likelihood-ratio tests (LRT) were used to determine if measurement invariance was plausible. An LRT between the invariant and non-invariant models revealed a statistically significant decline in model fit when equality constraints were imposed on the model (non-invariance: $\log$ likelihood $\mathrm{H} 0$ value $=-5893.82$, free parameters $=45 ;$ invariance: $\log$ likelihood $\mathrm{H} 0$ value $=-5958.62$, free parameters $=33 ; \chi^{2}$ $(12)=129.6, p<.001)$. The LRT was replicated using MLR estimation in Mplus 8.0 to produce a scaling correction factor. The results remained consistent with the previous LRT (non-invariance: $\log$ likelihood $\mathrm{H} 0$ value $=-5893.82$, free parameters $=45 ; \mathrm{H} 0$ scaling correction factor $=1.52$; invariance: $\log$ likelihood $\mathrm{H} 0$ value $=-5958.62$, free parameters $=33, \mathrm{H} 0$ scaling correction factor $\left.=1.18 ; \chi^{2}(12)=52.51, p<.001\right)$.

Other fit indices and estimation-related factors also suggested that measurement invariance would not hold. AIC and BIC values were lower for the model with full measurement non-invariance $(\mathrm{AIC}=11877.65 ; \mathrm{BIC}=12089.68)$ compared to the model with full measurement invariance $(\mathrm{AIC}=11983.25 ; \mathrm{BIC}=12138.74)$. Additionally, entropy values were also higher for the model with full measurement non-invariance (.77) compared to the model with full measurement invariance (.69). An additional issue was that when measurement invariance was imposed, three logit parameters had to be fixed due to empty cells in the joint distribution of the latent variables. This can lead to latent profile patterns with profile counts and proportions of zero. 
Based on these findings, the more restricted model provides worse model fit compared to the less restricted model (Collins \& Lanza, 2010). Thus, the additional parameters produced by the model with full measurement non-invariance were necessary. This was not necessarily surprising given that full measurement non-invariance is generally considered "most practical" when there are few time points (two in this case; Nylund, 2007). Because item-response probabilities could not reasonably be constrained to be equal across time, the remainder of the results had to be interpreted while considering both quantitative change (i.e., changes in latent status membership) and qualitative change (i.e., change over time in the meaning of the profiles; Collins \& Lanza, 2010; Lanza, Bray, \& Collins, 2013).

\section{LTA Model Specification}

Including covariates. With the additional information that covariates add to LTA models, changes in model parameters, including the latent status item means, membership proportions, and the latent transition probabilities are likely to occur (Nylund, 2007). The within-status item means for the baseline LTA (i.e., including both time points in the same model; regressing the Time 2 4-profile model on the Time 14 profile model) were nearly identical to the within-profile item means from the separate LPA models. For the sake of brevity, the means for the baseline LTA model without covariates are not provided in a separate table. However, upon including the eight binary covariates in the baseline model, the latent status item means changed compared to the separate LPA models at Times 1 and 2 (i.e., compared to the profiles described in Table 7). A portion of this change is likely attributed to the LTA model now being based on a single sample of 822 students (via the EM algorithm), as opposed to the previous Time 1 
sample size of 822 and Time 2 sample size of 678 . Additionally, it is important to remember while reviewing the results from the LTA model with covariates that these parameters changed once more in the final model with the distal outcome of one-year engineering retention. These changes are discussed in the next section 'Including the Distal Outcome'.

Given that measurement invariance did not hold across the two time points, interpretations must be made under the assumption that the latent statuses at Times 1 and 2 may not only be quantitatively different, but qualitatively different. Thus, latent status names vary between Times 1 and 2 . To help differentiate latent statuses across time, each latent status name is preceded by the prefix ' $S$ ' for status, followed by the Time (1 or 2), and then the latent status number for that time point $(1,2,3$, or 4; e.g., 'S11' would indicate Status 1 at Time 1, 'S21' would indicate Status 1 at Time 2, and so on). In the tables, latent statuses also have been arranged in order from what would be considered the least-adaptive to the most-adaptive latent status (left to right or top to bottom, depending on the table).

The latent status item means from the LTA model including covariates are provided in Table 9. Allowing the latent statuses to be non-invariant across time revealed that, in general, less-adaptive latent statuses emerged at Time 2 compared to Time 1. At Time 2, the minimum and maximum mean scores for the expectations of brilliance measure are lower at Time 2 compared to Time 1 (mean score range: Time $1=4.32$ to 5.00, Time $2=3.81$ to 4.55 ; score range: 1 to 7 ). These mean score ranges are similar to the ranges from the separate LPAs; however, now that the latent statuses at each time point should be considered qualitatively different, we can consider the additional 
variability in this measure at Time 2 and create a latent status that represents "moderate brilliance". Compared to the separate LPAs, there is less variability in the perceptions of belonging uncertainty measure, especially at Time 1 (mean score range: Time $1=2.39$ to 4.44, Time $2=1.76$ to 4.75 ; score range: 1 to 5 ). Unlike Time 1 , a latent status emerged at Time 2 that represented students who felt "excluded". For the final measure, students' self-efficacy, there is slightly greater variability in the mean scores at Time 1 compared to Time 2 (mean score range: Time $1=4.07$ to 5.82 , Time $2=4.13$ to 5.48 ; score range: 1 to 7$)$.

Similar to the profiles from the separate LPA models, in the LTA model with covariates, one latent status would represent the least-adaptive student perceptions at each time point (i.e, Time 1: S11: Some-Brilliance/Uncertain/Semi-Confident; Time 2: S21: Moderate-Brilliance/Excluded/Semi-Confident). Similarly, one latent status would represent the most-adaptive student perceptions at each time point (i.e., Time 1: S14: Less-Brilliance/Included/Quite-Confident; Time 2: S24: Less-Brilliance/Included/QuiteConfident). Once again, this supports the hypothesis that less-adaptive and more-adaptive statuses would emerge, as well as additional latent statuses resulting from various combinations of student perceptions. As seen with the previous models, the proportion of students best classified into the more-adaptive latent statuses at Time 2 is greater than the proportion of students best classified into the less-adaptive latent statuses. Although I did not provide figures (similar to Figures 1 and 2) for the within-status item means for the LTA model with covariates, I did create similar figures for the final LTA model in the next section. 
Table 9

Within-Status Item Means by Latent Status and Time: LTA Model with Covariates

\begin{tabular}{|c|c|c|c|c|c|c|}
\hline & Items & $\begin{array}{l}\text { Overall } \\
\text { Item } \\
\text { Means }\end{array}$ & $\begin{array}{c}\text { S11: } \\
\text { Some- } \\
\text { Brilliance/ } \\
\text { Uncertain/ } \\
\text { Semi- } \\
\text { Confident }\end{array}$ & $\begin{array}{c}\text { S12: } \\
\text { Less- } \\
\text { Brilliance/ } \\
\text { Uncertain/ } \\
\text { Confident }\end{array}$ & $\begin{array}{c}\text { S13: } \\
\text { Less- } \\
\text { Brilliance/ } \\
\text { Included/ } \\
\text { Semi- } \\
\text { Confident }\end{array}$ & $\begin{array}{c}\text { S14: } \\
\text { Less- } \\
\text { Brilliance/ } \\
\text { Included/ } \\
\text { Quite- } \\
\text { Confident }\end{array}$ \\
\hline \multirow[t]{6}{*}{$\begin{array}{c}\text { Membership } \\
\text { Proportions } \\
\text { Time } 1\end{array}$} & & & .10 & .14 & .19 & .56 \\
\hline & & & & \multicolumn{3}{|c|}{ Within-Status Item Means Time 1} \\
\hline & EB & 4.74 & 4.32 & 4.93 & 4.71 & 5.00 \\
\hline & PBU & 3.47 & 2.39 & 2.98 & 4.09 & 4.44 \\
\hline & SE & 4.92 & 4.07 & 5.36 & 4.43 & 5.82 \\
\hline & Items & $\begin{array}{l}\text { Overall } \\
\text { Item } \\
\text { Means }\end{array}$ & $\begin{array}{c}\text { S21: } \\
\text { Moderate- } \\
\text { Brilliance/ } \\
\text { Excluded/ } \\
\text { Semi- } \\
\text { Confident }\end{array}$ & $\begin{array}{c}\text { S22: } \\
\text { Some- } \\
\text { Brilliance/ } \\
\text { Uncertain/ } \\
\text { Confident }\end{array}$ & $\begin{array}{c}\text { S23: } \\
\text { Some- } \\
\text { Brilliance/ } \\
\text { Included/ } \\
\text { Confident }\end{array}$ & $\begin{array}{c}\text { S24: } \\
\text { Less- } \\
\text { Brilliance/ } \\
\text { Included/ } \\
\text { Quite- } \\
\text { Confident }\end{array}$ \\
\hline \multirow[t]{5}{*}{$\begin{array}{c}\text { Membershi } \\
\text { Proportions } \\
\text { Time } 2\end{array}$} & & & .05 & .19 & .28 & .48 \\
\hline & & & & \multicolumn{3}{|c|}{ Within-Status Item Means Time 2} \\
\hline & EB & 4.28 & 3.81 & 4.35 & 4.41 & 4.55 \\
\hline & $\mathrm{PBU}$ & 3.30 & 1.76 & 2.82 & 3.86 & 4.75 \\
\hline & $\mathrm{SE}$ & 4.79 & 4.13 & 4.66 & 4.88 & 5.48 \\
\hline
\end{tabular}

Notes. $N=822 ; \mathrm{EB}=$ expectations of brilliance (range: $1-7) ; \mathrm{PBU}=$ perceived belonging uncertainty (range: 1-5); SE = self-efficacy (range: 1-7). Model does not impose measurement invariance across time points. 
Table 10 provides the regression coefficients by latent status and time for the LTA model with covariates. The reference status that was used for the following analyses was the latent status with the most-adaptive student perceptions, which also happened to be the latent status with the largest membership proportions. For Time 1, this was the S14: Less-Brilliance/Included/Quite-Confident latent status and, for Time 2, this was the S24: Less-Brilliance/Included/Quite-Confident latent status. As a reminder, the intercepts represent the odds of membership in a latent status in relation to the reference status (Collins \& Lanza, 2010). The regression coefficients represent the change in the odds of membership in a latent status in relation to the reference status when the binary covariate $=1$ (refer to Table 3 for the coding scheme of the demographic covariates; Collins \& Lanza, 2010). Given the number of regression coefficients in Table 10, I will interpret the findings only for the statistically significant covariates.

Revisiting RQ 3 (How do student demographic and prior achievement characteristics (i.e., students' racelethnicity, gender, Pell Grant eligibility, firstgeneration college student status, reported previous identification as Gifted/Talented, and first-semester mathematics course) predict latent status membership?), it appears that there were several statistically significant effects for the Time 1 latent statuses. To begin, there was a statistically significant effect of gender for the S11: SomeBrilliance/Uncertain/Semi-Confident latent status compared to the more-adaptive reference status, S14: Less-Brilliance/Included/Quite-Confident. Specifically, the odds were 2.70 times greater for females than males to be classified into the S11: SomeBrilliance/Uncertain/Semi-Confident latent status compared to the S14: LessBrilliance/Included/Quite-Confident reference status, after controlling for other 
demographic characteristics $\left(\beta_{1}=1.00, p=.01\right)$. Similarly, the odds were 2.89 times greater for females than males to be classified into the S13: Less-

Brilliance/Included/Semi-Confident latent status compared to the reference group, after controlling for other demographic characteristics $\left(\beta_{1}=1.06, p=.002\right)$. Thus, females were more likely than males to be classified into latent statuses that represented more uncertainty when it comes to student belonging and lower levels of self-efficacy at the beginning of their first semester in their engineering programs.

There also was a significant effect of students' first-semester mathematics course for two of the latent statuses at Time 1. For students who were in the lower-level ENGR 190 course (as opposed to the higher-level ENGR 101 course), the odds were 3.34 times greater to be classified into the S11: Some-Brilliance/Uncertain/Semi-Confident $\left(\beta_{1}=\right.$ $1.21, p<.001)$ latent status and 4.71 times greater to be classified into the S13: LessBrilliance/Included/Semi-Confident $\left(\beta_{1}=1.55, p<.001\right)$ latent status compared to the more-adaptive reference latent status, after controlling for other demographic characteristics. Additionally, at Time 1, for first-generation college students and students who were from low-income households, the odds were 3.02 and 3.84 times greater (respectively) to be classified into the S11: Some-Brilliance/Uncertain/Semi-Confident latent status (Firstgen: $\beta_{1}=1.10, p=.003$; Pell: $\beta_{1}=1.35, p<.001$ ) compared to the more-adaptive reference status, after controlling for other demographic characteristics. From this, it appears that students who enroll in the lower-level first-semester mathematics course, first-generation college students, and students who are from lowincome households may attribute higher levels of brilliance or raw talent to the engineering discipline, tend to question if they belong in their programs, and have lower 
levels of self-efficacy at the beginning of their first semesters compared to their demographic counterparts.

Finally, at Time 1, there was a statistically significant cohort effect. The odds were smaller for students in the 2017 cohort compared to the 2016 cohort to be classified into the S12: Less-Brilliance/Uncertain/Confident and S13: LessBrilliance/Included/Semi-Confident latent statuses $\left(\right.$ S12: $\beta_{1}=-0.62$, OR $=0.54, p=.04$; S13: $\left.\beta_{1}=-0.91, \mathrm{OR}=0.40, p=.02\right)$ than the reference status. To understand this difference, one would have to examine, for example, potential differences in program structure, instruction, and students' personalities at the beginning of the 2016 and 2017 fall semesters.

There were also a small number of statistically significant effects for the Time 2 latent statuses. For students who identified as Black/African American, the odds were 5.06 times greater to be classified into the S21: Moderate-Brilliance/Excluded/SemiConfident latent status at Time 2 compared to the reference status, after controlling for other demographic characteristics $\left(\beta_{1}=1.62, p=.04\right)$. This was one of the least-adaptive latent statuses to emerge across time points. This suggests that, at the end of the students' first semesters, Black/African American students are likely to have very poor student perceptions related to the amount of brilliance or raw talent necessary to be successful in engineering, their sense of belonging in their programs, and their self-efficacy. Additionally, the odds of students who identified as first-generation college students were 2.46 times greater to be classified into the S22: Some-Brilliance/Uncertain/Confident latent status compared to the reference status, after controlling for other demographic characteristics $\left(\beta_{1}=0.90, p=.01\right)$. Finally, compared to students who were not 
considered low-income, the odds of low-income students to be classified into the $S 23$ :

Some-Brilliance/Included/Confident latent status at Time 2 were 1.72 times greater compared to the more-adaptive reference status, S24: Less-Brilliance/Included/QuiteConfident, after controlling for other demographic characteristics $\left(\beta_{1}=1.72, p=.04\right)$. For first-generation college students and students from low-income households, this is similar to their less-adaptive perceptions at the beginning of their first semesters. 
Table 10

Logistic Regression Coefficients by Latent Status and Time - LTA Model with Covariates (The Most-Adaptive Latent Statuses Served as the Reference Status)

\begin{tabular}{|c|c|c|c|c|c|}
\hline Latent Status & Covariate & Coefficient & S.E. & $p$ & $\begin{array}{l}\text { Odds } \\
\text { Ratio }\end{array}$ \\
\hline \multicolumn{6}{|l|}{ Time 1} \\
\hline & Cohort & -0.50 & 0.32 & .11 & 0.60 \\
\hline S11: & Gender* & 1.00 & 0.36 & .01 & 2.70 \\
\hline Some-Brilliance/ & Asian & -0.06 & 0.60 & .92 & 0.94 \\
\hline Uncertain/ & Black & -0.04 & 0.66 & .95 & 0.96 \\
\hline \multirow[t]{2}{*}{ Semi-Confident } & Gifted & -0.20 & 0.37 & .58 & 0.82 \\
\hline & Firstgen* & 1.10 & 0.37 & .003 & 3.02 \\
\hline \multirow[t]{3}{*}{ Intercept $=-2.57$} & Pell* & 1.35 & 0.33 & $<.001$ & 3.84 \\
\hline & Math Class* & 1.21 & 0.34 & $<.001$ & 3.34 \\
\hline & Cohort* & -0.62 & 0.30 & .04 & 0.54 \\
\hline S12: & Gender & 0.14 & 0.37 & .71 & 1.15 \\
\hline Less-Brilliance/ & Asian & 0.03 & 0.65 & .96 & 1.03 \\
\hline Uncertain/ & Black & 0.43 & 0.58 & .45 & 1.54 \\
\hline \multirow[t]{2}{*}{ Confident } & Gifted & -0.56 & 0.33 & .10 & 0.57 \\
\hline & Firstgen & -1.73 & 1.42 & .22 & 0.18 \\
\hline \multirow[t]{3}{*}{ Intercept $=-0.56$} & Pell & -0.06 & 0.44 & .89 & 0.94 \\
\hline & Math Class & -0.19 & 0.48 & .70 & 0.83 \\
\hline & Cohort* & -0.91 & 0.38 & .02 & 0.40 \\
\hline S13: & Gender* & 1.06 & 0.35 & .002 & 2.89 \\
\hline Less-Brilliance/ & Asian & 0.70 & 0.55 & .20 & 2.02 \\
\hline Included/ & Black & -0.93 & 1.12 & .40 & 0.39 \\
\hline \multirow[t]{2}{*}{ Semi-Confident } & Gifted & -0.53 & 0.34 & .12 & 0.59 \\
\hline & Firstgen & -0.83 & 0.60 & .16 & 0.44 \\
\hline \multirow[t]{2}{*}{ Intercept $=-1.09$} & Pell & 0.59 & 0.36 & .11 & 1.80 \\
\hline & Math Class* & 1.55 & 0.41 & $<.001$ & 4.71 \\
\hline \multicolumn{6}{|l|}{ Time 2} \\
\hline S21: & Cohort & 0.28 & 0.45 & .53 & 1.32 \\
\hline Moderate- & Gender & -0.07 & 0.57 & .91 & 0.93 \\
\hline Brilliance/ & Asian & -0.48 & 1.12 & .67 & 0.62 \\
\hline Excluded/ & Black* & 1.62 & 0.80 & .04 & 5.06 \\
\hline Semi- & Gifted & -0.71 & 0.47 & .13 & 0.49 \\
\hline Confident & Firstgen & 1.15 & 0.57 & .05 & 3.16 \\
\hline
\end{tabular}




\begin{tabular}{cccccc} 
& Pell & 0.79 & 0.62 & .20 & 2.20 \\
Intercept $=-2.66$ & Math Class & 0.66 & 0.49 & .18 & 1.93 \\
& & & & & \\
S22: & Cohort & -0.32 & 0.24 & .18 & 0.73 \\
Some-Brilliance/ & Gender & -0.44 & 0.31 & .16 & 0.64 \\
Uncertain/ & Asian & -1.11 & 0.79 & .16 & 0.33 \\
Confident & Black & 0.89 & 0.57 & .12 & 2.43 \\
& Gifted & -0.30 & 0.26 & .26 & 0.74 \\
Intercept $=-0.79$ & Firstgen* & 0.90 & 0.36 & .01 & 2.46 \\
& Pell & 0.34 & 0.30 & .25 & 1.41 \\
& Math Class & 0.50 & 0.28 & .07 & 1.65 \\
S23: & & & & & \\
Some-Brilliance/ & Cohort & 0.12 & 0.21 & .58 & 1.13 \\
Included/ & Gender & 0.07 & 0.25 & .79 & 1.07 \\
Confident & Asian & 0.71 & 0.42 & .09 & 2.03 \\
& Black & -0.14 & 0.64 & .83 & 0.87 \\
Intercept $=-0.86$ & Gifted & 0.01 & 0.26 & .97 & 1.01 \\
& Firstgen & 0.14 & 0.40 & .73 & 1.15 \\
& Pell* & 0.54 & 0.26 & .04 & 1.72 \\
& Math Class & 0.16 & 0.27 & .57 & 1.17 \\
\hline
\end{tabular}

Notes. $N=822$; The most-adaptive/largest latent statuses include Time 1: S14: Less-

Brilliance/Included/Quite-Confident; Time 2: S24: Less-Brilliance/Included/Quite-

Confident. Model does not impose measurement invariance across time points. This is the standard $p$ value used to determine statistical significance. Cohort: $0=2016,1=2017$; Gender: $0=$ male, $1=$ female; Asian: $0=$ not Asian, $1=$ Asian; Black: $0=$ not Black/African American, $1=$ Black/African American; Gifted: $0=$ did not report having been previously identified as Gifted/Talented, $1=$ reported having been previously identified as Gifted/Talented; Firstgen: $0=$ not a first-generation college student, $1=$ first-generation college student; Pell: $0=$ not from a low-income household, $1=$ from a low-income household; Math Class: 0 = higher-level ENGR 101 course, $1=$ lower-level ENGR 190 course.

$* p<.05$.

It is evident from observing the latent transition probabilities in Table 11 that the probability that students remained in the least-adaptive latent statuses across time $(S 11 \rightarrow$ S21) is relatively low (.08). On the other hand, the probability that students transitioned from the least-adaptive latent status at Time 1 to what would be considered the mostadaptive latent status at Time 2 is much higher $(S 11 \rightarrow S 24 ; .40)$. We also can consider 
students who started out in the most-adaptive latent status at Time 1. These students were more likely to transition to what would be considered the most-adaptive latent status at Time $2(S 14 \rightarrow S 24 ; .50)$ than they were to transition to a less-adaptive latent status $(S 21$, $S 22$, or $S 23$; probability ranges between .04 and .28). Although the latent statuses were qualitatively different across time, in general, the probability that a student transitioned from a less-adaptive latent status at Time 1 to a more-adaptive latent status at Time 2 was higher than the probability that a student transitioned to a less-adaptive (or "equivalent") latent status at Time 2 . This is supported by Table 12, which shows that the proportion of students who remained in a similar latent status was lower (as represented by the diagonal) compared to the proportion of students who transitioned to a more-adaptive latent status.

In general, membership proportions tend to increase as we look at transitions toward more-adaptive latent statuses. With the previous models (i.e., before testing for measurement invariance and establishing the baseline LTA model), I was unable to address the part of my original hypothesis that addressed how students transitioned between latent statuses. These findings contradict my original hypothesis that, if students transition between different latent profiles, they would move from more-adaptive to lessadaptive profiles or remain in less-adaptive profiles across transition periods. In this case, the opposite was actually true. 
Table 11

Latent Transition Probabilities by Latent Status and Time: LTA Model with Covariates

\begin{tabular}{|c|c|c|c|c|}
\hline Time 1 & $\begin{array}{c}\text { S21: } \\
\text { Moderate- } \\
\text { Brilliance/ } \\
\text { Excluded/ } \\
\text { Semi- } \\
\text { Confident }\end{array}$ & $\begin{array}{c}\text { S22: } \\
\text { Some- } \\
\text { Brilliance/ } \\
\text { Uncertain/ } \\
\text { Confident }\end{array}$ & $\begin{array}{c}\text { S23: } \\
\text { Some-Brilliance/ } \\
\text { Included/ } \\
\text { Confident }\end{array}$ & $\begin{array}{c}\text { S24: } \\
\text { Less-Brilliance/ } \\
\text { Included/ } \\
\text { Quite- } \\
\text { Confident }\end{array}$ \\
\hline $\begin{array}{c}\text { S11: } \\
\text { Some-Brilliance/ } \\
\text { Uncertain/ } \\
\text { Semi-Confident }\end{array}$ & .08 & .24 & .28 & .40 \\
\hline $\begin{array}{c}\text { S12: } \\
\text { Less-Brilliance/ } \\
\text { Uncertain/ } \\
\text { Confident }\end{array}$ & .04 & .19 & .27 & .51 \\
\hline $\begin{array}{c}\text { S13: } \\
\text { Less-Brilliance/ } \\
\text { Included/ } \\
\text { Semi-Confident }\end{array}$ & .05 & .20 & .29 & .46 \\
\hline $\begin{array}{c}\text { S14: } \\
\text { Less-Brilliance/ } \\
\text { Included/ } \\
\text { Quite Confident }\end{array}$ & .04 & .19 & .28 & .50 \\
\hline
\end{tabular}


Table 12

Membership Proportions Based on Latent Status Patterns: LTA Model with Covariates

\begin{tabular}{|c|c|c|c|c|}
\hline & \multicolumn{4}{|c|}{ Time 2} \\
\hline Time 1 & $\begin{array}{l}\text { S21: } \\
\text { Moderate- } \\
\text { Brilliance/ } \\
\text { Excluded/ } \\
\text { Semi- } \\
\text { Confident }\end{array}$ & $\begin{array}{c}\text { S22: } \\
\text { Some- } \\
\text { Brilliance/ } \\
\text { Uncertain/ } \\
\text { Confident }\end{array}$ & $\begin{array}{c}\text { S23: } \\
\text { Some-Brilliance/ } \\
\text { Included/ } \\
\text { Confident }\end{array}$ & $\begin{array}{c}\text { S24: } \\
\text { Less-Brilliance/ } \\
\text { Included/ } \\
\text { Quite- } \\
\text { Confident }\end{array}$ \\
\hline
\end{tabular}

S11:

Some-

Brilliance/

Uncertain/

.01

.03

.03

.04

Semi-

Confident

S12:

Less-

Brilliance/

.01

.03

.04

.07

Uncertain/

Confident

S13:

Less-

Brilliance/

Included/

.01

.04

.06

.09

Semi-

Confident

S14:

Less-

Brilliance/

Included/

.02

.10

.15

.28

Quite

Confident

Notes. $N=822$; Model does not impose measurement invariance across time points. 
Including the distal outcome. As previously mentioned, specifying a model that included the distal outcome, one-year engineering retention, changed several of the model parameters. This is especially true for the Time 2 parameters, given that including a distal outcome in an LTA model is essentially the same as including an additional indicator at Time 2. Thus, a large portion of the results from this model will be compared to the results produced from the previous model without the distal outcome (see the 'Including Covariates' section). The remainder of the results provides the parameter estimates for the final LTA model.

The latent status item means from the LTA model including covariates and the distal outcome are provided in Table 13 and displayed in Figures 3 and 4. The latent statuses for Time 1 were essentially the same given that the distal outcome was only included as an indicator for Time 2. There were some slight changes in the within-status item means for Time 2. Consequently, in order to accommodate the adjusted withinstatus item means, two of the latent status names were changed compared to the previous covariate model. Specifically, S22: Some-Brilliance/Uncertain/Confident became S22: Some-Brilliance/Included/Semi-Confident and S23: Some-Brilliance/Included/Confident became S23: Some-Brilliance/Uncertain/Confident. The least and most-adaptive latent status names remained the same at each time point compared to the previous covariate model. The least-adaptive latent statuses remain as S11: SomeBrilliance/Uncertain/Semi-Confident and S21: Moderate-Brilliance/Excluded/SemiConfident. Similarly, the most-adaptive latent statuses remain as S14: LessBrilliance/Included/Quite-Confident and S24: Less-Brilliance/Included/Quite-Confident. 
Similar to the previous model, in general, slightly less-adaptive latent statuses emerged at Time 2 compared to Time 1 . At Time 2, the minimum and maximum mean scores for the expectations of brilliance measure were lower compared to Time 1 (mean score range: Time $1=4.32$ to 5.00 , Time $2=3.85$ to 4.53 ; score range: 1 to 7 ). The same holds true for students' self-efficacy mean scores (mean score range: Time $1=4.07$ to 5.82, Time $2=3.18$ to 5.42 ; score range: 1 to 7 ). Finally, there was greater variability in students' perceptions of belonging uncertainty mean scores at Time 2 compared to Time 1 (mean score range: Time $1=2.39$ to 4.44 , Time $2=1.87$ to 4.54 ; score range: 1 to 5 ). The final LTA model is similar to the previous models in that both adaptive and lessadaptive latent statuses emerged and the proportion of students in the more-adaptive latent statuses at Time 2 is greater than the proportion of students in the less-adaptive latent statuses. 
Table 13

Within-Status Item Means by Latent Status and Time: Final LTA Model with Covariates and the Distal Outcome

\begin{tabular}{|c|c|c|c|c|c|c|}
\hline & Items & $\begin{array}{l}\text { Overall } \\
\text { Item } \\
\text { Means }\end{array}$ & $\begin{array}{c}\text { S11: } \\
\text { Some- } \\
\text { Brilliance/ } \\
\text { Uncertain/ } \\
\text { Semi- } \\
\text { Confident }\end{array}$ & $\begin{array}{c}\text { S12: } \\
\text { Less- } \\
\text { Brilliance/ } \\
\text { Uncertain/ } \\
\text { Confident }\end{array}$ & $\begin{array}{c}\text { S13: } \\
\text { Less- } \\
\text { Brilliance/ } \\
\text { Included/ } \\
\text { Semi- } \\
\text { Confident }\end{array}$ & $\begin{array}{c}\text { S14: } \\
\text { Less- } \\
\text { Brilliance/ } \\
\text { Included/ } \\
\text { Quite- } \\
\text { Confident }\end{array}$ \\
\hline \multicolumn{7}{|c|}{$\begin{array}{l}\text { Membership } \\
\text { Proportions } \\
\text { Time } 1\end{array}$} \\
\hline & & & & \multicolumn{3}{|c|}{ Within-Status Item Means Time 1} \\
\hline & $\mathrm{EB}$ & 4.74 & 4.32 & 4.93 & 4.71 & 5.00 \\
\hline & PBU & 3.47 & 2.39 & 2.98 & 4.08 & 4.44 \\
\hline & $\mathrm{SE}$ & 4.92 & 4.07 & 5.37 & 4.43 & 5.82 \\
\hline & Items & $\begin{array}{l}\text { Overall } \\
\text { Item } \\
\text { Means }\end{array}$ & $\begin{array}{c}\text { S21: } \\
\text { Moderate- } \\
\text { Brilliance/ } \\
\text { Excluded/ } \\
\text { Semi- } \\
\text { Confident }\end{array}$ & $\begin{array}{c}\text { S22: } \\
\text { Some- } \\
\text { Brilliance/ } \\
\text { Included/ } \\
\text { Semi- } \\
\text { Confident }\end{array}$ & $\begin{array}{c}\text { S23: } \\
\text { Some- } \\
\text { Brilliance/ } \\
\text { Uncertain/ } \\
\text { Confident }\end{array}$ & $\begin{array}{c}\text { S24: } \\
\text { Less- } \\
\text { Brilliance/ } \\
\text { Included/ } \\
\text { Quite- } \\
\text { Confident }\end{array}$ \\
\hline \multicolumn{7}{|c|}{$\begin{array}{l}\text { Membership } \\
\text { Proportions } \\
\text { Time } 2\end{array}$} \\
\hline & & & & \multicolumn{3}{|c|}{ Within-Status Item Means Time 2} \\
\hline & $\mathrm{EB}$ & 4.23 & 3.85 & 4.20 & 4.36 & 4.53 \\
\hline & PBU & 3.23 & 1.87 & 3.68 & 2.84 & 4.54 \\
\hline & SE & 4.39 & 3.18 & 4.05 & 4.90 & 5.42 \\
\hline
\end{tabular}

Notes. $N=822 ; \mathrm{EB}=$ expectations of brilliance (range: $1-7) ; \mathrm{PBU}=$ perceived belonging uncertainty (range: 1-5); SE = self-efficacy (range: 1-7). Model does not impose measurement invariance across time points. 


\section{Time 1}

$$
N=822
$$

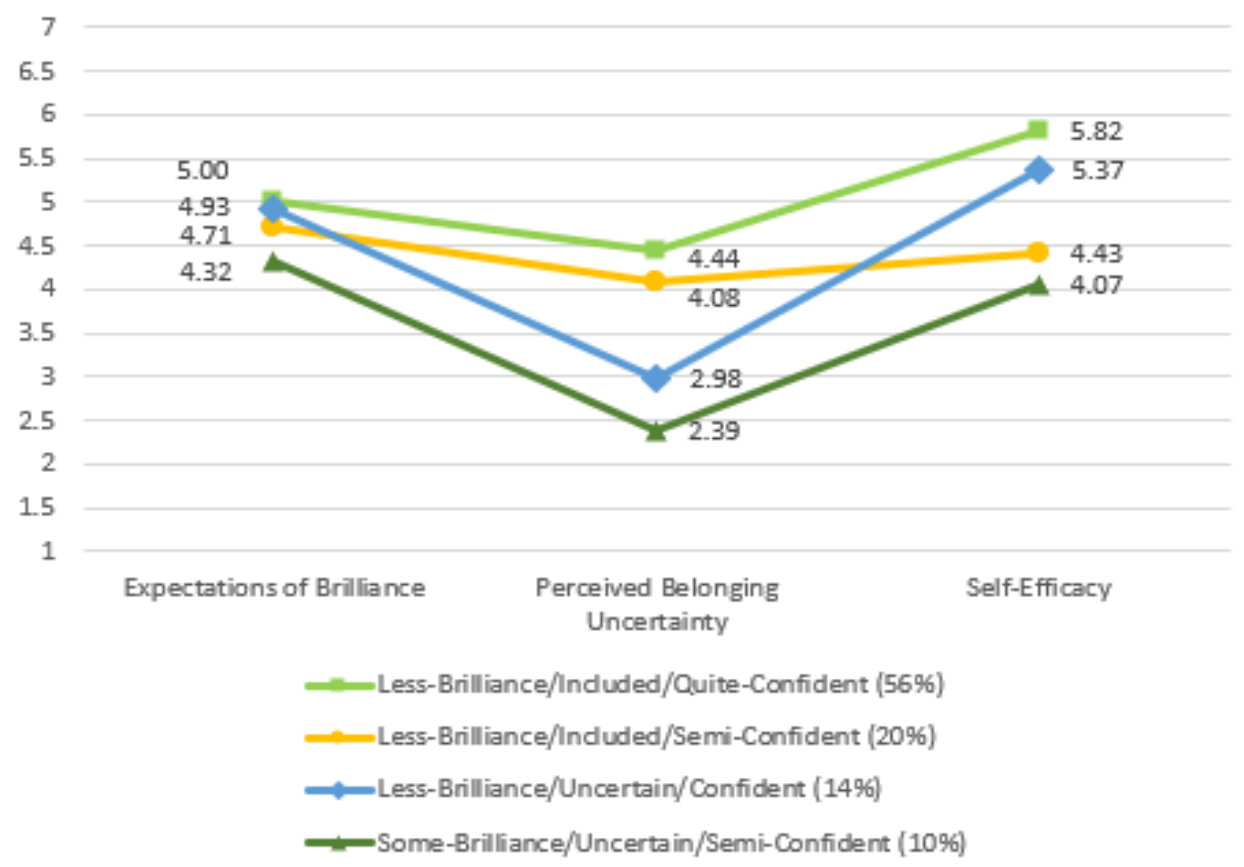

Figure 3. Within-Profile Item Means at Time 1 - Final LTA Model. 


\section{Time 2}

$N=822$

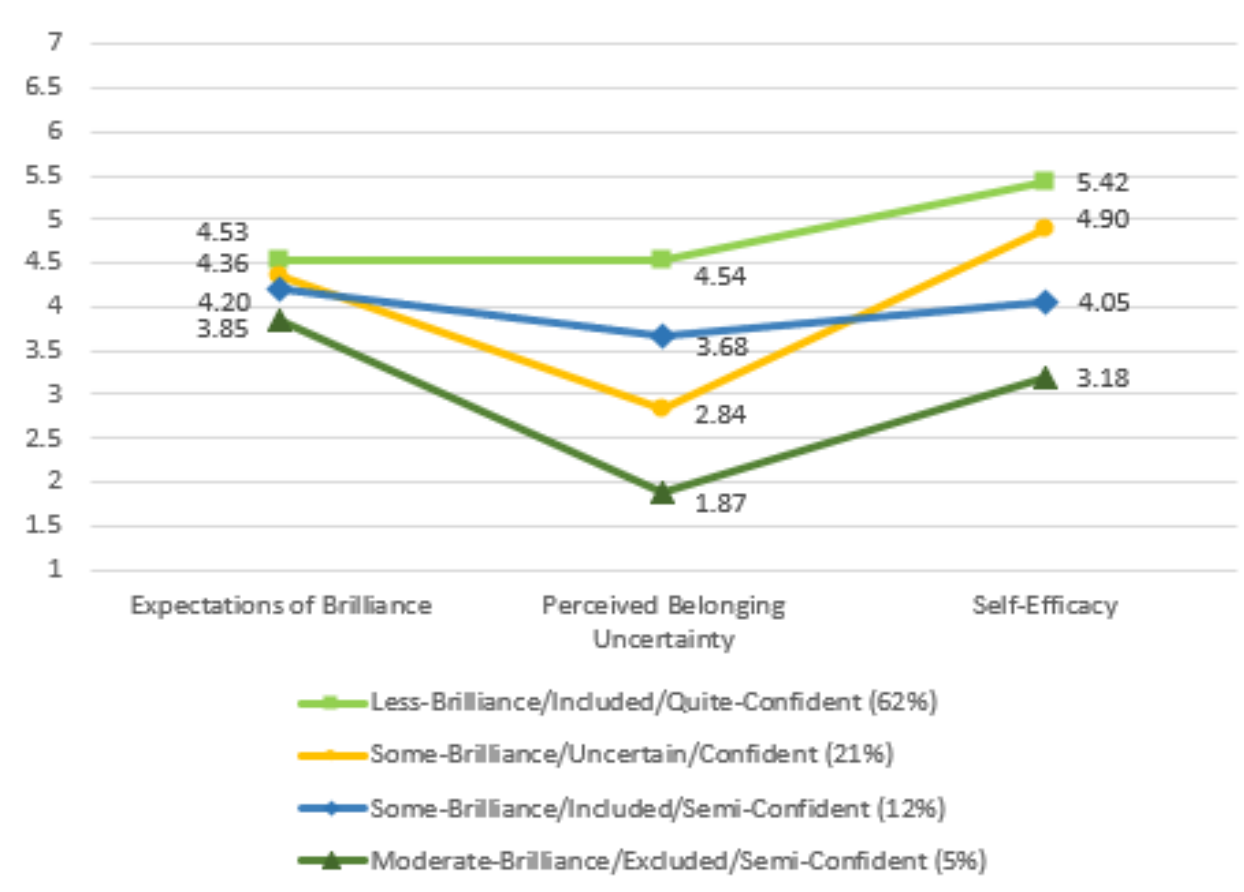

Figure 4. Within-Profile Item Means at Time 2 - Final LTA Model.

Table 14 provides the regression coefficients by latent status and time for the LTA model with covariates and the distal outcome of one-year retention. The reference statuses that were used for the following analyses were the same reference statuses that were previously used with the covariate model. These latent statuses represent the mostadaptive student perceptions and the largest membership proportions. This was the LessBrilliance/Included/Quite-Confident latent status for both Time 1 and Time 2 (S14 and $S 24$, respectively). The regression coefficients, odds ratios, and $p$ values for Time 1 are very similar to the values at Time 1 from the covariate model. Although important findings were presented in the previous section, 'Including Covariates', the following results reflect the findings from the final LTA model. These findings will help facilitate discussion, as it is useful to compare the results from the final model to the results from 
the previous covariate model to understand how model building and seemingly small changes in model specification can influence the LTA findings.

I will begin by presenting the significant Time 1 relationships for the final LTA model that were the same as those in the previous model without the distal outcome. First, there was a statistically significant covariate relationship for gender for the S11: Some-Brilliance/Uncertain/Semi-Confident latent status compared to the more-adaptive reference status $\left(\beta_{1}=1.00, \mathrm{OR}=2.71, p=.01\right)$. The same was true for the S13: LessBrilliance/Included/Semi-Confident latent status compared to the reference group, after controlling for other demographic characteristics $\left(\beta_{1}=1.06, \mathrm{OR}=2.88, p=.002\right)$. Thus, females were more likely than males to be classified into latent statuses that associated the engineering discipline with brilliance or raw talent, experience less of sense of belonging, and lower levels of self-efficacy at the beginning of their first semesters in their engineering programs.

After including the distal outcome in the LTA model, I still observed a statistically significant effect of students' first-semester mathematics course for two of the latent statuses at Time 1. For students who were in the lower-level ENGR 190 course, as opposed to the higher-level ENGR 101 course, the odds were 3.35 times greater to be classified into the S11: Some-Brilliance/Uncertain/Semi-Confident $\left(\beta_{1}=1.21, p<.001\right)$ latent status and 4.63 times greater to be classified into the S13: LessBrilliance/Included/Semi-Confident ( $\beta_{1}=1.53, p<.001$ ) latent status compared to the more-adaptive reference status, after controlling for other demographic characteristics. Additionally, at the beginning of their first semesters in their engineering programs, for first-generation college students and students who were from low-income households, the 
odds were 3.00 and 3.84 times greater (respectively) to be classified into the S11: SomeBrilliance/Uncertain/Semi-Confident latent status (Firstgen: $\beta_{1}=1.10, p=.003$; Pell: $\beta_{1}=$ $1.35, p<.001)$ compared to the more-adaptive reference status, after controlling for other demographic characteristics. This suggests that students who were enrolled in the lowerlevel first-semester mathematics course, first-generation college students, and students from low income households may attribute higher levels of brilliance or raw talent to the engineering discipline, may question if they belong in their programs, and may even experience lower levels of self-efficacy at the beginning of their first semesters after controlling for other demographic characteristics.

The statistically significant cohort differences in latent status were still present between students who started out in the engineering school in the fall of 2016 and those who were first enrolled in the fall of 2017. For students who were in the 2017 cohort, the odds of being classified into two of the less-adaptive latent statuses (S12: LessBrilliance/Uncertain/Confident and S13: Less-Brilliance/Included/Semi-Confident) at the beginning of their first semester $\left(S 12: \beta_{1}=-0.62, \mathrm{OR}=0.54 ; p=.04 ; S 13: \beta_{1}=-0.89, \mathrm{OR}\right.$ $=0.41, p=.02$ ) were smaller compared to the 2016 cohort. As previously mentioned, to understand this advantage, one would have to revisit potential programmatic and instructional differences that may have occurred in the engineering school during the fall of 2017 .

There was a noticeable change in the statistically significant covariate effects for the Time 2 latent statuses after including the distal outcome. At the end of the students' first semesters in their engineering programs, there was a statistically significant effect of students' first semester mathematics course for the two least-adaptive latent statuses 
compared to the more-adaptive reference status. This effect stood out especially for the students who were classified into the least-adaptive latent status at Time 2 ( $S 21$ :

Moderate-Brilliance/Excluded/Semi-Confident). The odds were 11.22 times greater for students enrolled in the lower-level introductory mathematics than students enrolled in the higher-level mathematics course to be classified into a latent status that associated the engineering discipline with brilliance or raw talent, experience feelings of exclusion in their programs, and feel less confident about their abilities in their engineering programs $\left(\beta_{1}=2.42, p<.001\right)$. Although the odds were not as high $(3.99$ times more likely compared to 11.22 times more likely), these findings were similar for students classified into the S22: Some-Brilliance/Included/Semi-Confident latent status at Time $2\left(\beta_{1}=1.38\right.$, $\mathrm{OR}=3.99 ; p=.01)$.

Although the previously mentioned covariate effects related to students' first semester mathematics course were not present in the covariate model, there are a few findings that were similar across models. To begin with, for students who identified as Black/African American, the odds were 2.80 times greater to be classified into the $S 23$ : Some-Brilliance/Uncertain/Confident latent status at Time 2 compared to the reference status, after controlling for other demographic characteristics $\left(\beta_{1}=1.03, p=.02\right)$. This suggests that, at the end of the students' first semesters, Black/African American students were more likely to have neutral perceptions related to the amount of brilliance or raw talent associated with the engineering discipline, their sense of belonging in their programs, and their self-efficacy related to engineering.

Additionally, the odds were 2.76 times greater for students who identified as firstgeneration college students than students who were not first-generation college students 
to be classified into a more neutral latent status at the end of their first semesters (S23: Some-Brilliance/Uncertain/Confident) compared to the reference status, after controlling for other demographic characteristics $\left(\beta_{1}=1.02, p=.004\right)$. Finally, the odds were 4.02 times greater for low-income students than students who were not considered low-income to be classified into the S22: Some-Brilliance/Included/Semi-Confident latent status at Time 2 compared to the more-adaptive reference status, S24: LessBrilliance/Included/Quite-Confident, after controlling for other demographic characteristics $\left(\beta_{1}=1.39, p=.001\right)$. For first-generation college students and students from low-income households this is similar to their less-adaptive or neutral perceptions at the beginning of their first semesters. 
Table 14

Logistic Regression Coefficients by Latent Status and Time - Final LTA Model with Covariates and the Distal Outcome (The Most-Adaptive Latent Statuses Served as the Reference Status)

\begin{tabular}{|c|c|c|c|c|c|}
\hline Latent Status & Covariate & Coefficient & S.E. & $p$ & Odds Ratio \\
\hline \multicolumn{6}{|l|}{ Time 1} \\
\hline & Cohort & -0.50 & 0.32 & .11 & 0.61 \\
\hline S11: & Gender* & 1.00 & 0.36 & .01 & 2.71 \\
\hline Some-Brilliance/ & Asian & -0.06 & 0.60 & .92 & 0.94 \\
\hline Uncertain/ & Black & -0.04 & 0.66 & .96 & 0.96 \\
\hline \multirow[t]{2}{*}{ Semi-Confident } & Gifted & -0.20 & 0.37 & .59 & 0.82 \\
\hline & Firstgen* & 1.10 & 0.37 & .003 & 3.00 \\
\hline \multirow[t]{3}{*}{ Intercept $=-2.57$} & Pell* & 1.35 & 0.33 & $<.001$ & 3.84 \\
\hline & Math Class* & 1.21 & 0.34 & $<.001$ & 3.35 \\
\hline & Cohort* & -0.62 & 0.30 & .04 & 0.54 \\
\hline S12: & Gender & 0.13 & 0.37 & .72 & 1.14 \\
\hline Less-Brilliance/ & Asian & 0.03 & 0.65 & .96 & 1.03 \\
\hline Uncertain/ & Black & 0.44 & 0.58 & .45 & 1.55 \\
\hline \multirow[t]{2}{*}{ Confident } & Gifted & -0.56 & 0.34 & .09 & 0.57 \\
\hline & Firstgen & -1.72 & 1.41 & .23 & 0.18 \\
\hline \multirow[t]{3}{*}{ Intercept $=-0.55$} & Pell & -0.07 & 0.44 & .88 & 0.93 \\
\hline & Math Class & -0.20 & 0.49 & .68 & 0.82 \\
\hline & Cohort* & -0.89 & 0.37 & .02 & 0.41 \\
\hline S13: & Gender* & 1.06 & 0.34 & .002 & 2.88 \\
\hline Less-Brilliance/ & Asian & 0.69 & 0.55 & .21 & 2.00 \\
\hline Included/ & Black & -0.89 & 1.09 & .41 & 0.41 \\
\hline \multirow[t]{2}{*}{ Semi-Confident } & Gifted & -0.53 & 0.34 & .12 & 0.59 \\
\hline & Firstgen & -0.83 & 0.59 & .16 & 0.44 \\
\hline \multirow[t]{2}{*}{ Intercept $=-1.08$} & Pell & 0.58 & 0.36 & .11 & 1.79 \\
\hline & Math Class* & 1.53 & 0.40 & $<.001$ & 4.63 \\
\hline \multicolumn{6}{|l|}{ Time 2} \\
\hline S21: & Cohort & -0.53 & 0.47 & .25 & 0.59 \\
\hline Moderate- & Gender & -0.23 & 0.63 & .71 & 0.79 \\
\hline Brilliance/ & Asian & 0.21 & 1.10 & .85 & 1.23 \\
\hline Excluded/ & Black & 0.17 & 0.86 & .84 & 1.19 \\
\hline Semi-Confident & Gifted & -0.20 & 0.49 & .68 & 0.82 \\
\hline
\end{tabular}




\begin{tabular}{|c|c|c|c|c|c|}
\hline \multirow{3}{*}{ Intercept $=-3.68$} & Firstgen & 0.95 & 0.69 & .17 & 2.59 \\
\hline & Pell & 0.90 & 0.51 & .08 & 2.46 \\
\hline & Math Class* & 2.42 & 0.57 & $<.001$ & 11.22 \\
\hline \multirow{5}{*}{$\begin{array}{c}\text { S22: } \\
\text { Some-Brilliance/ } \\
\text { Included/ } \\
\text { Semi-Confident }\end{array}$} & Cohort & -0.53 & 0.43 & .22 & 0.59 \\
\hline & Gender & 0.26 & 0.47 & .58 & 1.30 \\
\hline & Asian & 0.67 & 0.68 & .32 & 1.96 \\
\hline & Black $^{3}$ & -- & -- & -- & -- \\
\hline & Gifted & 0.68 & 0.86 & .43 & 1.97 \\
\hline \multirow{3}{*}{ Intercept $=-2.98$} & Firstgen & 0.65 & 0.62 & .29 & 1.92 \\
\hline & Pell* & 1.39 & 0.41 & .001 & 4.02 \\
\hline & Math Class* & 1.38 & 0.49 & .01 & 3.99 \\
\hline \multirow{5}{*}{$\begin{array}{c}\text { S23: } \\
\text { Some-Brilliance/ } \\
\text { Uncertain/ } \\
\text { Confident }\end{array}$} & Cohort & -0.16 & 0.23 & .47 & 0.85 \\
\hline & Gender & -0.45 & 0.31 & .15 & 0.64 \\
\hline & Asian & -1.38 & 0.88 & .12 & 0.25 \\
\hline & Black* & 1.03 & 0.45 & .02 & 2.80 \\
\hline & Gifted & -0.42 & 0.26 & .11 & 0.66 \\
\hline \multirow{3}{*}{ Intercept $=-0.81$} & Firstgen* & 1.02 & 0.36 & .004 & 2.76 \\
\hline & Pell & 0.30 & 0.31 & .33 & 1.35 \\
\hline & Math Class & -0.02 & 0.34 & .96 & 0.98 \\
\hline
\end{tabular}

Notes. $N=822$; The most-adaptive/largest latent statuses include Time 1: S14: LessBrilliance/Included/Quite-Confident; Time 2: S24: Less-Brilliance/Included/QuiteConfident. Model does not impose measurement invariance across time points. This is the standard $p$ value used to determine statistical significance. Cohort: $0=2016,1=2017$; Gender: $0=$ male, $1=$ female; Asian: $0=$ not Asian, $1=$ Asian; Black: $0=$ not Black/African American, 1 = Black/African American; Gifted: $0=$ did not report having been previously identified as Gifted/Talented, 1 = reported having been previously identified as Gifted/Talented; Firstgen: $0=$ not a first-generation college student, $1=$ first-generation college student; Pell: $0=$ not from a low-income household, $1=$ from a low-income household; Math Class: 0 = higher-level ENGR 101 course, 1 = lower-level ENGR 190 course. $* p<.05$.

Results related to latent transition probabilities and membership proportions were consistent between the covariate model and the model that included the distal outcome. Latent transition probabilities for the final LTA model are provided in Table 15. The

\footnotetext{
${ }^{3}$ Due to empty cells in the joint distribution of the latent and independent variables, the parameter was
} fixed. 
probability that students remained in the least-adaptive latent statuses across time $(S 11 \rightarrow$ S21) remained relatively low (.09), compared to the probability that students transitioned from the least-adaptive latent status at Time 1 to what would be considered the mostadaptive latent status at Time $2(S 11 \rightarrow S 24 ; .49)$. Students who started out in the mostadaptive latent status at Time 1 were more likely to transition to what would be considered the most-adaptive latent status at Time $2(S 14 \rightarrow S 24 ; .65)$ than they were to transition to a less-adaptive latent status ( $S 21, S 22$, or $S 23$; probability ranges between .04 and .21).

As previously found, students had a higher probability of transitioning from a less-adaptive latent status at Time 1 to a more-adaptive latent status at Time 2 compared to the probability of transitioning from a less-adaptive latent status at Time 1 to a lessadaptive (or "equivalent") latent status at Time 2 . This is evident after observing the proportion of students who remained in a similar latent status (as represented by the diagonal in Table 16), which was lower compared to the proportion of students who transitioned to a more-adaptive latent status. These findings continued to contradict my original hypothesis that students would move from more-adaptive to less-adaptive latent statuses or remain in less-adaptive latent statuses across transition periods, if they transitioned at all. 
Table 15

Latent Transition Probabilities by Latent Status and Time: Final LTA Model with Covariates and the Distal Outcome

\begin{tabular}{|c|c|c|c|c|}
\hline & \multicolumn{4}{|c|}{ Time 2} \\
\hline Time 1 & $\begin{array}{c}\text { S21: } \\
\text { Moderate- } \\
\text { Brilliance/ } \\
\text { Excluded/ } \\
\text { Semi- } \\
\text { Confident }\end{array}$ & $\begin{array}{c}\text { S22: } \\
\text { Some- } \\
\text { Brilliance/ } \\
\text { Included/ } \\
\text { Semi- } \\
\text { Confident }\end{array}$ & $\begin{array}{c}\text { S23: } \\
\text { Some-Brilliance/ } \\
\text { Uncertain/ } \\
\text { Confident }\end{array}$ & $\begin{array}{l}\text { S24: } \\
\text { Less- } \\
\text { Brilliance/ } \\
\text { Included/ } \\
\text { Quite- } \\
\text { Confident }\end{array}$ \\
\hline $\begin{array}{c}\text { S11: } \\
\text { Some-Brilliance/ } \\
\text { Uncertain/ } \\
\text { Semi-Confident }\end{array}$ & .09 & .20 & .22 & .49 \\
\hline $\begin{array}{c}\text { S12: } \\
\text { Less-Brilliance/ } \\
\text { Uncertain/ } \\
\text { Confident }\end{array}$ & .03 & .09 & .21 & .67 \\
\hline $\begin{array}{c}\text { S13: } \\
\text { Less-Brilliance/ } \\
\text { Included/ }\end{array}$ & .07 & .16 & .18 & .59 \\
\hline $\begin{array}{l}\text { Semi-Confident } \\
\text { S14: } \\
\text { Less-Brilliance/ } \\
\text { Included/ } \\
\text { Quite Confident }\end{array}$ & .04 & .10 & .21 & .65 \\
\hline
\end{tabular}


Table 16

Membership Proportions Based on Latent Status Patterns: Final LTA Model with Covariates and the Distal Outcome

\begin{tabular}{|c|c|c|c|c|}
\hline \multirow[b]{2}{*}{ Time 1} & \multicolumn{4}{|c|}{ Time 2} \\
\hline & $\begin{array}{c}\text { S21: } \\
\text { Moderate- } \\
\text { Brilliance/ } \\
\text { Excluded/ } \\
\text { Semi- } \\
\text { Confident }\end{array}$ & $\begin{array}{c}\text { S22: } \\
\text { Some- } \\
\text { Brilliance/ } \\
\text { Included/ } \\
\text { Semi- } \\
\text { Confident }\end{array}$ & $\begin{array}{c}\text { S23: } \\
\text { Some- } \\
\text { Brilliance/ } \\
\text { Uncertain/ } \\
\text { Confident }\end{array}$ & $\begin{array}{c}\text { S24: } \\
\text { Less- } \\
\text { Brilliance/ } \\
\text { Included/ } \\
\text { Quite- } \\
\text { Confident }\end{array}$ \\
\hline $\begin{array}{c}\text { S11: } \\
\text { Some- } \\
\text { Brilliance/ } \\
\text { Uncertain/ } \\
\text { Semi- }\end{array}$ & .01 & .02 & .02 & .05 \\
\hline Confident & & & & \\
\hline $\begin{array}{c}\text { S12: } \\
\text { Less- } \\
\text { Brilliance/ } \\
\text { Uncertain/ } \\
\text { Confident }\end{array}$ & .01 & .01 & .03 & .09 \\
\hline $\begin{array}{c}\text { S13: } \\
\text { Less- } \\
\text { Brilliance/ } \\
\text { Included/ } \\
\text { Semi- }\end{array}$ & .01 & .03 & .04 & .11 \\
\hline Confident & & & & \\
\hline $\begin{array}{c}\text { S14: } \\
\text { Less- } \\
\text { Brilliance/ } \\
\text { Included/ } \\
\text { Quite }\end{array}$ & .02 & .06 & .12 & .36 \\
\hline Confident & & & & \\
\hline
\end{tabular}

Notes. $N=822$; Model does not impose measurement invariance across time points. 
To address the final research question, RQ 4 (Ultimately, how do latent transitions predict 1-year retention in undergraduate engineering programs?), it is necessary to observe the proportion of students who were still enrolled in their engineering programs one year later versus the proportion of students who had left their engineering programs within a year. Table 17 provides the proportion of students who were and were not enrolled in their engineering programs one year later based on the latent status that the students transitioned to by the end of their first semesters in their engineering programs.

It is evident that students who transitioned to the least-adaptive latent status at Time 2, S21: Moderate-Brilliance/Excluded/Semi-Confident, were the least likely to remain in their programs one year later (.04; 4\% still enrolled). Students who attributed less brilliance or raw talent to the engineering discipline and felt a sense of inclusion in their programs (i.e., students who transitioned to the S22: Some-

Brilliance/Included/Semi-Confident latent status at Time 2) had an increased likelihood of remaining in their programs compared to the least-adaptive latent status, but the proportion of students who were enrolled one year later was still quite low $(.33 ; 33 \%$ still enrolled).

The two most-adaptive latent statuses are associated with a relatively high proportion of students still enrolled in their engineering programs 1 year later. Although the S23: Some-Brilliance/Uncertain/Confident latent status represents more neutral perceptions of belonging compared to the S22: Some-Brilliance/Included/Semi-Confident latent status, the proportion of students who were enrolled in their programs one year later is much higher (.80 or $80 \%$ compared to .33 or $33 \%$ ). This could be due to the 
higher levels of self-efficacy associated with the S23: Some-

Brilliance/Uncertain/Confident latent status. Finally, the students classified into the mostadaptive latent status, S24: Less-Brilliance/Included/Quite-Confident, were the most likely to remain in their programs one year later. Though the proportion of students who transitioned to this latent status and remained in their engineering programs one year later is quite high $(.82 ; 82 \%$ still enrolled), the retention rate is similar to the 523 : SomeBrilliance/Uncertain/Confident latent status (.80; $80 \%$ still enrolled). These findings supported my original hypothesis that transitions into less-adaptive latent statuses at the end of the students' first semester would be associated with lower 1-year retention rates and transitions into more-adaptive latent statuses would be associated with higher 1-year retention rates. 
Table 17

Retention Rates Based on Final Latent Status at the End of the Students' First Two Semesters

\begin{tabular}{lcc}
\hline $\begin{array}{c}\text { Final Latent Status } \\
\text { S21: }\end{array}$ & $\begin{array}{c}\text { Enrolled One Year } \\
\text { Later }\end{array}$ & $\begin{array}{c}\text { Not Enrolled One } \\
\text { Year Later }\end{array}$ \\
$\begin{array}{c}\text { Moderate-Brilliance/Excluded/ } \\
\text { Semi-Confident }\end{array}$ & .04 & .96 \\
S22: & .33 & .67 \\
Some-Brilliance/Included/ & \\
Semi-Confident & .20 \\
S23: & .80 & \\
Some-Brilliance/Uncertain/ & \\
Confident \\
S24: \\
$\begin{array}{l}\text { Less-Brilliance/Included/ } \\
\text { Quite-Confident }\end{array}$
\end{tabular}




\section{CHAPTER FIVE}

\section{DISCUSSION}

Understanding and increasing the retention of students in STEM programs, including students in undergraduate engineering programs, has previously been described as the "lowest-cost, fastest policy option" to increasing the number of STEM professionals critical to economic and societal well-being (President's Council of Advisors on Science and Technology, 2012, p. i). Upon reviewing existing literature, it appears that most researchers have taken a variable-centered approach when examining engineering retention (e.g., Marra et al., 2012). On the other hand, a person-centered approach can be used to uncover differing profiles based on student perceptions (Bergman \& Trost, 2006; Laursen \& Hoff, 2006; Magnusson, 1998), and this approach could be used to uncover specific profiles that could be considered more adaptive than others when it comes to understanding retention in engineering programs. Thus, the goals of this study were to understand the types of latent profiles that would emerge from combinations of students' expectations of brilliance, perceived belonging uncertainty, and self-efficacy and how these profiles and the proportion of students best classified into each latent profile might change across the course of the students' first semester.

Additionally, I examined how student demographics predicted latent profile membership. In the end, these results were combined in order to better understand how latent profile 
membership at the end of the students' first semester predicts 1-year retention in undergraduate engineering programs. Although LTA is a model-building process and the results of each step were presented in the previous chapter, the present discussion will focus on the results of the final LTA model which included the three perceptions indicators, student demographic covariates, and the distal outcome of one-year retention. To begin, throughout the model-building process, four latent profiles emerged. These profiles are referred to as latent statuses after transitioning from separate LPAs to a baseline LTA model. It was only after establishing measurement noninvaraince that I could conclude that these statuses were both quantitatively and qualitatively different at the beginning and end of the students' first semester. Compared to the expectations of brilliance and self-efficacy measures, greater variability was present in the perceived belonging uncertainty measure, which allowed for latent statuses with both adaptive and less-adaptive attributes to emerge at each time point.

In the final LTA model, each time point had what could be considered a leastadaptive (S11: Some-Brilliance/Uncertain/Semi-Confident; S21: ModerateBrilliance/Excluded/Semi-Confident) and most-adaptive latent status (S14: LessBrilliance/Included/Quite-Confident; S24: Less-Brilliance/Included/Quite-Confident). There were also two statuses at each time point that emerged between the least- and most-adaptive latent statuses, including S12: Less-Brilliance/Uncertain/Confident, S13: Less-Brilliance/Included/Semi-Confident, S22: Some-Brilliance/Included/Semi-Confident, S23: Some-Brilliance/Uncertain/Confident. This aligned with my original hypothesis that both adaptive and less-adaptive latent statuses would emerge. However, it was not the case that an "adaptive triad" (i.e., low expectations of brilliance, low levels of perceived 
belonging uncertainty, and high self-efficacy) or "maladaptive triad" (i.e., high expectations of brilliance, high perceived levels of belonging uncertainty, and low selfefficacy) emerged as I had anticipated.

There has not been a study that has looked at combinations of students' expectations of brilliance, perceived belonging uncertainty, and self-efficacy through a person-centered approach, even though these perceptions have each been found to be related to different engineering-related outcomes, including representation of women and racial/ethnic minorities in the engineering discipline (e.g., Leslie et al., 2015) and retention in engineering programs (e.g.,Litzler et al., 2014; Marra et al., 2012). This provided the opportunity to uncover profiles of student perceptions and address heterogeneity across the different latent profiles. Specifically, taking a person-centered approach uncovered a more neutral latent status at each time point: S12: LessBrilliance/Uncertain/Confident and S23: Some-Brilliance/Uncertain/Confident. Often, the unique challenges of students with these types of average or neutral beliefs are overlooked when using a variable-centered approach (Conley, 2012; Wormington \& Linnenbrink-Garcia, 2017). Similarly, a person-centered approach provided the opportunity to unmask the subtle differences between students who endorsed the highest levels of a particular set of beliefs (Chen, 2012). Specifically, although most latent statuses represented greater emphasis on hard work and effort in engineering (high mean scores for expectations of brilliance) and higher levels of engineering confidence (high means scores for self-efficacy), the addition of students' perceived belonging uncertainty provided new insight into differences in students' sense of belonging among students with higher levels of the other perceptions. 
Another goal of this study was to observe how students transitioned between these latent statuses over the course of a semester. Contrary to my original hypotheses, students were more likely to transition from a less-adaptive latent status at Time 1 to a moreadaptive latent status at Time 2 than they were to transition from a less-adaptive latent status at Time 1 to a less adaptive or similar latent status at Time 2. Specifically, the probability that a student would remain in the least-adaptive latent status across time (.09) was much lower than the probability that students would transition to a more-adaptive latent status (probability range: 20 to .49). Additionally, students who were in the mostadaptive latent status at Time 1 were much more likely to transition to the most-adaptive latent status at Time $2(.65)$ than they were to transition to a less-adaptive latent status (probability range .04 to .21). In general, membership percentages tended to increase in the more-adaptive latent statuses across the students' first semester. As previously mentioned, 147 students did not provide data at Time 2 because either the students left their programs or decided not to complete the survey for some reason. Given this, it is possible that these findings could be somewhat attributed to students with less-adaptive student perceptions leaving their programs and not completing the post-survey. Including the demographic covariates into the LTA model provided additional insight into the factors that may negatively influence undergraduate engineering retention. To review, the eight demographic covariates included cohort $(2016,2017)$, gender (male, female), two dummy-coded variables for race/ethnicity (Asian, Black/African American; Hispanic/Latinx students were removed due to the small sample size) with White serving as the reference group, reported previous identification as Gifted/Talented, first-generation college student status, Pell Grant eligibility (as a proxy 
for low-income household status), and introductory mathematics course that the students completed during their first semester (lower-level ENGR 190, higher-level ENGR 101). Based on the findings from the present study, females, first-generation college students, low-income students, Black/African American students, and students enrolled in lower-level introductory mathematics courses may benefit from retention interventions. Specifically, researchers and educators who are developing interventions might emphasize the importance of hard work and effort in the engineering discipline (as opposed to innate ability or raw talent), help connect students who may feel as if they do not belong or could potentially benefit from an added sense of comradery or peer support within their engineering programs, and include practices that might help students with lower levels of engineering confidence improve their perceived competence related to their engineering coursework.

Before discussing how these demographic characteristics predict latent status memberships, it is important to mention that each of the following comparisons is made with the most-adaptive latent status at each time point (S14: Less-

\section{Brilliance/Included/Quite-Confident; S24: Less-Brilliance/Included/Quite-Confident)} serving as the reference status. In general, the odds were greater for female students than males to be classified into latent statuses that associated the engineering discipline with brilliance or raw talent, experience uncertainty when it comes to their sense of belonging, and experience lower-levels of self-efficacy in engineering at the beginning of their first semester. This is reflective of the work of Leslie and colleagues (2015), which found that females generally associate higher levels of brilliance with the engineering discipline. Specifically, the odds were 2.71 times greater for female students than male students to 
be classified into the least-adaptive latent status, S11: Some-Brilliance/Uncertain/SemiConfident, and 2.88 times greater to be classified into the S13: LessBrilliance/Included/Semi-Confident latent status at Time 1 compared to the reference status.

Similarly, the odds were greater for first-generation college students, students from low-income households, and Black/African American students than their demographic counterparts to be classified into latent statuses that associated the engineering discipline with higher levels of brilliance or raw talent, higher levels of belonging uncertainty, and lower-levels of self-efficacy. At Time 1, for first-generation college students and students from low-income households, the odds were 3.00 and 3.84 times greater (respectively) to be classified into the least-adaptive latent status (S11: Some-Brilliance/Uncertain/Semi-Confident) compared to the reference status. The same types of beliefs were present at the end of the students' first semester. Namely, at Time 2, for first-generation college students and students from low-income households, the odds were 2.76 and 4.02 times greater to be classified into the S23: Some-

Brilliance/Uncertain/Confident (i.e., a more neutral latent status) and S22: SomeBrilliance/Included/Semi-Confident latent statuses, respectively. Additionally, the odds were 2.80 times greater for Black/African American students than White students to be classified into the more neutral latent status (S23: Some-Brilliance/Uncertain/Confident). Again, these findings are supported by the research of Leslie and colleagues (2015) that found that individuals identifying with specific racial/ethnic minority groups (e.g., Black/African American) tend to perceive the engineering discipline as requiring higher levels of brilliance compared to hard work or increased effort. 
The most notable effects were observed with students who were enrolled in the lower-level mathematics course during their first semester, especially at the end of the students' first semester. The specific combination of the student perceptions, rather than a single factor, helps to explain engineering retention for students in lower-level introductory mathematics courses. These students attribute higher levels of brilliance to the engineering discipline, are more likely to question if they belong in their undergraduate engineering programs and are more likely to experience lower levels of self-efficacy compared to students in the higher-level introductory mathematics course. At the beginning of their first semester, for students in the lower-level course, the odds were 3.35 and 4.63 times greater to be classified into the S11: SomeBrilliance/Uncertain/Semi-Confident (i.e., the least adaptive status) and S13: LessBrilliance/Included/Semi-Confident latent statuses, respectively. At the end of the students first semester, for students in lower-level introductory mathematics course, the odds were 3.99 times greater to be classified into the $S 22$ : SomeBrilliance/Included/Semi-Confident latent status and 11.22 times greater to be classified into the least-adaptive latent status (S21: Moderate-Brilliance/Excluded/Semi-Confident). As expected, several of the model parameters changed after including the covariates in the baseline LTA model, and again when including the distal outcome in the model with the demographic covariates. For example, in the model including the three student perception indicators and demographic covariates, the odds were 1.93 times greater for students in the lower-level introductory mathematics course than students in the higher-level introductory mathematics course to be classified into the least-adaptive latent status (this covariate is not statistically significant in this model). However, after 
including the distal outcome, introductory mathematics course became a statistically significant covariate $(p<.001)$, and the odds were 11.22 times greater for students in the lower-level introductory mathematics course than students in the higher-level introductory mathematics course to be classified into the least-adaptive latent status at Time 2. This is often the case as including new parameters into the model introduces new information that is ultimately used to predict latent status memberships and retention outcomes (Nylund, 2007). If the parameters had changed in a way that contradicted theory about how the demographic covariate and retention outcome are related, this might suggest issues with the baseline LTA model that was selected (Nylund, 2007). However, I would anticipate the changes that occurred given that advanced quantitative and analytical skills can be crucial early in students' programs as they try to complete the introductory "weeding-out" courses (Seymour \& Hewitt, 1997). Considering that the parameters changed in the expected direction and significance, I feel confident in the interpretations of the significant covariate relationships for the final LTA model.

The findings somewhat align with my original hypotheses that specific demographic covariates would be predictive of classification into less-adaptive latent statuses. Namely, females, Black/African American students, first-generation college students, students from low-income households, students who had not reported previous identification as Gifted/Talented, and students who were enrolled in a lower-level mathematics course during their first semester in their engineering program would be more likely to be classified into less-adaptive latent statuses across time. Although this is the case for female students, first-generation college students, students from low-income households, Black/African American students, and students who were enrolled in lower- 
level introductory mathematics courses, there were not significant findings based on students reported previous Gifted/Talented status.

Most researchers have looked at the relationship between student demographics and perceptions separately, most often by using a variable-centered approach. For example, researchers have found that Black/African American students (Litzler et al., 2014), low-income students (Donaldson et al., 2008), and first-generation college students (Chen, 2013) have lower levels of engineering confidence and this can negatively influence retention. One variable-centered study found that lack of belonging and lower-levels of self-efficacy contribute to females' decisions to leave their engineering programs (Marra et al., 2014). However, given that a variable-centered approach has been used in most studies related to engineering retention, researchers have been unable to provide support for the types of profiles that might emerge from the combinations of these beliefs. In general, variable-centered research is useful for providing guidance about which variables may be informative if one chooses to move forward with a person-centered approach.

The final goal of this study was to understand how the latent statuses that students transition into at the end of their first semester predict 1-year retention. To begin, few students who transitioned into the least-adaptive status at Time 2 (S21: ModerateBrilliance/Excluded/Semi-Confident) were enrolled in their engineering programs 1 year later $(.04$ or $4 \%)$. The proportion of students who transitioned to a latent status associated with less brilliance attributed to the engineering discipline and stronger feelings of inclusion (S22: Some-Brilliance/Included/Semi-Confident) and remained in their engineering programs one year later was slightly higher (.33 or 33\%). Surprisingly, the 
latent status that represented more neutral student perceptions (S23: Some-

Brilliance/Uncertain/Confident) had a much higher proportion of students who were enrolled 1 year later (.80 or $80 \%)$ compared the previous latent status (S22: SomeBrilliance/Included/Semi-Confident). This is possibly due to the higher levels of engineering confidence associated with the S23: Some-Brilliance/Uncertain/Confident latent status.

In the end, students who transitioned to the most-adaptive latent status (S24: LessBrilliance/Included/Quite-Confident) were the most likely to remain in their undergraduate engineering programs one year later (.82 or $82 \%)$; however, this retention rate is not much higher than the more neutral latent status (S23: SomeBrilliance/Uncertain/Confident; .80 or $80 \%$ compared to .82 or $82 \%)$. These findings support my original hypothesis that students who transitioned to the less-adaptive latent statuses by the end of their first semester would be less likely to remain in their undergraduate engineering programs 1 year later. Similarly, I anticipated that students who transitioned to the most-adaptive latent statuses by the end of their first semester would be more likely to persist in their programs.

One of the biggest limitations of the present study also serves as one of the greatest strengths. Given that measurement invariance could not be established across both time points, this can make the interpretation of transitions more difficult to describe and understand as one must consider both quantitative and qualitative change across time (Nylund, 2007). However, as I describe later, this provided the opportunity to uncover changes over time in the types of student perception profiles that were uncovered and this may not have occurred had full measurement invariance been imposed or assumed 
(Nylund, 2007). An additional limitation is that internal consistency reliability was poor for the expectations of brilliance scale on the pre- and post-surveys. Additionally, modeldata fit was less than desirable for the each of the perceptions measures. Although a post hoc correlation improved model-data fit for the expectations of brilliance and perceived belonging uncertainty scales, this is still with the limitation that the measures were included as mean scores rather than latent variables which does not account for the correlated error terms. The self-efficacy scale did not include correlated error terms; however, given that model-data fit was acceptable at one time point, I decided to continue with the scale in the analyses.

A final limitation would be that students' self-efficacy judgements may be inaccurate. Based on prior engineering retention research, one would expect that certain student subgroups might express lower levels of engineering confidence (e.g., Donaldson et al., 2008; Litzler et al., 2014; Marra et al., 2009). However, there was little variability in students' self-efficacy judgements across latent statuses and across time. This could be because judgements were made when students were beginning their programs and had not yet had exposure to the more challenging course content or become aware of all of the demands (i.e., academic demands, challenges with work-life balance) associated with their engineering programs. Similarly, students also may not be aware if they possess the necessary skills or abilities to be successful in their engineering programs this early in their studies. This is supported by previous research that describes the decline in students' self-efficacy during the first year of their engineering programs given that, as students progress through their first year, they may discover the added difficulty of college coursework compared to high school classwork, and they may have received negative 
feedback on their course performance (i.e., grades on assignments, projects, and exams; Jones, Paretti, Hein, \& Knott, 2010).

Despite the previously mentioned limitations, there are notable strengths in the present study. Most noteworthy is that, although student perceptions have been previously studied in engineering retention research (e.g., Marra et al., 2012), the current study provides the first example of studying three important student perceptions (expectations of brilliance, perceived belonging uncertainty, and self-efficacy) simultaneously. This allowed for the examination of new latent profiles that have not been previously considered when seeking to understand undergraduate engineering retention. Additionally, in the past, when conducting a latent transition analysis, most researchers have given little attention to measurement invariance or the exploration of potential measurement invariance (Nylund, 2007). Thus, the default for most researchers is to assume full measurement invariance (Nylund, 2007). I conducted an extensive investigation of measurement invariance (e.g., constraining item-response probabilities, multiple LRTs, replication the LRTs with MLR estimation, observing changes in AIC and BIC values). In the end, measurement invariance could not be assumed. Although this made the interpretation of latent statuses more challenging, this provided the opportunity to uncover important changes in latent statuses across time. Namely, slightly less-adaptive statuses at Time 2 compared to Time 1 (i.e., lower mean scores for expectations of brilliance and self-efficacy, as well as greater variability in students' perceived belonging uncertainty at Time 2).

For future studies, researchers might want to consider where students go once they leave their engineering programs. Do students who leave their programs move to 
another college or program or do they choose to leave the university? Although

examining students post-engineering pursuits is beyond the scope of the present study, it could provide valuable insight into the decisions students make once they choose to leave their engineering programs. Additionally, researchers may wish to look at changes in student perceptions over a longer period of time as opposed to across a single semester. If data were collected for multiple time points across multiple semesters, this could provide insight into whether or not there is a specific point during a student's engineering program where there is a substantial shift in student perceptions, becoming more or less adaptive for the retention. However, it could be possible that the most substantial shifts in student perceptions occur during the first semester and level out across their remainder of the students' studies. This would help researchers and educators know when it is most critical to identify specific subgroups of students or students reporting less-adaptive combinations of perceptions in order to intervene.

The current study provides an example of why it is necessary to move beyond the tendency of researchers to rely on a variable-centered approach to identify the best predictors of retention or to find a direct link between a specific academic or student perceptions factor and engineering retention (e.g., Litzler et al., 2014; Marra et al., 2012). Rather, researchers should focus on how student perceptions coexist when seeking to understand undergraduate engineering retention. For example, there was considerable variability in students' perceived belonging uncertainty across latent statuses at each time point. Students' perceptions of belonging within their engineering programs has been regarded as one of the most influential factors when it comes to explaining students' decisions to leave their engineering programs or to persist (Marra et al., 2012). Not only 
is belonging closely tied to self-efficacy in other variable-centered research (Marra et al., 2012), but it varies greatly according to a student's race/ethnicity (Walton \& Cohen, 2007; Zirkel, 2004), socioeconomic background (Ostrove \& Long, 2007), and gender (Amelink \& Creamer, 2010). Although the previous findings of variable-centered research suggest that perceived belonging uncertainty would be an important factor to focus on when examining engineering retention, a person-centered approach was necessary to truly understand how this factor coexisted with the other student perceptions to predict retention. Consequently, this variability might not have been uncovered had students' perceptions of belonging uncertainty not been simultaneously studied alongside students' expectations of brilliance and self-efficacy.

When considering interventions within the engineering school, it is imperative that researchers look for students who report combinations of beliefs that are associated with the less-adaptive profiles and consider how students' perceptions may contribute to their likelihood of remining in their engineering programs. Drawing on a person-centered approach could help those who are designing and implementing interventions within the engineering school as they consider different demographic characteristics that are related to classification into less-adaptive profiles. Specifically, females, first-generation college students, students from low-income households, Black/African American students, and students who were enrolled in lower-level mathematics courses, as these students were more likely to be classified into less-adaptive latent statuses in the present study. Additionally, a person-centered approach can shed light on other groups of students (i.e., students with more neutral perceptions or higher levels of a particular set of beliefs) that might have been overlooked had the factors been considered separately. 
Although it may be commonplace to identify academic factors that one would assume to explain the most variance in engineering retention, it may be even more beneficial to examine the reciprocal interactions between students' perceptions and their behaviors (Bandura 1986, 2001). Specifically, researchers might consider the interactions between a student's environment, latent profiles of perceptions, and their behaviors. In line with the social cognitive theory, researchers and educators should consider how specific combinations of perceptions might shape students' interpretations of their experiences (Dweck \& Leggett, 1988) and how their experiences within their engineering programs might influence students' decisions to leave their programs or to persist. 


\section{CHAPTER SIX}

\section{CONCLUSION}

Results from a latent transition analysis (LTA) suggested that both adaptive and maladaptive latent statuses emerged at the beginning and end of students' first semester in their undergraduate engineering programs, with the greatest variability present in the perceived belonging uncertainty measure. Although different latent statuses emerged, a distinct "adaptive triad" (i.e., low expectations of brilliance, low levels of perceived belonging uncertainty, and high self-efficacy) or "maladaptive triad" (i.e., high expectations of brilliance, high perceived levels of belonging uncertainty, and low selfefficacy) did not emerge. Contrary to my original hypothesis, students were more likely to transition to more-adaptive latent statuses than they were to remain in or transition to a less-adaptive latent status by the end of their first semester in their engineering programs. Including covariates in the LTA model revealed that females, Black/African American students, first-generation college students, low-income students, and students who were enrolled in lower-level introductory mathematics courses were more likely to be classified into latent statuses that associated the engineering discipline with higher levels of brilliance, higher levels of belonging uncertainty, and lower-levels of selfefficacy. The most notable effects were among students enrolled in lower-level introductory mathematics courses. In the end, students who were best classified into the 
less-adaptive latent statuses at the end of the first semester of their programs were less likely to remain in their undergraduate engineering programs one year later. On the other hand, students who remained in or transitioned into the most-adaptive latent statuses were more likely to persist.

Although a variable-centered approach generally is useful for providing guidance for researchers who are planning a person-centered study and considering which variables to include, a person-centered approach allows researchers to create a more holistic picture of undergraduate engineering retention. This is especially true for students who might endorse more neutral or particularly high levels of a set of beliefs (Chen, 2012; Conley, 2012; Wormington \& Linnenbrink-Garcia, 2017). As a result, researchers and educators may be able to provide better support to many students who are considering leaving their engineering programs, even those students who, academicallyspeaking, are considered the highest-performing (Besterfield-Sacre et al., 2001; Bettinger, 2010). Ultimately, the results from this study emphasizes the importance of considering not only different combinations of students' beliefs, but also the interactions between students' environments, latent profiles of perceptions, and their behaviors when designing and implementing interventions. 


\section{REFERENCES}

Akaike, H. (1987). Factor analysis and AIC. Psychometrika, 52, 317-332

Amelink, C. T., \& Creamer, E. G. (2010). Gender differences in elements of the undergraduate experience that influence satisfaction with the engineering major and the intent to pursue engineering as a career. Journal of Engineering Education, 99, 81-92. doi: 10.1002/j.2168-9830.2010.tb01044.x

Angrove, K. E. (2017). First-year seminar course and academic performance: An examination of differences by student characteristics (Doctoral dissertation).

Aronson, J. M. (Ed.) (2002). Improving academic achievement: Impact of psychological factors in education. San Diego, CA: Academic Press. doi: 10.1016/b978$012064455-1 / 50017-8$

Asparouhov, T., \& Muthén, B. (2012). Using Mplus TECH11 and TECH14 to test the number of latent classes. Mplus Web Notes, 14, 1-17. Retrieved from http://statmodel2.com/examples/webnotes/webnote14.pdf

Attewell, P., Heil, S., \& Reisel, L. (2012). What is academic momentum? And does it matter? Educational Evaluation and Policy, 34, 27-44. doi: $10.3102 / 0162373711421958$

Bandura, A. (1986). Social foundations of thought and action: A social cognitive theory. Englewood Cliffs, NJ: Prentice Hall.

Bandura, A. (1989). Human agency in social cognitive theory. American Psychologist, 44, 1175-1184. doi: 10.1037//0003-066x.44.9.1175 
Bandura, A. (2001). Social cognitive theory: An agentic perspective. Annual Review of Psychology, 52, 1-26. doi: 10.1146/annurev.psych.52.1.1

Bauer, D. J., \& Curran, P. J. (2004). The integration of continuous and discrete latent variable models: Potential problems and promising opportunities. Psychological Methods, 9, 3-29. doi: 0.1037/1082-989x.9.1.3

Bauer, D. J., \& Shanahan, M. J. (2007). Modeling complex interactions: Person-centered and variable-centered approaches. In T. D. Little, J. A. Bovaird, \& N. A. Card (Eds.), Modeling contextual effects in longitudinal studies (pp. 255-284).

Mahwah, NJ: Erlbaum.

Belasco, A. S., Rosinger, K. O., \& Hearn, J. C. (2015). The test-optional movement at America's selective liberal arts colleges: A boon for equity or something else? Educational Evaluation and Policy Analysis, 37, 206-223. doi: $10.3102 / 0162373714537350$

Bergman, L. R. (2001). A person approach to adolescence: Some methodological challenges. Journal of Adolescent Research, 16, 28-53. doi:

$10.1177 / 0743558401161004$

Bergman, L. R., \& Magnusson, D. (1997). A person-oriented approach in research on developmental psychopathology. Development and Psychopathology, 9, 291-319. doi: $10.1017 /$ s095457949700206x

Bergman, L. R., \& Trost, K. (2006). The person-oriented versus the variable-oriented approach: Are they complementary, opposites, or exploring different worlds? Merrill-Palmer Quarterly, 52, 601-632. doi: 10.1353/mpq.2006.0023 
Besterfield-Sacre, M., Moreno, M., Shuman, L. J., \& Atman, C. J. (2001). Gender and ethnicity differences in freshmen engineering student attitudes: A crossinstitutional study. Journal of Engineering Education, 90, 477-489. doi: 10.1002/j.2168-9830.2001.tb00629.x

Bettinger, E. (2010). To be or not to be: Major choices in budding scientists. In C.T. Clotfelter (Ed.), American Universities in a Global Market (pp. 68-98). Chicago: University of Chicago Press. doi: 10.1007/s10734-011-9472-5

Blackwell, L. S., Trzesniewski, K. H., \& Dweck, C. S. (2007). Implicit theories of intelligence predict achievement across an adolescent transition: A longitudinal study and an intervention. Child Development, 78, 246-263. doi: 10.1111/j.14678624.2007.00995.x

Blickenstaff, J. C. (2005). Women and science careers: Leaky pipeline or gender filter? Gender and Education, 17, 369-386. doi: 10.1080/09540250500145072

Bong, M., \& Skaalvik, E. M. (2003). Academic self-concept and self-efficacy: How different are they really? Educational Psychology Review, 15, 1-40. doi:10.1023/A:1021302408382

Burtner, J. (2004). Critical-to-quality factors associated with engineering student persistence: The influence of freshman attitudes. In ASEE/IEEE Frontiers in Education conference proceedings. doi: 10.1109/fie.2004.1408601

Burtner, J. (2005). The use of discriminant analysis to investigate the influence of non-cognitive factors on engineering school persistence. Journal of Engineering Education, 94, 335-338. doi: 10.1002/j.2168-9830.2005.tb00858.x 
Cech, E., Rubineau, B., Silbey, S., \& Seron, C. (2011). Professional role confidence and gendered persistence in engineering. American Sociological Review, 76, 641-666. doi: $10.1177 / 0003122411420815$

Chen, J. A. (2012). Implicit theories, epistemic beliefs, and science motivation: A personcentered approach. Learning and Individual Differences, 22, 724-735. doi: 10.1016/j.lindif.2012.07.013

Chen, X. (2013). STEM attrition: College students' paths into and out of STEM fields. Statistical Analysis Report. NCES 2014-001. National Center for Education Statistics.

Chen, X., \& Carroll, C. D. (2005). First-generation students in postsecondary education: A look at their college transcripts. Postsecondary Education Descriptive Analysis Report. NCES 2005-171. National Center for Education Statistics.

Chung H, Park Y, Lanza ST. (2005) Latent transition analysis with covariates: Pubertal timing and substance use behaviours in adolescent females. Statistics in Medicine, 24, 2895-2910. doi: 10.1002/sim.2148

Collins, L. M., \& Lanza, S. T. (2010). Latent class and latent transition analysis: With applications in the social, behavioral, and health sciences. New York, NY: Wiley.

Conley, A. M. (2012). Patterns of motivation beliefs: Combining achievement goal and expectancy-value perspectives. Journal of Educational Psychology, 104, 32. doi: $10.1037 / \mathrm{a} 0026042$ 
Conrad, S., Canetto, S. S., MacPhee, D., \& Farro, S. (2009). What attracts highachieving, socioeconomically disadvantaged students to the physical sciences and engineering? College Student Journal, 43, 1359-1370. doi: 10.1037/e602862009001

Cordero, E. D., Porter, S. H., Israel, T., \& Brown, M. T. (2010). Math and science pursuits: A self-efficacy intervention comparison study. Journal of Career Assessment, 18, 362. doi: 10.1177/1069072710374572

Daempfle, P. A. (2003). An analysis of the high attrition rates among first year college science, math, and engineering majors. Journal of College Student Retention: Research, Theory \& Practice, 5, 37-52. doi: 10.2190/dwqt-tya4-t20w-rcwh

Deci, E. L., \& Ryan, R. M. (Eds.). (2002). Handbook of self-determination research. Rochester, NY: University of Rochester Press.

Dempster, A. P., Laird, N. H., \& Rubin, D. B. (1977). Maximum likelihood from incomplete data via the EM algorithm. Journal of the Royal Statistical Society, B39, 1-38.

Donaldson, K., Lichtenstein, G., \& Sheppard, S. (2008). Socioeconomic status and the undergraduate engineering experience: Preliminary findings from four American universities. Research Brief. Center for the Advancement of Engineering Education (NJ1).

Douglass, J., \& Thomson, G. (2012). Poor and rich: Student economic stratification and academic performance in a public research university system. Higher Education Quarterly, 66, 65-89. doi: 10.1111/j.1468-2273.2011.00511.x 
Dweck, C. S. (2000). Self-theories: Their role in motivation, personality, and development. Philadelphia, PA: Psychology Press. doi: $10.1017 / \mathrm{s} 0021963099316413$

Dweck, C. S. (2002). The development of ability conceptions. In A. Wigfield \& J. Eccles (Eds.), The development of achievement motivation. New York: Academic Press. doi: 10.1016/b978-012750053-9/50005-x

Dweck, C. S., Chiu, C., \& Hong, Y. (1995). Implicit theories and their role in judgments and reactions: A world from two perspectives. Psychological Inquiry, 6, 267-285. doi: s15327965pli0604_1

Dweck, C. S., \& Leggett, E. L. (1988). A social-cognitive approach to motivation and personality. Psychological Review, 95, 256-273. doi: 0033-295x.95.2.256

Dweck, C. S., \& Molden, D. C. (2005). Self-theories: Their impact on competence motivation and acquisition. In A. J. Elliot \& C. S. Dweck (Eds.), Handbook of competence and motivation (pp. 122-140).

Fernandez, M. J., Trenor, J. M., Zerda, K. S., \& Cortes, C. (2008). First generation college students in engineering: A qualitative investigation of barriers to academic plans. In Frontiers in Education Conference, 2008. FIE 2008. 38th Annual (pp. T4D-1). IEEE.

Field, Andy. (2009). Discovering Statistics Using SPSS. London: Sage

Gandhi-Lee, E., Skaza, H., Marti, E., Schrader, P. G., \& Orgill, M. (2017). Faculty perceptions of student recruitment and retention in STEM fields. European Journal of STEM Education, 2, 1-11. doi: 10.20897/esteme.201702 
Garriott, P. O., Navarro, R. L., \& Flores, L. Y. (2017). First-generation college students' persistence intentions in engineering majors. Journal of Career Assessment, 25, 93-106. doi: 10.1177/1069072716657533

George-Jackson, C. E., Rincon, B., \& Martinez, M. G. (2012). Low-income engineering students: Considering financial aid and differential tuition. Journal of Student Financial Aid, 42, 4-24.

Grant, H., \& Dweck, C. S. (2003). Clarifying achievement goals and their impact. Journal of Personality and Social Psychology, 85, 541-553. doi: $10.1037 / 0022-3514.85 .3 .541$

Gravetter, F. and Wallnau, L. (2014) Essentials of Statistics for the Behavioral Sciences. 8th Edition, Wadsworth, Belmont, CA.

Griffith, A. L. (2010). Persistence of women and minorities in STEM field majors: Is it the school that matters? Economics of Education Review, 29, 911-922. doi: 10.1016/j.econedurev.2010.06.010

Harter, S., Whitesell, N. R., \& Kowalski, P. (1992). Individual differences in the effects of educational transitions on young adolescents' perceptions of competence and motivational orientation. American Educational Research Journal, 29, 777-807. doi: 10.2307/1163407

Hayenga, A. O., \& Corpus, J. H. (2010). Profiles of intrinsic and extrinsic motivations: A person-centered approach to motivation and achievement in middle school. Motivation and Emotion, 34, 371-383. doi; 10.1007/s11031-010-9181-x 
Hill, C., Corbett, C., \& St Rose, A. (2010). Why so few? Women in science, technology, engineering, and mathematics. American Association of University Women. 111 Sixteenth Street NW, Washington, DC 20036.

Hollifield-Hoyle, H., \& Hammons, J. (2015). The neglected minority: Interviews with successful community college students from poverty. Community College Enterprise, 21, 29-61.

Hu, L., and Bentler, P. M. (1999). Cutoff criteria for fit indexes in covariance structure analysis: conventional criteria versus new alternatives. Structural Equation Modeling 6, 1-55. doi: 10.1080/10705519909540118.

Huang, G., Taddese, N., \& Walter, E. (2000). Entry and persistence of women and minorities in college science and engineering education (NCES 2000-601). National Center for Education Statistics, U.S. Department of Education. Washington, DC.

Huang, P. M., \& Brainard, S. G. (2001). Identifying determinants of academic selfconfidence among science, math, engineering and technology students. Journal of Women and Minorities in Science and Engineering, 7, 317-339. doi: 10.1615/jwomenminorscieneng.v7.i4.40

Jones, B. D., Paretti, M. C., Hein, S. F., \& Knott, T. W. (2010). An analysis of motivation constructs with first-year engineering students: Relationships among expectancies, values, achievement, and career plans. Journal of Engineering Education, 99, 319-336. doi: 10.1002/j.2168-9830.2010.tb01066.x 
Jung, T., \& Wickrama, K. A. S. (2008). An introduction to latent class growth analysis and growth mixture modeling. Social and Personality Psychology Compass, 2, 302-317. doi: 10.1111/j.1751-9004.2007.00054.x

Kenny, D. A., Kaniskan, B., \& McCoach, D. B. (2015). The performance of RMSEA in models with small degrees of freedom. Sociological Methods \& Research, 44, 486-507. doi: 10.1177/0049124114543236

Kline, P. (2013). Handbook of psychological testing. Routledge.

Lanza, S. T., Bray, B. C., \& Collins, L. M. (2013). An introduction to latent class and latent transition analysis. In J. A. Schinka, W. F. Velicer, \& I. B. Weiner (Eds.), Handbook of psychology (2nd ed.,Vol. 2, pp. 691-716). Hoboken, NJ: Wiley.

Lanza, S. T., \& Collins, L. M. (2008). A new SAS procedure for latent transition analysis: Transitions in dating and sexual risk behavior. Developmental Psychology, 44, 446-456.

Laursen, B., \& Hoff, E. (2006). Person-centered and variable-centered approaches to longitudinal data. Merrill Palmer Quarterly, 52, 377-389. doi:10.1353/mpq.2006.0029

Leslie, S. J., Cimpian, A., Meyer, M., \& Freeland, E. (2015). Expectations of brilliance underlie gender distributions across academic disciplines. Science, 347, 262-265. doi: $10.1126 /$ science. 1261375

Litzler, E., Samuelson, C. C., \& Lorah, J. A. (2014). Breaking it down: Engineering student STEM confidence at the intersection of race/ethnicity and gender. Research in Higher Education, 55, 810-832. doi: 10.1007/s11162-0149333-Z 
Litzler, E., \& Young, J. (2012). Understanding the risk of attrition in undergraduate engineering: Results from the project to assess climate in engineering. Journal of Engineering Education, 101, 319-345. doi: 10.1002/j.2168-9830.2012.tb00052.x

Lohman, D. F., \& Korb, K. A. (2006). Gifted today but not tomorrow? Longitudinal changes in ability and achievement during elementary school. Journal for the Education of the Gifted, 29, 451-484. doi: 10.4219/jeg-2006-245

Magnusson, D. (1998). The logic and implications of a person-oriented approach. In R. Cairns, L. Bergman, \& J. Kagan (Eds.), Methods and models for studying the individual (pp. 33-64). Thousand Oaks, CA: Sage.

Magnusson, D. (1999). Holistic interactionism: A perspective for research on personality development. Handbook of Personality: Theory and Research, 2, 219-249.

Makel, M. C., Snyder, K., Thomas, C., Malone, P., Putallaz, M. (2015). Gifted students' implicit beliefs about intelligence and giftedness, Gifted Child Quarterly, 59, 203212. doi: $10.1177 / 0016986215599057$

Marra, R. M., Rodgers, K. A., Shen, D., \& Bogue, B. (2009). Women engineering students and self-efficacy: A multi-year, multi-institution study of women engineering student self-efficacy. Journal of Engineering Education, 98, 27-38. doi: 10.1002/j.2168-9830.2009.tb01003.x

Marra, R. M., Rodgers, K. A., Shen, D., \& Bogue, B. (2012). Leaving engineering: A multi-year single institution study. Journal of Engineering Education, 101, 6-27. doi: 10.1002/j.2168-9830.2012.tb00039.x 
Martin, J. P., Miller, M. K., \& Simmons, D. R. (2014). Exploring the theoretical social capital "deficit" of first generation college students: Implications for engineering education. International Journal of Engineering Education, 30, 822-836.

May, G. S., \& Chubin, D. E. (2003). A retrospective on undergraduate engineering success for underrepresented minority students. Journal of Engineering Education, 92, 27-39. doi: 10.1002/j.2168-9830.2003.tb00735.x

McLachlan, G. \& Peel, D. (2000). Finite Mixture Models. New York: Wiley.

Murdock, T. B., \& Miller, A. (2003). Teachers as sources of middle school students' motivational identity: Variable-centered and person-centered analytic approaches. The Elementary School Journal, 103, 383-399. doi: 10.1086/499732

Muthén, B. O., \& Asparouhov, T. (2006). Growth mixture analysis: Models with nonGaussian random effects. Forthcoming In G. Fitzmaurice, M. Davidian, G. Verbeke, \& G. Molenberghs (Eds.), Advances in Longitudinal Data Analysis. Boca Raton, FL: Chapman \& Hall/CRC Press.

Muthén, B. O., \& Shedden, K. (1999). Finite mixture modeling with mixture outcomes using the EM algorithm. Biometrics, 55, 463-469. doi: 10.1111/j.0006341x.1999.00463.x

Muthén, L. K., \& Muthén, B. O. (1998-2015). MPLUS user's guide. Seventh Edition. Los Angelos, CA: Muthén \& Muthén.

Nagin, D. S. (2005). Group-based modelling of development. Cambridge, MA: Harvard University Press. doi: 10.1017/s0012217300001323 
National Science Board. (2018). Science and engineering indicators 2018. NSB-2018-1. Alexandria, VA: National Science Foundation. Available at https://www.nsf.gov/nsb/sei/companion-brief/NSB-2018-7.pdf.

National Science Foundation (NSF). National Center for Science and Engineering Statistics (NCSES) (2017). Women, minorities, and persons with disabilities in science and engineering. Arlington, VA: National Science Foundation.

National Student Clearinghouse (2016). High school benchmarks: National college progression rates. Retrieved from: https://nscresearchcenter.org/wpcontent/uploads/HighSchoolBenchmarks2016.pdf

Nurmi, J. E., \& Aunola, K. (2005). Task-motivation during the first school years: A person-oriented approach to longitudinal data. Learning and Instruction, 15, 103 122. doi: 10.1016/j.learninstruc.2005.04.009

Nylund, K. L. (2007). Latent transition analysis: Modeling extensions and an application to peer victimization (Doctoral dissertation, University of California, Los Angeles).

Nylund, K. L., Asparouhov, T., \& Muthén, B. O. (2007). Deciding on the number of classes in latent class analysis and growth mixture modeling: A Monte Carlo simulation study. Structural Equation Modeling, 14, 535-569. doi: $10.1080 / 10705510701575396$

Orr, M. K., Ramirez, N. M., \& Ohland, M. W. (2011). Socioeconomic trends in engineering: Enrollment, persistence, and academic achievement. 2011 ASEE Annual Conference and Exposition, Vancouver, BC. Retrieved from: https://peer.asee.org/18499 
Ostrove, J. M., \& Long, S. M. (2007). Social class and belonging: Implications for college adjustment. The Review of Higher Education, 30, 363-389. doi: 10.1353/rhe. 2007.0028

Pastor, D. A., Barron, K. E., Miller, B. J., \& Davis, S. L. (2007). A latent profile analysis of college students' achievement goal orientation. Contemporary Educational Psychology, 32, 8-47. doi: 10.1016/j.cedpsych.2006.10.003

Patterson, M. M., Kravchenko, N., Chen-Bouck, L., \& Kelley, J.A. (2016). General and domain-specific beliefs about intelligence, ability, and effort among preservice and practicing teachers. Teaching \& Teacher Education, 59, 180-190. doi: 10.1016/j.tate.2016.06.004

Pintrich, R. R., \& DeGroot, E. V. (1990). Motivational and self-regulated learning components of classroom academic performance, Journal of Educational Psychology, 82, 33-40. doi: 10.1037//0022-0663.82.1.33

Pintrich, P. R., Smith, D. A. F., García, T., \& McKeachie, W. J. (1991). A manual for the use of the motivated strategies questionnaire (MSLQ). Ann Arbor, MI: University of Michigan, National Center for Research to Improve Postsecondary Teaching and Learning Motivated Strategies for Learning Questionnaire (MSLQ) Manual. Available from: https://www.researchgate.net/publication/280741846 _Motivated_Strategies_for_Learning_Questionnaire_MSLQ_Manual.

Preckel, F., Goetz, T., Pekrun, R., \& Kleine, M. (2008). Gender differences in gifted and average-ability students: Comparing girls' and boys' achievement, self-concept, interest, and motivation in mathematics. Gifted Child Quarterly, 52, 146-159. doi: $10.1177 / 0016986208315834$ 
President's Council of Advisors on Science and Technology (PCAST). (2012). Engage to excel: Producing one million additional college graduates with degrees in science, technology, engineering, and mathematics. Washington, DC: Author

Rask, K. (2010). Attrition in STEM fields at a liberal arts college: The importance of grades and pre-collegiate preferences. Economics of Education Review, 29, 892900. doi: 10.1016/j.econedurev.2010.06.013

Robins, R. W., \& Pals, J. L. (2002). Implicit self-theories in the academic domain: Implications for goal orientation, attributions, affect, and self-esteem change. Self and Identity, 1, 313-336. doi:10.1080/15298860290106805

Roeser, R. W., Strobel, K. R., \& Quihuis, G. (2002). Studying early adolescents' academic motivation, social-emotional functioning, and engagement in learning: Variable-and person-centered approaches. Anxiety, Stress \& Coping, 15, 345-368. doi: 10.1080/1061580021000056519

Schwartz, G. (1978). Estimating the dimension of a model. The Annals of Statistics, 6, 461-464.

Seymour, E., \& Hewitt, N. (1997). Talking about leaving: Why undergraduates leave the sciences, Boulder: Westview Press. doi: doi.org/10.2307/2655673

Shaw, E.J., \& Barbuti, S. (2010). Patterns of persistence in intended college major with a focus on STEM majors. The National Academic Advising Association Journal, 30, 19-34. doi: 10.12930/0271-9517-30.2.19

Simonton, D. K. (2005). Giftedness and genetics: The emergenic-epigenetic model and its implications. Journal for the Education of the Gifted, 28, 270-286. doi: 10.4219/jeg-2005-338 
Smith, J. L., Lewis, K. L., Hawthorne, L., \& Hodges, S. D. (2013). When trying hard isn't natural: Women's belonging with and motivation for male-dominated STEM fields as a function of effort expenditure concerns. Personality and Social Psychology Bulletin, 39, 131-143. doi: 10.1177/0146167212468332

Snyder, K. E., Barger, M., Wormington, S. V., Schwartz-Bloom, R., \& LinnenbrinkGarcia, L. (2013). Identification as gifted and implicit beliefs about intelligence: An examination of potential moderators. Journal of Advanced Academics, 24, 242-258. doi: 10.1177/1932202X13507971

Snyder, K. E., Barr, S. M., Honken, N. B., Pittard, C. M., \& Ralston, P. A. (2018). Navigating the first semester: An exploration of short-term changes in motivational beliefs among engineering undergraduates. Journal of Engineering Education, 107, 11-29. doi: 10.1002/jee.20187

Sterba, S. K., \& Bauer, D. J. (2010). Matching method with theory in person-oriented developmental psychopathology research. Development and Psychopathology, 22, 239-254. doi: 10.1017/s0954579410000015

Strenta, A. C., Elliott, R., Adair, R., Matier, M., \& Scott, J. (1994). Choosing and leaving science in highly selective institutions. Research in Higher Education, 35, 513547. doi: 10.1007/bf02497086

Strutz, M. L., Orr, M. K., \& Ohland, M. W. (2012). Low socioeconomic status individuals: An invisible minority in engineering. In C. Baillie (Ed.), Engineering and social justice: In the university and beyond (pp. 143-156). Purdue University Press 
Tate, E. D., \& Linn, M. C. (2005). How does identity shape the experiences of women of color engineering students? Journal of cience Education and Technology, 14, 483-493. doi: 10.1007/s10956-005-0223-1

Trochim, W.M. and Donnelly, J.P. (2006) The Research Methods Knowledge Base. 3rd Edition, Atomic Dog, Cincinnati, OH.

Veenstra, C. P., Dey, E. L., \& Herrin, G. D. (2009). A model for freshman engineering retention. Advances in Engineering Education, 1, 1-33.

von Eye, A., \& Bogat, G. A. (2006). Person-oriented and variable-oriented research: Concepts, results, and development. Merrill-Palmer Quarterly, 52, 390-420. doi: 10.1353/mpq.2006.0032

Walton, G. M., \& Cohen, G. L. (2007). A question of belonging: Race, social fit, and achievement. Journal of Personality and Social Psychology, 92, 82-96. doi: 10.1037/0022-3514.92.1.82

Walton, G. M., \& Cohen, G. L. (2011). A brief social-belonging intervention improves academic and health outcomes of minority students. Science, 331, 1447-1451. doi: 10.1126/science.1198364

Wormington, S. V., Corpus, J. H., \& Anderson, K. G. (2012). A person-centered investigation of academic motivation and its correlates in high school. Learning and Individual Differences, 22, 429-438. doi: 10.1016/j.lindif.2012.03.004

Wormington, S. V., \& Linnenbrink-Garcia, L. (2017). A new look at multiple goal pursuit: The promise of a person-centered approach. Educational Psychology Review, 29, 407-445. doi: 10.1007/s10648-016-9358-2 
Yeager, D. S., \& Dweck, C. S. (2012). Mindsets that promote resilience: When students believe that personal characteristics can be developed. Educational Psychologist, 47, 302-314. doi: $10.1080 / 00461520.2012 .722805$

Zirkel, S. (2004). What will you think of me? Racial integration, peer relationships and achievement among White students and students of color. Journal of Social Issues, 60, 57-74. doi: 10.1111/j.0022-4537.2004.00099.x 


\section{APPENDIX A}

A1: Model Fit Indices Prior to Including Post Hoc Correlations

Model Fit Indices for the Expectations of Brilliance and Perceived Belonging Uncertainty Measures Prior to Including Post Hoc Correlations

\begin{tabular}{|c|c|c|c|c|}
\hline Model & $\chi^{2}(\mathrm{df}), p$ & CFI & TLI & RMSEA $[90 \% \mathrm{CI}]$ \\
\hline $\begin{array}{l}\text { Expectations of } \\
\text { Brilliance } \\
\text { Pre-Survey }\end{array}$ & $\begin{array}{c}\chi^{2}(2)=116.21 \\
p<.001\end{array}$ & .80 & .39 & $.26[.22, .30]$ \\
\hline $\begin{array}{l}\text { Expectations of } \\
\text { Brilliance } \\
\text { Post-Survey }\end{array}$ & $\begin{array}{c}\chi^{2}(2)=114.34 \\
p<.001\end{array}$ & .82 & .47 & $.29[.24, .33]$ \\
\hline $\begin{array}{l}\text { Perceived Belonging } \\
\text { Uncertainty } \\
\text { Pre-Survey }\end{array}$ & $\begin{array}{c}\chi^{2}(2)=44.37 \\
p<.001\end{array}$ & .97 & .90 & $.16[.12, .20]$ \\
\hline $\begin{array}{c}\text { Perceived Belonging } \\
\text { Uncertainty } \\
\text { Post-Survey }\end{array}$ & $\begin{array}{c}\chi^{2}(2)=29.95 \\
p<.001\end{array}$ & .98 & .93 & $.14[.10, .19]$ \\
\hline
\end{tabular}




\section{APPENDIX B}

B1: Time 1/Pre-Survey LPA Fit Indices Including Hispanic/Latinx Students

Time 1/Pre-Survey LPA Fit Indices Including Hispanic/Latinx Students

\begin{tabular}{|c|c|c|c|c|c|c|c|}
\hline $\begin{array}{l}\text { Number } \\
\text { of } \\
\text { Profiles }\end{array}$ & $\begin{array}{l}\text { Counts and } \\
\text { Proportion of } \\
\text { Participants }\end{array}$ & AIC & BIC & $\begin{array}{c}\log \\
\text { Likelihood }\end{array}$ & Entropy & BLRT & LMR \\
\hline 2 & $\begin{array}{l}\text { Profile 1: } 637.96(.76) \\
\text { Profile 2: } 196.04(.24)\end{array}$ & 6636.51 & 6683.77 & -3308.26 & .82 & $<.001$ & $<.001$ \\
\hline 3 & $\begin{array}{l}\text { Profile 1: } 207.51(.25) \\
\text { Profile 2: } 76.60(.09) \\
\text { Profile 3: } 549.88(.66)\end{array}$ & 6598.21 & 6664.38 & -3285.10 & .79 & $<.001$ & .08 \\
\hline 4 & $\begin{array}{l}\text { Profile 1: } 52.68(.06) \\
\text { Profile 2: } 149.36(.18) \\
\text { Profile 3: } 352.04(.42) \\
\text { Profile 4: } 279.92(.34)\end{array}$ & 6555.85 & 6640.92 & -3259.93 & .79 & $<.001$ & .003 \\
\hline 5 & $\begin{array}{l}\text { Profile 1: } 37.42(.04) \\
\text { Profile 2: } 88.91(.11) \\
\text { Profile 3: } 126.35(.15) \\
\text { Profile 4: } 272.17(.33) \\
\text { Profile 5: } 309.14(.37)\end{array}$ & 6533.03 & 6637.01 & -3244.52 & .82 & $<.001$ & .03 \\
\hline 6 & $\begin{array}{l}\text { Profile 1: } 144.99(.17) \\
\text { Profile 2: } 15.69(.02) \\
\text { Profile 3: } 306.77(.37) \\
\text { Profile 4: } 38.35(.05) \\
\text { Profile 5: } 255.54(.31) \\
\text { Profile 6: } 72.67(.09)\end{array}$ & 6535.22 & 6658.10 & -3241.61 & .76 & .67 & .72 \\
\hline
\end{tabular}

Notes. $N=834$; AIC = Akaike Information Criterion; BIC = Bayesian Information Criterion; BLRT $=$ Bootstrap Likelihood Ratio Test; LMR = Lo-Mendell-Rubin Test; Final class solutions were also guided by theory 
B2: Time 2/Post-Survey LPA Fit Indices Including Hispanic/Latinx Students

Time 2/Post-Survey LPA Fit Indices Including Hispanic/Latinx Students

\begin{tabular}{|c|c|c|c|c|c|c|c|}
\hline $\begin{array}{l}\text { Number } \\
\text { of } \\
\text { Profiles }\end{array}$ & $\begin{array}{l}\text { Counts and } \\
\text { Proportion of } \\
\text { Participants }\end{array}$ & AIC & BIC & $\begin{array}{c}\text { Log } \\
\text { Likelihood }\end{array}$ & Entropy & BLRT & LMR \\
\hline 2 & $\begin{array}{l}\text { Profile 1: } 185.95(.27) \\
\text { Profile 2: } 501.05(.73)\end{array}$ & 5798.97 & 5844.29 & -2889.49 & .82 & $<.001$ & $<.001$ \\
\hline 3 & $\begin{array}{l}\text { Profile 1: } 444.04(.65) \\
\text { Profile 2: } 55.26(.08) \\
\text { Profile 3: } 187.70(.27)\end{array}$ & 5747.68 & 5811.13 & -2859.84 & .82 & $<.001$ & .15 \\
\hline 4 & $\begin{array}{l}\text { Profile 1: } 31.62(.05) \\
\text { Profile 2: } 131.89(.19) \\
\text { Profile 3: } 330.41(.48) \\
\text { Profile 4: } 193.08(.28)\end{array}$ & 5679.38 & 5760.96 & -2821.69 & .86 & $<.001$ & .40 \\
\hline 5 & $\begin{array}{l}\text { Profile 1: } 50.51(.07) \\
\text { Profile 2: } 8.44(.01) \\
\text { Profile 3: } 192.29(.28) \\
\text { Profile 4: } 116.35(.17) \\
\text { Profile 5: } 319.41(.46)\end{array}$ & 5629.32 & 5729.03 & -2792.66 & .89 & $<.001$ & $<.001$ \\
\hline 6 & $\begin{array}{l}\text { Profile 1: } 92.46(.13) \\
\text { Profile 2: } 46.94(.07) \\
\text { Profile 3: } 148.41(.22) \\
\text { Profile 4: } 8.47(.01) \\
\text { Profile 5: } 102.20(.15) \\
\text { Profile 6: } 288.53(.42)\end{array}$ & 5610.27 & 5728.11 & -2779.13 & .87 & $<.001$ & .14 \\
\hline
\end{tabular}

Notes. $N=687$; AIC = Akaike Information Criterion; BIC = Bayesian Information Criterion; BLRT $=$ Bootstrap Likelihood Ratio Test; LMR = Lo-Mendell-Rubin Test;

Final class solutions were also guided by theory. 


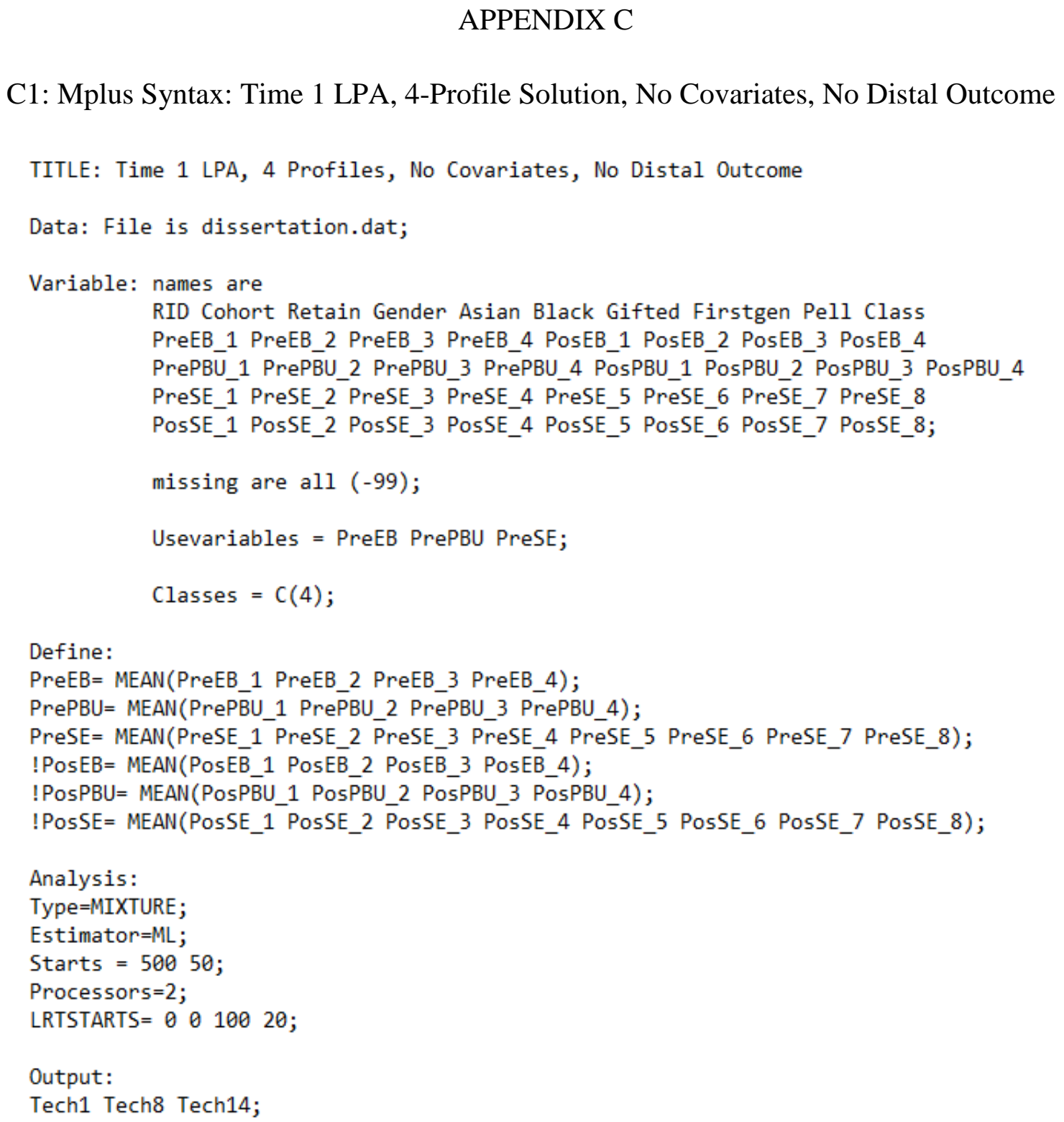


C2: Mplus Syntax: Time 2 LPA, 4-Profile Solution, No Covariates, No Distal Outcome

TITLE: Time 2 LPA, 4 Profiles, No Covariates, No Distal Outcome

Data: File is dissertation.dat;

Variable: names are

RID Cohort Retain Gender Asian Black Gifted Firstgen Pell Class PreEB_1 PreEB_2 PreEB_3 PreEB_4 PosEB_1 PosEB_2 PosEB_3 PosEB_4

PrePBU_1 PrePBU 2 PrePBU 3 PrePBU 4 PosPBU_1 PosPBU 2 PosPBU 3 PosPBU 4

PreSE_1 PreSE_2 PreSE_3 PreSE_4 PreSE_5 PreSE_6 PresE_7 PreSE_8

PosSE_1 PosSE_2 PosSE_3 PosSE_4 PosSE_5 PosSE_6 PosSE_7 PosSE_8;

missing are all (-99);

Usevariables $=$ PosEB PosPBU PosSE;

Classes $=C(4)$;

Define:

! PreEB= MEAN(PreEB_1 PreEB_2 PreEB_3 PreEB_4);

! PrePBU= MEAN(PrePBU_1 PrePBU_2 PrePBU_3 PrePBU_4);

! PreSE $=$ MEAN(PreSE_1 PreSE_2 PreSE_3 PreSE_4 PreSE_5 PreSE_6 PreSE_7 PreSE 8);

PosEB $=$ MEAN (PosEB $\overline{1}$ PosEB $\overline{2}$ PoseB $\overline{3}$ PosEB $\overline{4})$;

PosPBU $=$ MEAN(PosPBU_1 PosPBU_2 PosPBU_3 PosPBU_4);

PosSE $=$ MeAN(PosSE_1 PosSE_2 PosSE_3 PosSE_4 PosSE_5 PosSE_6 PosSE_7 PosSE_8);

Analysis:

Type=MIXTURE;

Estimator $=M L$;

Starts = 50050 ;

Processors $=2$;

LRTSTARTS $=0010020$;

Output:

Tech1 Tech8 Tech14; 
C3: Mplus Syntax: Baseline LTA Model, Full Measurement Non-invariance, No Covariates, No Distal Outcome

TITLE: LTA Item-Response Probabilities Not Constrained To Be Equal No Covariates, No Distal Outcome

Data: File is dissertation.dat;

Variable: names are

RID Cohort Retain Gender Asian Black Gifted Firstgen Pell Class PreEB_1 PreEB_2 PreEB_3 PreEB_4 PosEB_1 PosEB_2 PosEB_3 PosEB_4 PrePBU_1 PrePBU_2 PrePBU_3 PréPBU_4 PosPBU_1 PosPBU_2 PosPBU_ 3 PosPBU_4 PreSE_1 PreSE_2 PreSE_3 PreSE_4 PreSE_5 PreSE_6 Pres̄ 7 PreSE_8 PosSE_1 PosSE_2 PosSE_3 PosSE_4 PosSE_5 PosSE_6 PosSE_7 PosSE_8; missing are all (-99); Usevariables $=$ PreEB PrePBU PreSE PosEB PosPBU PosSE;

Classes $=\mathrm{C} 1(4) \mathrm{C} 2(4)$;

Define:

PreEB $=$ MEAN(PreEB_1 PreEB_2 PreEB_3 PreEB_4);

PrePBU $=$ MEAN (PrePBU_1 PrePBU_2 PrePBU_3 PrePBU_4);

PreSE $=$ MEAN(PreSE_1 PreSE_2 PreSE_3 PreSE_4 PreSE_5 PreSE_6 PreSE_7 PreSE_8);

PosEB = MEAN (PosEB_1 PosEB_2 PosEB_3 PosEB_4);

PosPBU $=$ MEAN (PosPBU_1 PosPBU_2 PosPBU_3 PosPBU_4);

PosSe $=$ MeAn (PosSE_1 PosSE_2 PosSE_3 PosSE_4 PosSE_5 PosSE_6 PosSe_7 PosSE_8);

Analysis:

Type=MIXTURE;

Estimator $=M L$;

Starts $=50050$;

Model:

\%Overall\%

$\mathrm{C} 2 \mathrm{ON} \mathrm{C1}$;

Model C1:

\%C1\#1\%

[PreEB-PreSE];

\%C1\#2\%

[PreEB-PreSE];

\% $1 \# 3 \%$

[PreEB-PreSE];

$\%$ C1\#4\%

[PreEB-PreSE];

Model C2:

\% $2 \# 1 \%$

[PosEB-PosSE];

$\% \mathrm{C} 2 \# 2 \%$

[PosEB-PosSE];

$\% \mathrm{C} 2 \# 3 \%$

[PosEB-PosSE];

$\% \mathrm{C} 24 \%$

[PosEB-PosSE]; 
C4: Mplus Syntax: Baseline LTA Model, Full Measurement Invariance, No Covariates, No Distal Outcome

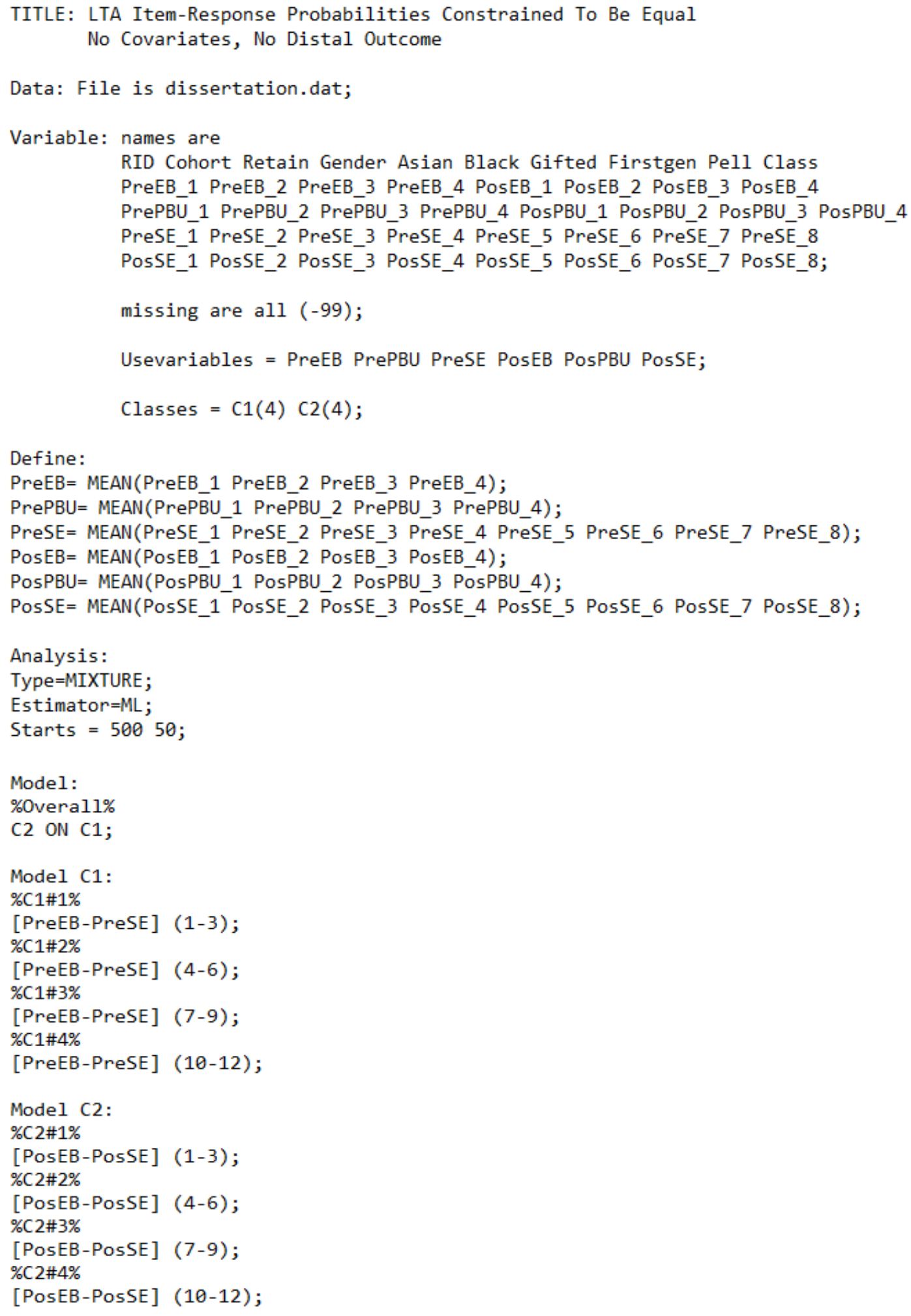


C5: Mplus Syntax: LTA Model Covariates Included

TITLE: LTA Covariates Included, No Distal Outcome

Data: File is dissertation.dat;

Variable: names are

RID Cohort Retain Gender Asian Black Gifted Firstgen Pell Class PreEB_1 PreEB_2 PreEB_3 PreEB_4 PosEB_1 PosEB_2 PosEB_3 PosEB_4 PrePBU_1 PrePBU_2 PrePBU_3 PrePBU_4 PosPBU_1 PosPBU_2 PosPBU_3 PosPBU_4 PreSE_1 PreSE_2 PreSE_3 PreSE_4 PreSE_5 PreSE_6 PreSE_7 PreSE_8 PosSE_1 PosSE_2 PosSE_3 PosSE_4 PosSE_5 PosSE_6 PosSE_7 PosSE_8; missing are all (-99);

Usevariables $=$ Cohort Gender Asian Black Gifted Firstgen Pell Class PreEB PrePBU PreSE PosEB PosPBU PosSE;

Classes $=\mathrm{C} 1(4) \mathrm{C} 2(4) ;$

Define:

PreEB $=$ MEAN(PreEB_1 PreEB_2 PreEB_3 PreEB_4);

PrePBU $=$ MEAN(PrePBU_1 PrePBU_2 PrePBU_3 PrePBU_4);

PreSE $=$ MEAN(PreSE_1 PreSE_2 PreSE_3 PreSE_4 PreSE_5 PreSE_6 PreSE_7 PreSE_8); PosEB $=$ MEAN(PosEB_1 PosEB_2 PosEB_3 PosEB_4);

PosPBU = MEAN(PosPBU_1 PosPBU_2 PosPBU_3 PosPBU_4);

PosSE $=$ MEAN(PosSE_1 PosSE_2 PosSE_3 PosSE_4 PosSE_5 PosSE_6 PosSE_7 PosSE_8);

Analysis:

Type=MIXTURE;

Estimator $=\mathrm{ML}$;

Starts $=5000500$;

Processors=2;

Model:

\%0verall\%

C2 C1 ON Cohort Gender Asian Black Gifted Firstgen Pell Class;

Model C1:

\%C1\#1\%

[PreEB-PreSE];

$\% \mathrm{C} 1 \# 2 \%$

[PreEB-PreSE];

$\%$ C1\#3\%

[PreEB-PreSE];

$\%$ C1\#4\%

[PreEB-PreSE];

Model C2:

$\% \mathrm{C} 2 \# 1 \%$

[PosEB-PosSE];

$\% \mathrm{C} 2 \# 2 \%$

[PosEB-PosSE];

$\% \mathrm{C} 2 \# 3 \%$

[PosEB-PosSE];

$\%$ C $\# 4 \%$

[PosEB-PosSE]; 
C6: Mplus Syntax: LTA Model Covariates and Distal Outcome Included

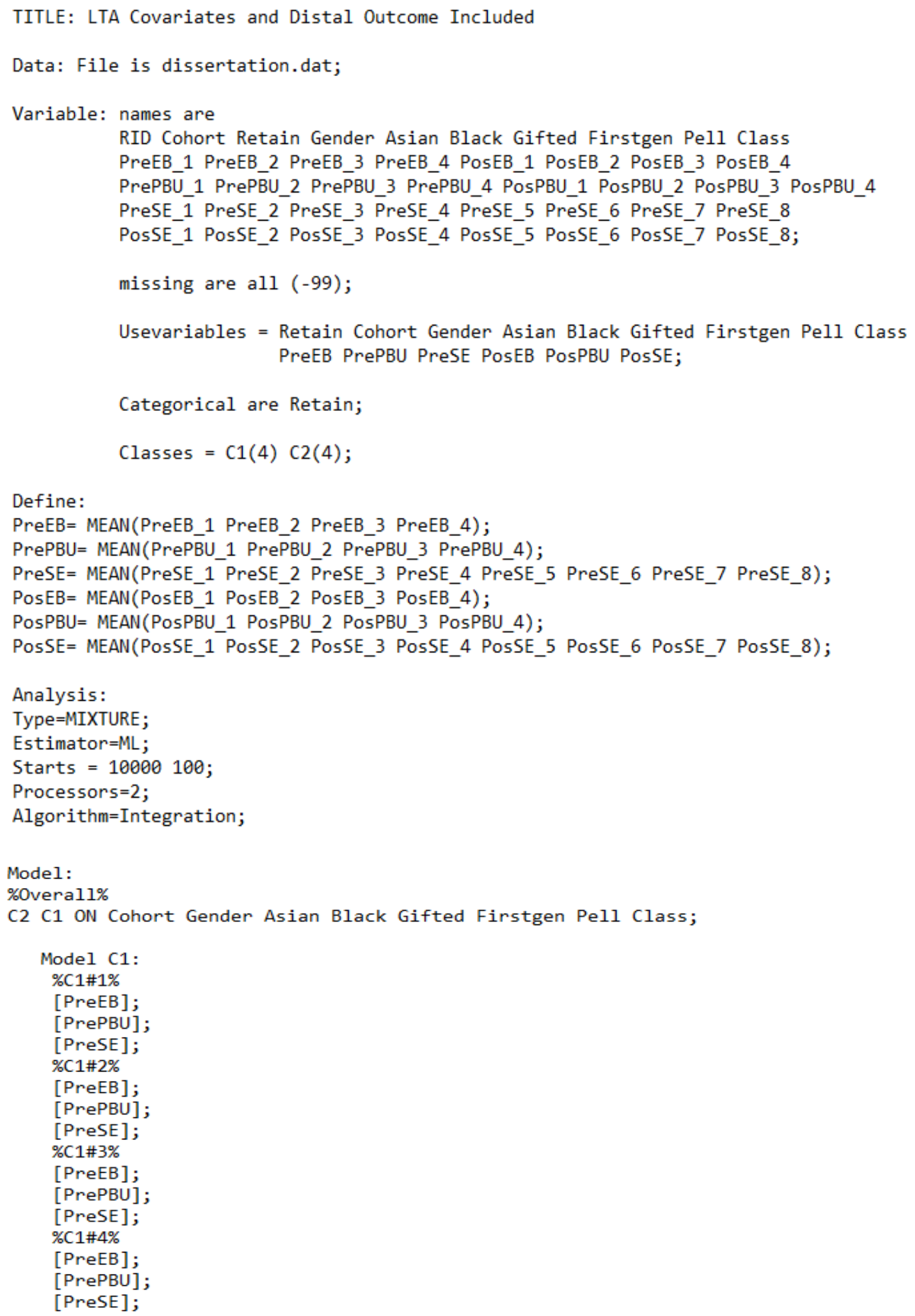


Model C2:

$\%$ C2\#1\%

[PosEB];

[PosPBU];

[PosSE];

[Retain\$1];

\% $2 \# 2 \%$

[PosEB];

[PosPBU];

[PosSE];

[Retain\$1];

\% 2 \#4\%

[PosEB];

[PosPBU];

[PosSE];

[Retain\$1];

\% 2 \# $3 \%$

[PosEB];

[PosPBU];

[PosSE];

[Retain\$1];

Output:

Tech1; 


\title{
CURRICULUM VITA
}

\author{
NAME: $\quad$ Brittany Flanery Crawford \\ EDUCATION B.S., Mathematics; Minor: Psychology \\ \& TRAINING University of Kentucky \\ Lexington, KY \\ 2011-2015 \\ Ph.D., Educational Psychology, Measurement, and Evaluation \\ University of Louisville \\ Louisville, KY \\ 2015-2019
}

PROFESSIONAL

Research Scientist, 2019-Present

EXPERIENCE

Human Resources Research Organization, Louisville, KY

Research Associate, 2018-2019 (Full-Time), 2016-2017 (Part-Time)

Human Resources Research Organization, Louisville, KY

Graduate Research Assistant, 2017-2018

University of Louisville, Louisville, KY

Evaluation Specialist (Intern), 2015-2016

Jefferson County Public Schools, Louisville, KY

STEM Research Assistant, 2013-2014

University of Kentucky, Lexington, KY 
PROFESSIONAL Division D (Measurement and Research Methodology) Member AFFILIATIONS \& American Educational Research Association, 2015-Present SERVICE:

Division D Membership Committee

American Educational Research Association, 2016 - 2017

Research on Giftedness, Creativity, and Talent SIG Member American Educational Research Association, 2017 - Present

Graduate Student Issues Committee Member

National Council on Measurement in Education, 2016-2018

Outreach and Partnerships Committee Member

National Council on Measurement in Education, 2017 - 2018

Division 5 (Quantitative and Qualitative Methods) Member American Psychological Association, 2018-Present

Division 15 (Educational Psychology) Member

American Psychological Association, 2018-Present

Internship Committee

Human Resources Research Organization, 2019-Present

PUBLICATIONS: Peer Reviewed Journals and Books

Crawford, B. F., Snyder, K. E., \& Adelson, J. L. (2019).

Exploring obstacles faced by gifted minority students through Bronfenbrenner's bioecological systems theory. High Ability

Studies. doi: 10.1080/13598139.2019.1568231

Palmer, S. B., Adelson, J. L., Crawford, B. F., Asher, N., \& Switalski, W. (2019). Newborn hearing screenings for babies born at home: Report from an initiative in Michigan. Journal of Early Hearing Detection and Intervention

Roark, R., Cummane, P., Crawford, B. F., Jong, C., \& Fisher, M. H. (2018). Understanding preservice elementary teachers' perceptions. Virginia Mathematics Teacher, 44, 24-28.

Flanery, B., Roark, R., Cummane, P., Fisher, M. H., \& Jong, C. (2014). Using professional noticing in elementary school mathematics. Virginia Mathematics Teacher, 41, 21-23.

Adelson, J. L., Osborne, J. W., \& Crawford, B. F. (2019). Correlation and other measures of association. In G. Hancock, 
R. Mueller, \& L. Stapleton (Eds.), The reviewer's guide to quantitative methods in the social sciences (2nd ed.). NY: Routledge.

\section{Selected Technical Reports}

Snyder, K. E., Crawford, B. F., \& Adelson, J. L. (2017, December). Perceptions of intelligence and giftedness: Reaching Academic Potential (RAP) project intervention and changes in educators' implicit beliefs. Report submitted to Kentucky Department of Education.

Adelson, J. L., Snyder, K. E., \& Crawford, B. F. (2017, December). Executive summary of Project RAP evaluation data. Report submitted to Kentucky Department of Education and to Institute of Education Sciences.

Thacker, A. A., Crawford, B. F., \& Sinclair A. L. (2017, April). Observation of the spring 2017 Kentucky Academic Standards (KAS) Science Field Test Administration (2017 No. 035). Alexandria, VA: Human Resources Research Organization.

Thacker, A. A., \& Crawford, B. F. (2017, February). Recommendations for college-readiness benchmarks for Minnesota State Colleges and Universities (2017 No. 160). Alexandria, VA: Human Resources Research Organization.

Banjanovic, E. S., Crawford, B. F., Deatz, R., \& Thacker, A. A. (2017, March). Independent alignment review of the Oklahoma School Testing Program (OSTP) English language arts, mathematics, and science tests (2016 No. 089). Alexandria, VA: Human Resources Research Organization.

Thacker, A. A., Lau, T., \& Crawford, B. F. (2016, July). An investigation of the stability of Kentucky's end-of-course assessments (2016 No. 042). Alexandria, VA: Human Resources Research Organization.

PRESENTATIONS Crawford, B. F. (2018, November). Student perceptions and persistence: Taking a person-centered approach to understand undergraduate engineering retention. Poster presented at the 64th annual meeting of the National Association for Gifted Children, Minneapolis, MN. 
Crawford, B. F., Adelson, J. L., Immekus, J. C., \& McGee, C. D. (2017, April). Giftedness and motivation for taking low- and high-stakes tests. Poster presented at the 2017 American Educational Research Association Annual Meeting and Exhibition, San Antonio, TX. * 2017 Graduate Student Travel Fellowship Award for AERA ROGCT SIG.

Reece, T., Crawford, B. F., \& Immekus, J. C. (2016, March). Jumping to conclusions about item bias: Analysis of differential item functioning in the jumpstart school success checklist. Paper presented at the 2016 University of Louisville, University of Cincinnati, and University of Kentucky Spring Research Conference, Lexington, KY.

Crawford, B. F., \& Snyder, K. E. (2016, March). Causation and correlation: Assessing undergraduate students' misconceptions of research design. Paper presented at the 2016 University of Louisville, University of Cincinnati, and University of Kentucky Spring Research Conference, Lexington, KY.

Crawford, B. F., Immekus, J. C., Adelson, J. L., \& McGee, C. D. (2016, February). The relationship of giftedness and testtaking motivation with low- and high-stakes tests. Poster presented at the 2016 Annual Conference of the Kentucky Association for Gifted Education, Lexington, KY.

Flanery, B., Roark, R., \& Cummane, P. (2014, April). Using professional noticing in elementary school mathematics. Paper presented at the National Conference on Undergraduate Research (NCUR), Lexington, KY. 